Um data warehouse de publicações científicas: indexação automática da dimensão tópicos de pesquisa dos data marts 



\section{Um data warehouse de publicações científicas: indexação automática da dimensão tópicos de pesquisa dos data marts}

\section{Augusto Kanashiro}

Orientador: Prof. Dr. Alneu de Andrade Lopes

Dissertação apresentada ao Instituto de Ciências Matemáticas e de Computação - ICMC/USP como parte dos requisitos para obtenção do título de Mestre em Ciência de Computação e Matemática Computacional.

\section{"VERSÃO REVISADA APÓS A DEFESA"}

Data da defesa: 04 / 05 / 2007

Visto do Orientador:

USP - São Carlos

Julho/2007 



\section{Agradecimentos}

Agradeço a minha família pelo apoio e suporte em todos os momentos. Meus pais, Roberto e Rosa, pela educação, amor e por me ensinarem os verdadeiros valores da vida, e meu irmão Alexandre.

Ao Professor Alneu pela orientação e principalmente por sua compreensão e apoio nos momentos mais difíceis.

Agradeço aos professores Mauro Biajiz e Caetano Traina pelas sugestões e correções no exame de qualificação que foram fundamentais ao rumo deste projeto. Aos professores Gustavo Nonato e Odemir Bruno pelas sugestões e ajuda nos experimentos com wavelets.

Agradeço ao meu amigo Valmir, que desde o início se prontificou a me ajudar, me orientando em todo projeto e implementação de banco de dados. Sua ajuda foi essencial para este trabalho.

Aos colegas do Labic, incluindo os keepers Ronaldo, Edson e Richardson, que sempre estiveram prontamente dispostos a me ajudar e aos colegas de projeto Chris, Beto e, em especial, ao Vinicius que me ajudou em diversos momentos. Também tenho que agradecer colegas de outras áreas como Mário, Joselene e Bruno.

Aos amigos e companheiros com quem convivi grande parte do tempo nesse período de mestrado, Jean, Maikon e Luis Henrique, e outros amigos muito próximos a mim no dia a dia, Valter e Guilherme.

Agradeço a todos amigos da turma PgCompUSP04.

Às secretárias da pós-graduaçao, sempre muito prestativas, e todos os funcionários do ICMC.

Agradeço aos meus familiares, amigos e todas as pessoas que me ajudaram a chegar até aqui.

Por fim, agradeço ao CNPq pelo auxílio financeiro imprescindível para a realização deste trabalho. 

Este trabalho de mestrado insere-se no contexto do projeto de uma Ferramenta Inteligente de Apoio à Pesquisa (FIP), sendo desenvolvida no Laboratório de Inteligência Computacional do ICMC-USP. A ferramenta foi proposta para recuperar, organizar e minerar grandes conjuntos de documentos científicos (na área de computação). Nesse contexto, faz-se necessário um repositório de artigos para a FIP. Ou seja, um Data Warehouse que armazene e integre todas as informações extraídas dos documentos recuperados de diferentes páginas pessoais, institucionais e de repositórios de artigos da Web. Para suportar o processamento analítico on-line (OLAP) das informações e facilitar a "mineração" desses dados é importante que os dados estejam armazenados apropriadamente. Dessa forma, o trabalho de mestrado teve como objetivo principal projetar um Data Warehouse (DW) para a ferramenta FIP e, adicionalmente, realizar experimentos com técnicas de mineração e Aprendizado de Máquina para automatizar o processo de indexação das informações e documentos armazenados no data warehouse (descoberta de tópicos). Para as consultas multidimensionais foram construídos data marts de forma a permitir aos pesquisadores avaliar tendências e a evolução de tópicos de pesquisa. 

This dissertation is related to the project of an Intelligent Tool for Research Supporting (FIP), being developed at the Laboratory of Computational Intelligence at ICMC-USP. The tool was proposed to retrieve, organize, and mining large sets of scientific documents in the field of computer science. In this context, a repository of articles becomes necessary, i.e., a Data Warehouse that integrates and stores all extracted information from retrieved documents from different personal and institutional web pages, and from article repositories. Data appropriatelly stored is decisive for supporting online analytical processing (OLAP), and "data mining" processes. Thus, the main goal of this MSc research was design the FIP Data Warehouse (DW). Additionally, we carried out experiments with Data Mining and Machine Learning techniques in order to automatize the process of indexing of information and documents stored in the data warehouse (Topic Detection). Data marts for multidimensional queries were designed in order to facilitate researchers evaluation of research topics trend and evolution. 



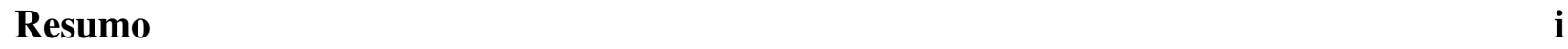

$\begin{array}{lll}\text { Abstract } & \text { iii }\end{array}$

1 Introdução $\quad 1$

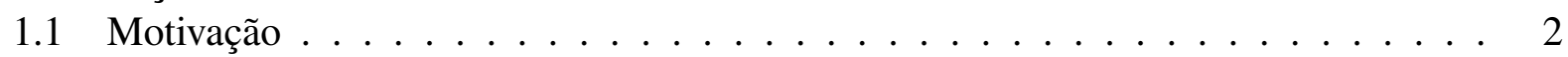

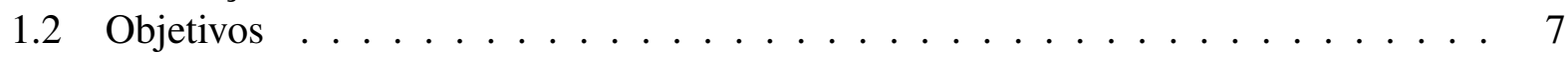

1.3 Organização do Trabalho . . . . . . . . . . . . . . . 8

2 Uma visão geral sobre Data Warehousing e Data Mining 11

2.1 Data Warehousing . . . . . . . . . . . . . . . . . . 11

2.1.1 ETL - Extração, Transformação e Carga dos Dados . . . . . . . . . . . . . . 14

2.1 .2 Data Marts . . . . . . . . . . . . . . . . . . . . . . 14

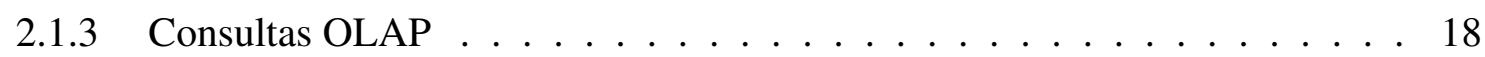

2.2 Mineração de Dados . . . . . . . . . . . . . . . . . . . . . . . . . . . . . . . . . . . . . . . . . . . . . .

2.2 .1 Etapas do KDD . . . . . . . . . . . . . . . . 20

2.2.2 Aprendizado de Máquina . . . . . . . . . . . . . . . . . 21

2.2 .3 Medidas de avaliação . . . . . . . . . . . . . . . . . 23

2.2.4 Detecção de tópicos de pesquisa . . . . . . . . . . . . . 25

3 Repositórios de Artigos Científicos 27

3.1 Introdução . . . . . . . . . . . . . . . . . . . . . . . 27

3.2 Repositórios de artigos na Internet . . . . . . . . . . . . . . . . . . 27

3.3 Índices bibliométricos ISI . . . . . . . . . . . . . . . . . . . . . . . . . 29

3.4 Outros importantes repositórios . . . . . . . . . . . . . . . 33

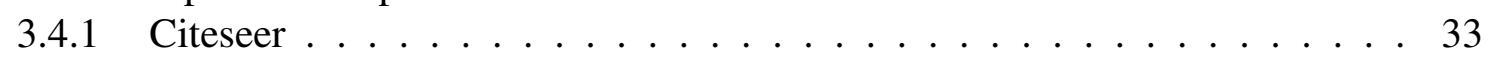

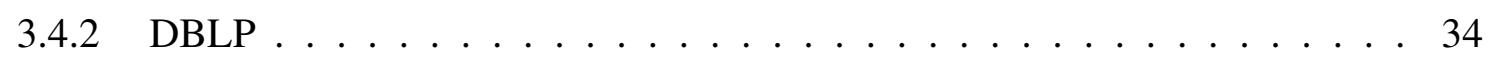

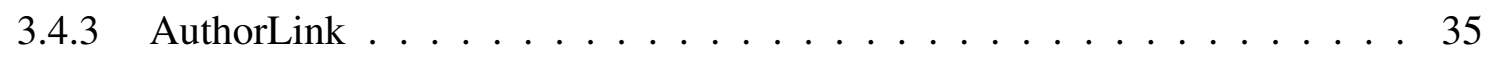

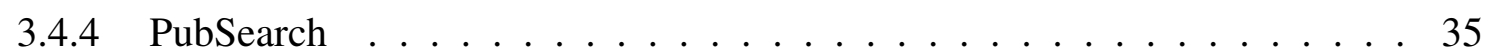

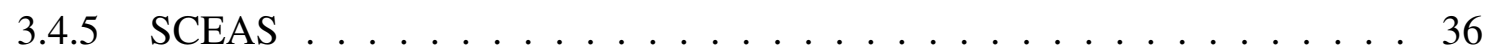

3.5 Novas propostas para índices bibliométricos . . . . . . . . . . . . . . 36

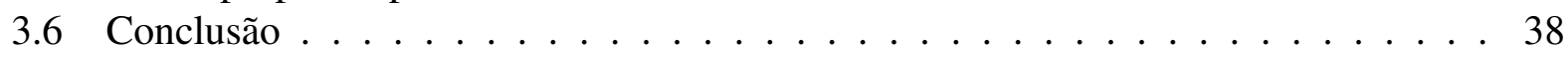


4 Desenvolvimento do Data Warehouse $\quad 39$

4.1 Justificativa . . . . . . . . . . . . . . . . . . . . . . . . . 39

4.1.1 Persistência das informações na Web . . . . . . . . . . . . . . . 41

4.1 .2 O modelo conceitual . . . . . . . . . . . . . . . . . 42

4.2 Planejamento . . . . . . . . . . . . . . . . . . . 44

4.2 .1 A arquitetura do repositório da FIP . . . . . . . . . . . . . . . 44

4.2.2 O acesso dos usuários ao corpora de documentos . . . . . . . . . . . 45

4.2.3 A integração dos dados no data warehouse . . . . . . . . . . . . . . . . 46

4.2 .4 Os snapshots no data warehouse . . . . . . . . . . . . . . . . . 48

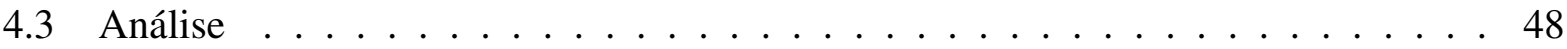

4.3 .1 Data marts . . . . . . . . . . . . . . . . 49

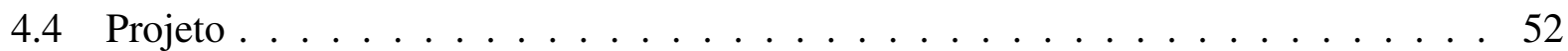

4.5 Implementação . . . . . . . . . . . . . . . . . . . . 53

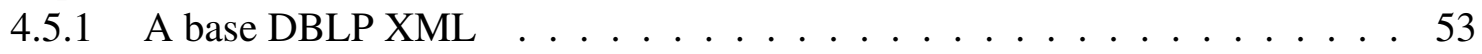

4.5.2 As consultas multidimensionais ................. 56

5 Indexação automática de documentos $\quad \mathbf{6 1}$

5.1 Descrição dos experimentos . . . . . . . . . . . . . . . . 63

5.1 .1 Os softwares utilizados . . . . . . . . . . . . . . . . 64

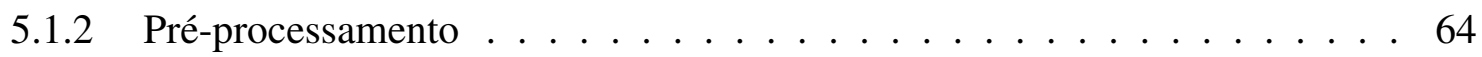

5.1 .3 Indução de classificadores . . . . . . . . . . . . . . . . . 69

5.2 Análise dos resultados . . . . . . . . . . . . . . . . . 72

6 Conclusões $\quad 75$

$\begin{array}{ll}\text { Referências } & 85\end{array}$

$\begin{array}{lll}\text { A Especificação das tabelas } & 87\end{array}$

A.1 Tabelas principais . . . . . . . . . . . . . . . . . 87

A.2 Tabelas secundárias . . . . . . . . . . . . . . . . 91

A.3 Tabelas auxiliares . . . . . . . . . . . . . . . . . . 92 


\section{Lista de Figuras}

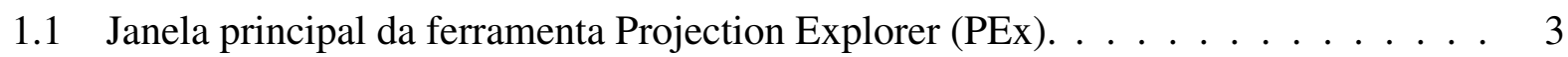

1.2 Resumo do mapa de CBR, ILP e RI com regras de associação. . . . . . . . . . . . . 4

1.3 Uma visão aprofundada da área de ILP. . . . . . . . . . . . . . . . . . . . 5

1.4 Módulos da ferramenta . . . . . . . . . . . . . . . . . . . 6

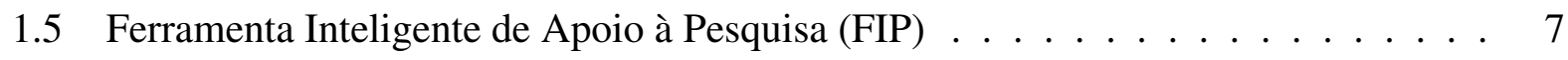

2.1 Diferentes formatos encontrados em referências bibliográficas de artigos. . . . . . 13

2.2 Integração de informações de documentos recuperados de diversas fontes da Web. . 15

2.3 Esquema Estrela de citações entre artigos científicos . . . . . . . . . . . . . . 16

2.4 Esquema Snowflake. Normalização das tabelas do esquema estrela. . . . . . . . . . 18

2.5 A operação Pivot rotaciona o cubo de dados . . . . . . . . . . . . . . . . . . 19

2.6 Etapas do processo de Data Mining(Rezende et al., 2003) . . . . . . . . . . . . 20

3.1 Gráfico do número de citações . . . . . . . . . . . . . . . . . . . . . 34

3.2 Grafo interativo de 24 autores do sistema Authorlink (Buzydlowski et al., 2002) . . 35

3.3 Grafo de conferências (Sidiropoulos e Manolopoulos, 2003) . . . . . . . . . . 36

4.1 Modelo conceitual . . . . . . . . . . . . . . . . . . . . . . 43

4.2 Arquitetura do repositório da ferrramenta FIP . . . . . . . . . . . . . . . . 45

4.3 Modelo lógico do repositório relacional . . . . . . . . . . . . . . . . . . . . . . . . . . . . . . . . . . . . .

4.4 O esquema estrela utilizado no data mart. . . . . . . . . . . . . . . . . 50

4.5 Tela do Oracle Discoverer em consulta sobre citações entre atrigos. . . . . . . . . . . 57

4.6 Congressos que publicaram artigos sobre o assunto abstract data types. . . . . . . . 57

4.7 Gráfico de congressos que abordaram o tópico abstract data types e as quantidades de citações recebidas. . . . . . . . . . . . . . . . . . . . . . 58

4.8 Consulta por tópicos de revistas . . . . . . . . . . . . . . . 58

4.9 Esquema estrela de quantidades de publicações $\ldots \ldots$. . . . . . . . . . . . . . 59

4.10 Tópicos e quantidades de publicações durantes os anos. . . . . . . . . . . . . . . 59

4.11 Outros tópicos ordenados pela quantidade de publicações total . . . . . . . . . 60

4.12 Gráfico dos tópicos e sua evolução nos anos de 1990 a 2004 . . . . . . . . . . . . 60

5.1 Quantidades de publicações sobre Análise Bayesiana durante os anos 1981-2001 (Corfield e Williamson, 2001). . . . . . . . . . . . . . . . . . 62

5.2 Quantidades de publicações da base de dados DBLP XML desde o ano da primeira publicação (1936) até o ano de 2004 . . . . . . . . . . . . . . . . . . 67

5.3 A árvore gerada para janela de tamanho $4 \ldots \ldots \ldots$. . . . . . . . . 72 
5.4 Gráfico comparativo de desempenho dos experimentos . . . . . . . . . . . 73 


\section{Lista de Tabelas}

2.1 Matriz de confusão para duas classes . . . . . . . . . . . . . . . . . . 24

3.1 Vida média de citações . . . . . . . . . . . . . . . . . 31

4.1 Quantidades de publicações da base DBLP . . . . . . . . . . . . . . . . 54

5.1 Representação dos exemplos de treinamento do algoritmo C4.5 . . . . . . . . . . 67

5.2 Conjunto de treinamento inicial de 2 -grams (CT1) . . . . . . . . . . . . . . 68

5.3 Conjunto de treinamento inicial de 3 -grams (CT2) . . . . . . . . . . . . . . . 69

5.4 Experimentos com 3 -grams. O sinal $*$ indica dados normalizados. . . . . . . . 70

5.5 Experimento com 3-grams após correção manual . . . . . . . . . . . . . 70

5.6 Representação dos exemplos de treinamento usando janela de tamanho 4 . . . . . . 71

5.7 Desempenho dos experimentos com diferentes tamanhos de janelas de tempo. . . . 71

5.8 Tabela de descrição dos experimentos . . . . . . . . . . . . . . . . 72

5.9 Tabela com resultados dos experimentos . . . . . . . . . . . . 73 
A disponibilização de artigos e publicações em formato eletrônico na Internet proporcionou um maior e mais rápido compartilhamento de informações. No entanto, na medida em que a quantidade de documentos aumenta, torna-se mais difícil a tarefa da seleção dos documentos relevantes, pois, uma grande quantidade de informações indesejadas é retornada ao usuário que utiliza ferramentas de busca da Web. Nesse sentido tem sido dada ênfase às pesquisas relacionadas com recuperação de informação, extração de informação, bem como mineração e exploração de grandes coleções de documentos.

Num contexto mais específico, no âmbito da pesquisa científica, hoje, milhares de artigos, sobre qualquer tema, estão disponíveis on-line na Web. O que torna a tarefa de selecionar documentos relevantes difícil, principalmente para novatos em uma área, por não possuírem uma visão geral da área que os auxilie nesta seleção. O resultado apresentado pelas ferramentas de busca tradicionais pode não ser adequado às necessidades do usuário. Estes sistemas, em sua maioria, fornecem ao pesquisador uma enorme lista de documentos obtida com a utilização de um ranking, no qual é levado em conta, principalmente, o número de visitas à página, o número de links que fazem referência à mesma, e o número de termos da busca (Lawrence e Giles, 1999).

Nesse contexto foi proposto um sistema automatizado, a Ferramenta Inteligente de apoio à Pesquisa (FIP), para recuperação, organização e exploração de coleções de documentos científicos. Este trabalho de mestrado insere-se no contexto desta ferramenta e trata dos aspectos do projeto de um repositório para armazenar as informações de artigos recuperados. Nas próximas seções são apresentados uma breve descrição da ferramenta, o contexto deste trabalho, os objetivos e a organização dos capítulos da dissertação. 


\subsection{Motivação}

A Ferramenta Inteligente de apoio à Pesquisa (FIP) foi proposta para recuperar, organizar e explorar grandes conjuntos de documentos científicos, principalmente com auxílio da visualização de "mapas" que representem assuntos ou tópicos pesquisados.

O funcionamento da ferramenta inicia-se com a recuperação automática na Web dos documentos de áreas ou tópicos de pesquisa. Decidiu-se limitar os documentos recuperados à área de ciência da computação. Esses documentos irão constituir os corpora de artigos científicos. A partir desses corpora, as informações serão extraídas para um Data Warehouse (DW). Data Warehouse, resumidamente, trata-se de banco de dados otimizado para consultas e, conseqüentemente, análise sobre dados. A partir do data warehouse, técnicas de mineração de dados podem ser aplicadas afim de explorar coleções de documentos facilitando a compreensão e formação de um "modelo mental" de um grande conjunto de documentos. Técnicas de visualização, principalmente, permitem uma compreensão rápida dos principais tópicos, artigos, autores presentes na coleção.

Alguns trabalhos referentes ao estabelecimento e representação gráfica da coleção de artigos estão sendo realizados pelo grupo do projeto da ferramenta FIP em conjunto com pesquisadores e alunos do grupo de Computação Gráfica e Processamento de Imagens do ICMC-USP (Minghim et al., 2006; Lopes et al., 2006, 2007), sobre um outro conjunto de ferramentas denominado Projection Explorer (PEx) (Paulovich e Minghim, 2006). O PEx foi desenvolvido para fornecer suporte ao processo de criação e exploração de mapas de documentos. A janela principal do PEx é apresentada na Figura 1.1.

Como exemplo dessa exploração visual, a seguir é apresentada uma exploração em um corpus com 574 documentos nas áreas de Programação Lógica Indutiva (ILP), Raciocínio Baseado em Casos (CBR) e Recuperação de Informação (RI).

O mapa ilustrado na Figura 1.2, além de agrupar os documentos similares, apresenta um conjunto de rótulos para descrever as (5) áreas selecionadas no mapa, determinadas visualmente (ou automaticamente). Deve-se observar que os rótulos foram gerados automáticamente usando técnicas de Regras de Associação (Lopes et al., 2006). Neste mapa, manteve-se os rótulos na forma das regras. A regra de associação para a região 1 indica documentos relacionados com comunicação, protocolos e criptologia, com 100\% de confiança, onde o termo "beimel" (um autor da área) aparece. As regras para as regiões 2 e 4 são relacionadas a área de RI. Para a região 3, a regra indica documentos da área de ILP. Finalmente, a regra para a região 5 relaciona documentos sobre CBR e Processo de Adaptação em CBR.

Uma vez detectadas as grandes (principais) áreas de pesquisa, o usuário pode aprofundar o seu conhecimento sobre uma determinada área. A ferramenta PEx possibilita que o usuário selecione e explore uma área previamente detectada, com o objetivo de identificar as principais subáreas, os temas centrais abordados e os relacionamentos existentes. 


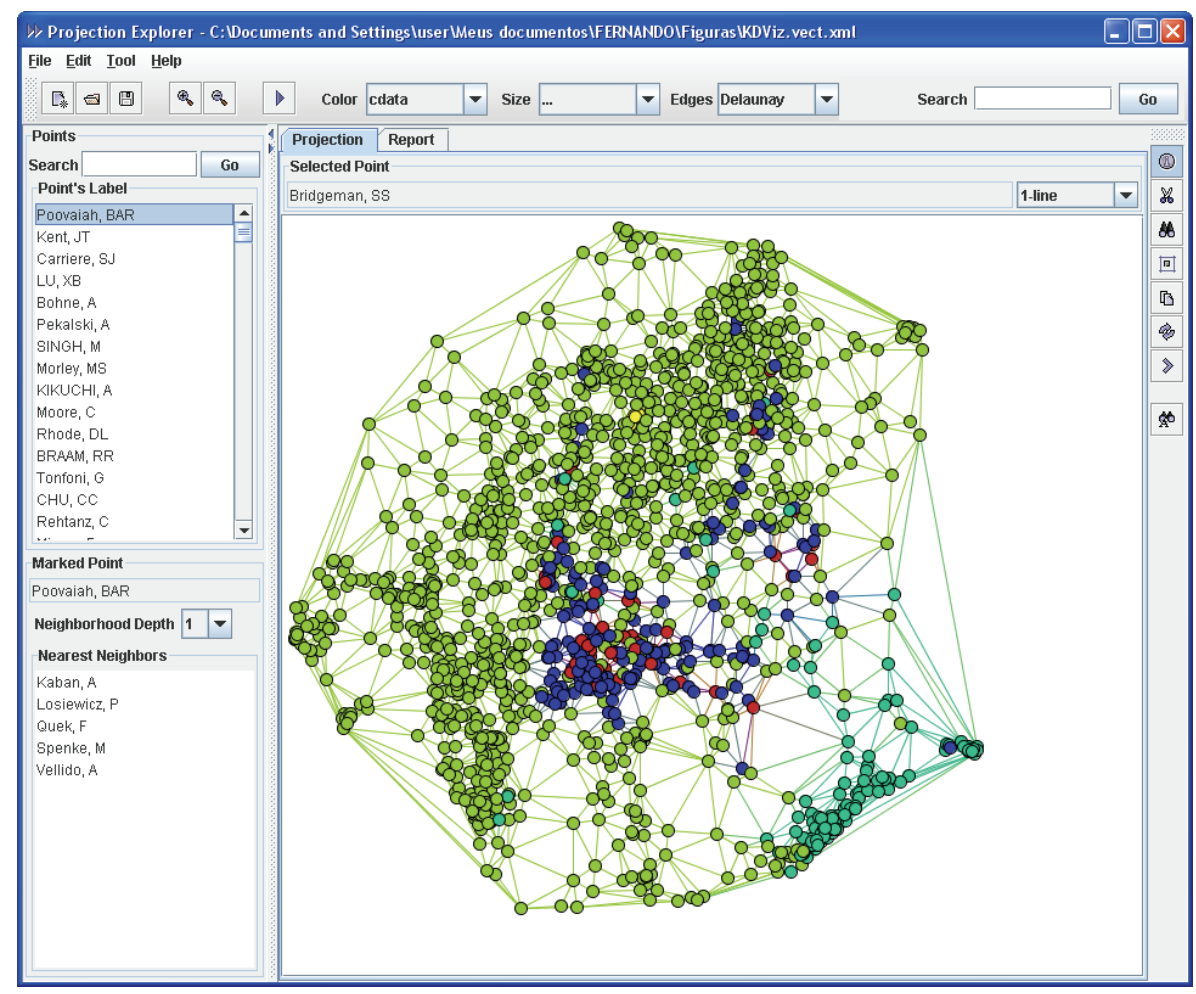

Figura 1.1: Janela principal da ferramenta Projection Explorer (PEx).

O mapa apresentado na Figura 1.3 foi obtido como resultado da exploração da área de Programação Lógica Indutiva (região 3) do mapa anterior. Nesse novo mapa, os documentos, no caso artigos, do grupo representado pela regra [language <- system] estão relacionados com inductive learning and language, e especialmente com part-of-speech (POS) taggin usando abordagens de ILP ([speech <- part]).

As principais características do PEx para explorar mapas de documentos incluem:

- a possibilidade de encontrar os vizinhos mais próximos de um documento;

- coloração de documentos (pontos) no mapa conforme a freqüência de uma palavra ou grupos de palavras;

- criação de rótulos para identificar um grupo de documentos no mapa. Esses rótulos são baseados nas freqüências dos termos e, também, em regras de associação;

- visualização do conteúdo de um documento representado no mapa;

- coloração de um grupo de documentos considerando a distância dos mesmos a um documento pré-selecionado;

- possibilidade de utilizar, além de uma coleção de documentos em formato ASCII, o resultado de um consulta na Web como entrada para a ferramenta. 


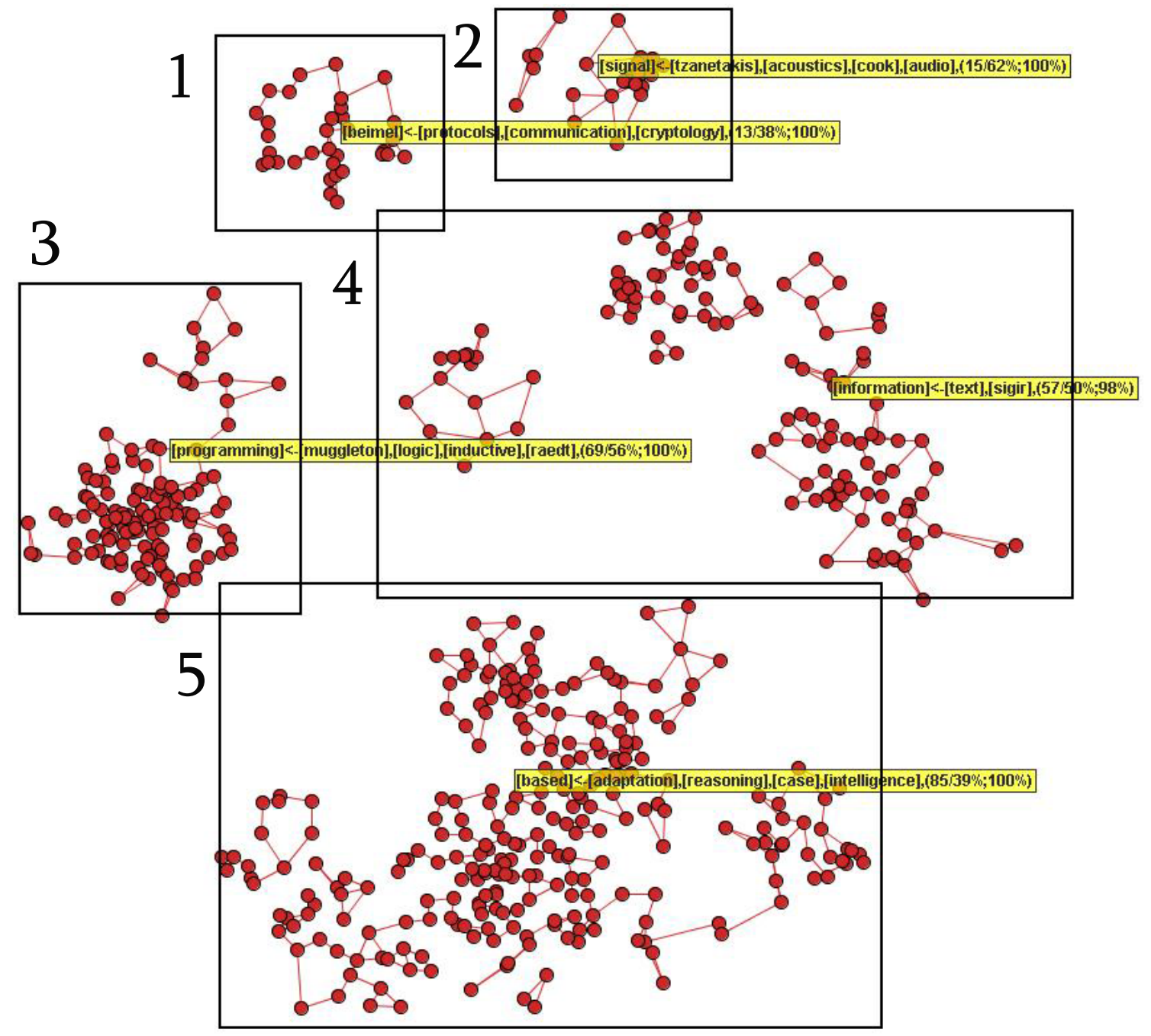

Figura 1.2: Resumo do mapa de CBR, ILP e RI com regras de associação.

Com o intuito de diversificar a representação da coleção de documentos e oferecer mais recursos de visualização aos usuários, na construção dos mapas gerados por ferramentas como o PEx poderão ser utilizadas outras informações dos artigos e publicações científicas como título, autores, data de publicação, palavras-chaves, referências citadas, etc. Por meio destas informações poderia ser avaliada a importância de um artigo levando em conta a quantidade de referências recebidas de outros artigos ou a importância dos congressos, revistas ou periódicos nos quais foram publicados.

A utilização de ferramentas que permitem a representação gráfica de coleções de documentos, possui vantagens como a facilidade da visualização dos pesos e das relações entre as abordagens e as sub-áreas, além da visualização das fronteiras entre as áreas de pesquisa. Pode-se assim, entender a estrutura geral de uma coleção de documentos e identificar os principais tópicos e temas da coleção.

Sistemas semelhantes à FIP, que recuperam e armazenam publicações disponíveis na Web, têm sido construídos em instituições de pesquisa estrangeiras, tais como DBLP ${ }^{1}$, ISI Web of Kno-

\footnotetext{
${ }^{1}$ dblp.uni-trier.de
} 


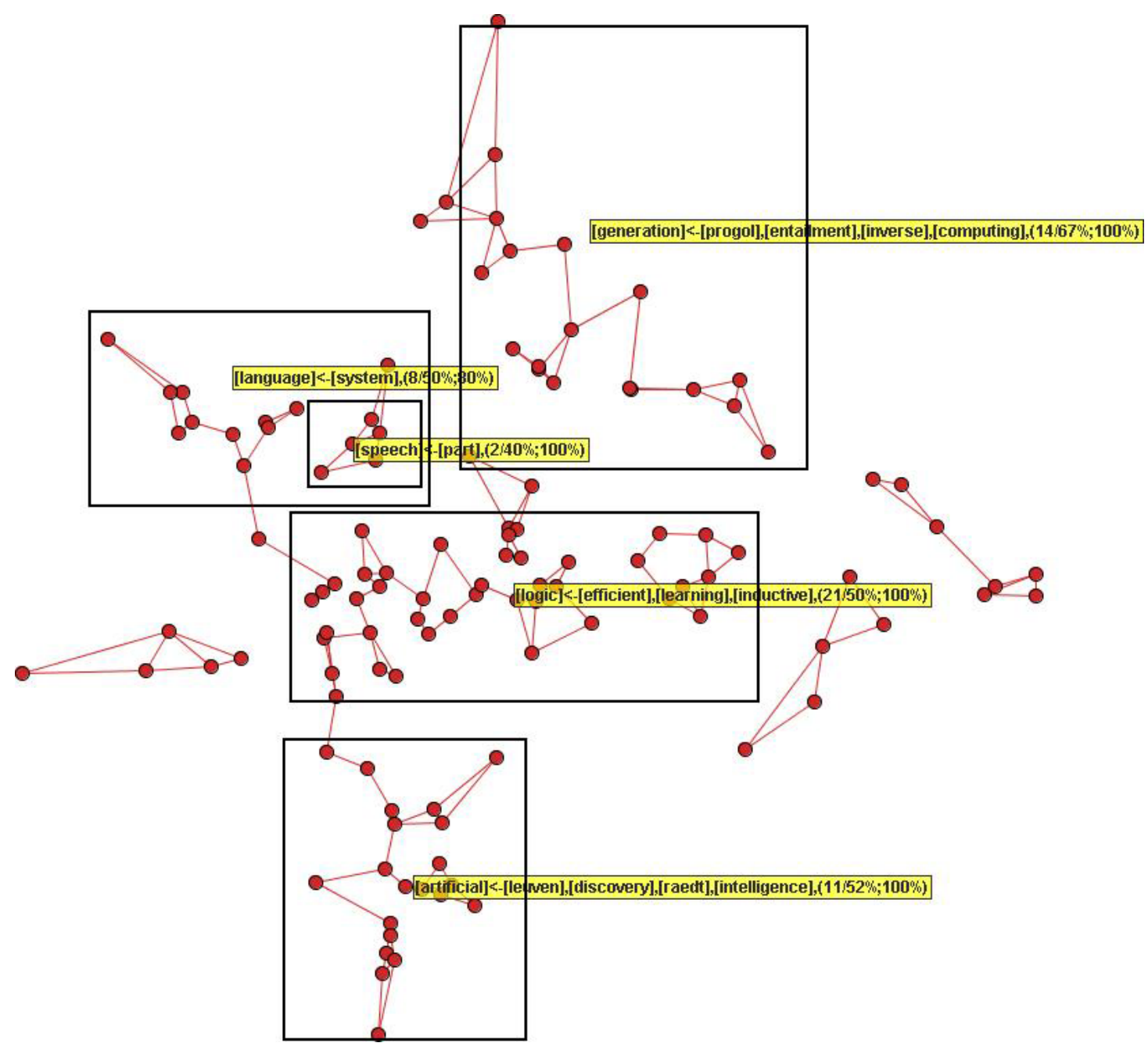

Figura 1.3: Uma visão aprofundada da área de ILP.

wledge $^{2}$ e Citeseer ${ }^{3}$. No entanto, esses sistemas não disponibilizam uma representação gráfica do conteúdo dos seus bancos de dados, nem almejam desenhar um mapa da área ou tema pesquisado.

As técnicas envolvidas no projeto da ferramenta FIP podem ser divididas em três módulos fundamentais relacionados com a recuperação, a análise e a visualização de informações (Figura 1.4), lembrando que as técnicas relacionadas com o módulo 3, hoje estão sendo desenvolvidas junto ao PEx, apresentado anteriormente. Os módulos permitem a exploração de diversos conceitos relacionados com as áreas de Mineração de Dados (Data Mining), Aprendizado de Máquina, Extração de Conhecimento em Base de Dados (KDD), Recuperação de Informação, Mineração de Texto, Similaridade entre Casos (Raciocínio Baseado em Casos), Mineração na Web, Clustering, Visualização de Dados, entre outras técnicas.

\footnotetext{
${ }^{2}$ http://www.isinet.com/isi/

${ }^{3}$ http://www.citeseer.com/
} 


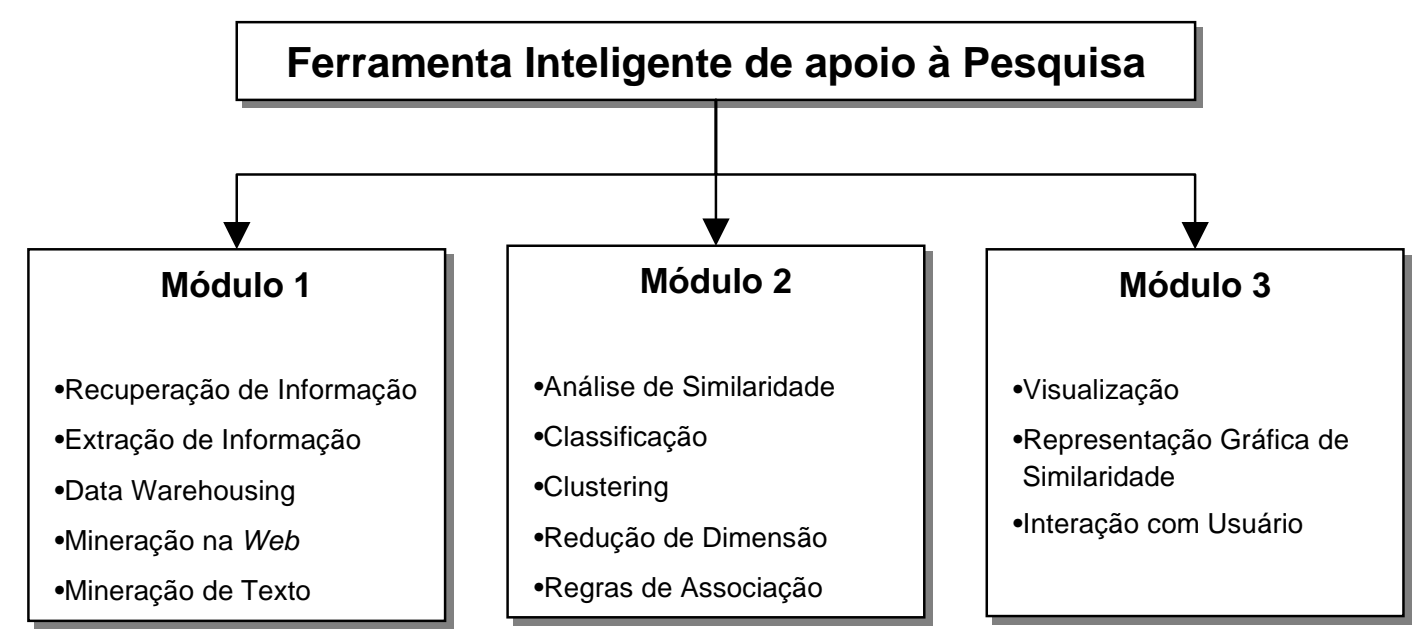

Figura 1.4: Módulos da ferramenta

Módulo 1 - trata da recuperação de artigos disponíveis na Internet, da extração de informações e do armazenamento das informações dos artigos. Este projeto de mestrado faz parte do módulo 1, mais especificamente, na tarefa de especificação e construção do repositório da FIP. Seu objetivo é projetar um Data Warehouse (DW) que armazene as informações dos artigos dos corpora.

Módulo 2 - responsável pela mineração propriamente dita: avaliação e análise de similaridades e relações entre artigos recuperados, tais como procedência, importância, áreas e sub-áreas as quais pertencem. Nesse módulo são utilizadas técnicas de Mineração de Dados e Aprendizado de Máquina, tais como clustering para agrupar documentos similares, classificação e regras de associação.

Módulo 3 - constrói uma representação gráfica da similaridade entre os artigos recuperados. Neste módulo são criados os mapas que representam os níveis de similaridade obtidos no módulo 2. Este módulo também é responsável pela interação com o usuário.

A arquitetura básica da ferramenta e a sequiência de procedimentos e técnicas utilizadas na mesma são descritas a seguir e representadas na Figura 1.5. É importante ressaltar que, além dos mapas que serão obtidos com a mineração dos dados, os usuários poderão fazer consultas no Data Warehouse para obter informações sobre os artigos recuperados da Web.

Na representação da ferramenta FIP (Figura 1.5), a primeira fase é responsável pela coleta de artigos da Web realizada por um sistema denominado WebMiner que teve o início do seu desenvolvimento em um trabalho de mestrado (Brasil, 2006; Brasil e Lopes, 2004) e continua em um trabalho atual. Nesta fase, são aplicadas técnicas de RI (Recuperação de Informação), assim como técnicas de mineração na Web e de mineração de texto, visando obter uma coleção de documentos relevantes que constituirão os corpora. 


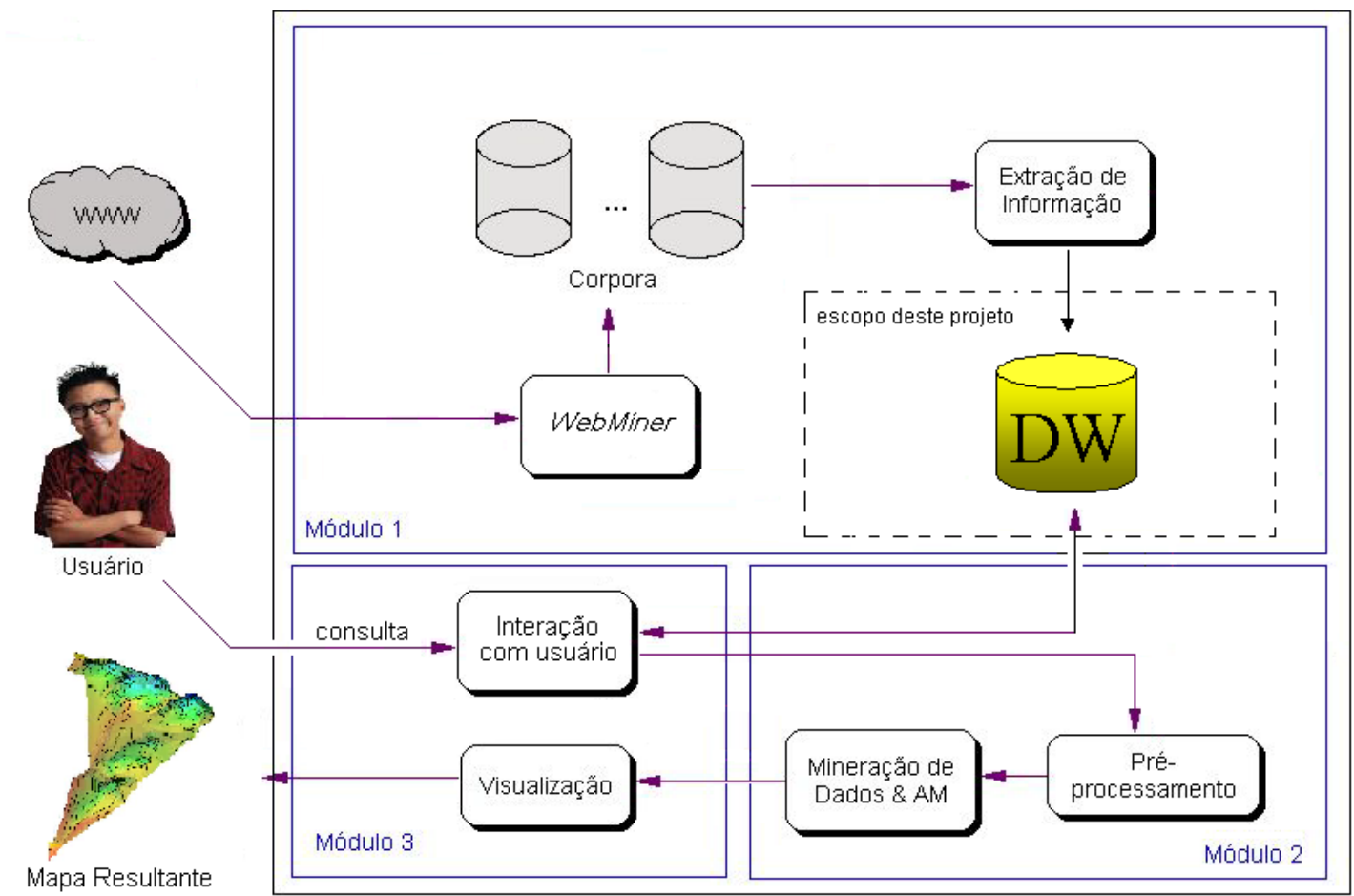

Figura 1.5: Ferramenta Inteligente de Apoio à Pesquisa (FIP)

Após a construção dos corpora, ocorre a extração das informações dos artigos científicos, tais como autores, resumo, referências, palavras-chave, etc. Um aluno está na fase de finalização do mestrado, onde desenvolveu um trabalho referente ao módulo 1 com técnicas indutivas, para construção de regras de extração das informações dos textos (Alvarez, 2006).

Em outro projeto de mestrado (Melo, 2005; Melo e Lopes, 2004b), referente ao módulo 2, utilizou-se técnicas de análise de agrupamentos (clustering) em textos científicos e definição automática de rótulos aos grupos obtidos. Para melhorar o desempenho da clusterização, o aluno trabalhou na extração e estruturação de referências bibliográficas de artigos científicos, propondo uma técnica baseada em regras para identificar registros duplicados (Melo et al., 2003; Melo e Lopes, 2004a, 2005).

\subsection{Objetivos}

Este trabalho de mestrado tem como objetivo projetar um Data Warehouse para armazenar as informações de artigos científicos que constituirão o repositório da ferramenta FIP.

$\mathrm{O}$ trabalho reuniu duas grandes áreas, data warehousing e data mining. Um data warehouse facilita a tarefa de mineração de dados ao fornecer dados integrados e pré-processados fazendo com que o esforço necessário na etapa de pré-processamento da mineração de dados seja enormemente reduzido. 
Aqui, a simbiose entre data warehouse e data mining tornou-se ainda maior, pois foram utilizados algoritmos de Data Mining / Aprendizado de Máquina para a indexação automática dos documentos, índices esses, necessários à modelagem multidimensional.

Para atingir o objetivo deste trabalho, foram realizadas as seguintes tarefas:

- Levantamento de requisitos, etapa na qual se determinou as informações relevantes sobre materiais científicos a serem armazenadas no data warehouse. Foram definidas as informações necessárias e úteis a pesquisadores em consultas e aplicação de técnicas de mineração de dados.

- Definição da arquitetura do data warehouse que atenda as necessidades da ferramenta FIP, levando em conta as dificuldades que surgem ao lidar com fontes de dados que mudam constantemente, como a Web, e informações não-estruturadas.

- Execução do primeiro ciclo da construção do data warehouse. A implementação permitiu a verificação de algumas potencialidades, vantagens e a viabilidade do uso das técnicas de data warehousing no projeto da ferramenta FIP.

- Outro importante assunto para os propósitos da FIP são os tópicos de pesquisa utilizados na construção dos mapas de documentos. Estes tópicos permitem aos usuários identificar os temas ou assuntos dos documentos explorados durante a visualização dos mapas. Neste trabalho de mestrado, os tópicos de pesquisa tiveram especial importância por terem sido utilizados na indexação de data marts da FIP. Uma das vantagens da construção de um data warehouse, que possui o aspecto histórico associado a seus dados é possibilitar a observação e detecção de tendências por meio de consultas. Ferramentas OLAP permitem essas consultas e melhoram o desempenho de tempo em relação àquelas feitas em bancos de dados convencionais. Algumas análises feitas em um data warehouse sobre publicações científicas podem se tornar interessantes ao levarem em consideração tópicos de pesquisa: um pesquisador pode, por exemplo, observar como certo tópico evolui no decorrer do tempo, observar aqueles que estão sendo mais explorados ou perdendo prioridade nas pesquisas ou ainda identificar tópicos novos que estão sendo investigados.

É importante salientar que este trabalho não tem em seu objetivo principal a tarefa de obter todas as informações contidas nos documentos recuperados da web. A forma como os documentos são recuperados da Web, ou como as informações são extraídas dos documentos são assuntos para outros trabalhos citados anteriormente.

\subsection{Organização do Trabalho}

Os próximos capítulos desta dissertação estão organizados da seguinte forma: no segundo capítulo são apresentados os dois assuntos centrais deste trabalho, Data Warehousing e Data Mining. No terceiro capítulo são apresentados os principais Repositórios de Artigos Científicos encontrados na Web, avaliando o atual estado destes repositórios e apresentando os principais índices utilizados por eles. O estudo sobre Repositórios de Artigos Científicos auxiliou na especificação 
dos tipos de informações que a FIP poderá disponibilizar em seu repositório. No quarto capítulo é descrito o desenvolvimento do data warehouse para a Ferramenta FIP, assim como algumas análises dos dados com uma ferramenta OLAP. No quinto capítulo são apresentados os experimentos com algoritmos de Data Mining/Aprendizado de Máquina para realizar a indexação automática dos documentos da FIP. Por último, no sexto capítulo são apresentadas as conclusões sobre este trabalho de mestrado. 



\section{Uma visão geral sobre Data Warehousing e Data Mining}

A construção de um data warehouse pode auxiliar o processo de análise de dados e de descoberta de conhecimento em base de dados (KDD - Knowledge Discovery in Databases). Mesmo não sendo essencial ao KDD, a utilização de um data warehouse faz com que a tarefa de préprocessamento dos dados, que é uma das mais custosas e trabalhosas no KDD, possa ser reduzida drasticamente (Pyle, 1999; Inmon, 1996b), permitindo ainda aos analistas focarem apenas na etapa da mineração de dados em si (extração de padrões). As técnicas utilizadas para a contrução de um data warehouse dão, portanto, suporte à mineração de dados. Além de auxiliar a etapa de préprocessamento dos dados, podem facilitar a comprovação das hipóteses encontradas na mineração (Rezende et al., 2003). Além disso, algumas técnicas de mineração de dados têm sido desenvolvidas de forma específica para aproveitar melhor o potencial de um data warehouse (Nestorov e Jukic, 2003).

Neste capítulo, são abordados os principais assuntos deste projeto de mestrado, data warehousing e data mining, apresentando seus conceitos e aplicações para a ferramenta FIP no domínio das publicações científicas.

\subsection{Data Warehousing}

A tomada de decisões rápidas e eficientes em empresas e organizações e o crescimento da quantidade de dados armazenados em seus bancos de dados criaram a necessidade do desenvolvimento de novas técnicas e tecnologias voltadas para a análise de dados (Inmon, 1996a). 
As tecnologias tradicionais atendem às necessidades de operações transacionais, também conhecidas como OLTP (On-Line Transaction Processing) (Kimball e Merz, 2000). Um exemplo desse tipo de operação é a movimentação de contas correntes em uma instituição financeira, sendo as principais operações neste tipo de sistema, alteração, inclusão, exclusão e consultas que acessam registros individuais e não grandes conjuntos de registros. Este tipo de operação ocorre muitas vezes em um mesmo dia e pode ser requisitada ao sistema simultaneamente por muitos usuários, necessitando uma resposta quase imediata do sistema.

Os sistemas OLAP (On-Line Analytical Processing), por sua vez, são projetados para apoiar análises e consultas, além de auxiliar seus usuários a sintetizar informações através de comparações, visões personalizadas e análises históricas (Inmon, 1996a; Ferreira, 2002). Os sistemas OLAP têm como característica principal permitir uma visão multidimensional dos dados, que é mais fácil e intuitiva, por meio de análises em diferentes perspectivas. Alguns tipos de informações podem ser interessantes ao gerente de um banco: "qual foi o crescimento do número de transações de um determinado tipo de cliente em certo período?", ou ainda, "houve redução do número de transações em agências de determinado Estado?”. Para obter respostas a estas perguntas, muitas vezes, é necessário percorrer diversas tabelas inteiras de um banco de dados. A consulta pode ainda ser realizada em mais de um lugar como, por exemplo, nos bancos de dados de cada agência. Nas consultas exemplificadas acima, seria necessário ainda que as tabelas consultadas armazenassem todo o histórico do cliente ao invés de manter apenas as informações mais recentes, o que resultaria em uma queda de desempenho dos sistemas de banco de dados.

O processamento analítico é necessário em diversas situações no qual se deseja obter informações referentes à evolução histórica. Consultas de mesma natureza da citada acima podem ser úteis a usuários da ferramenta FIP: "qual o crescimento do número de citações em determinada área de pesquisa em certo período?". O usuário poderia, por exemplo, observar tendências em pesquisas de determinadas áreas.

Uma das técnicas destinadas ao processamento analítico é o Data Warehousing que consiste nos processos de projeto, construção, acesso e gerenciamento de um Data Warehouse. Um Data Warehouse (DW) pode ser definido como um repositório de dados voltado à tomada de decisões gerenciais, que armazena grandes quantidades de dados centralizados, integrados, organizados por assuntos, históricos, resumidos e não voláteis (Kimball, 1996; Kimball et al., 1998; Inmon, 1996a; Rezende et al., 2003). O data warehouse, diferentemente de um banco de dados transacional, é otimizado essencialmente para a consulta.

As tecnologias de bancos de dados transacionais podem atender bem as operações sobre registros individuais, como a busca por um determinado artigo em um banco de dados de informações científicas. No entanto, elas podem não ser eficientes para o processamento analítico de grande quantidade de dados como um conjunto de registros sobre artigos. Por exemplo, consultas para obter informações como a quantidade de referências recebidas por um determinado artigo em alguns anos e em determinado lugar, podem apresentar um tempo de resposta na consulta muito menor utilizando técnicas de data warehousing. 
Os dados de um Data Warehouse podem ser coletados de diversas fontes tais como arquivos, outros bancos de dados e até mesmo outros data warehouses, centralizando toda informação em um único repositório. Assim, torna-se necessário integrar os dados provenientes de diversas fontes eliminando inconsistências dos dados originais e obtendo uma representação única.

Essa integração de dados faz com que um data warehouse deva ser construído de acordo com o interesse dos seus usuários, sendo assim, organizado de acordo com um assunto. No projeto da FIP, os assuntos são as publicações científicas na área de computação.

A questão da integração e centralização de informações de um DW torna-se fundamental para a ferramenta FIP. Diversos repositórios de artigos científicos na Web, sites de revistas e páginas pessoais de pesquisadores, que surgem de forma autônoma, servem como fonte de dados para a FIP. Entre outras diferenças de formatos encontradas nos materiais destas fontes, vale comentar as encontradas nas referências bibliográficas que são descritas de diferentes formas (Figura 2.1). A padronização dos dados dos artigos na FIP é feita imediatamente após da fase da extração de informação. Após serem identificadas as informações como título, nome do autor, data de publicação de cada documento, os dados são armazenados em um formato único no data warehouse da ferramenta FIP.

\begin{tabular}{l}
\hline $\begin{array}{l}\text { A. Aamodt. Knowledge intensive case-based reasoning and sustained learning. In } \\
\text { Proceedings of ECAI-90, pages 1-6, Stockholm, 1990. }\end{array}$ \\
\hline $\begin{array}{l}\text { [Aamodt, 1990] Agnar Aamodt. Knowledge intensive case-based reasoning and } \\
\text { sustained learning. }\end{array}$ \\
\hline $\begin{array}{l}\text { Aamodt, A. "Knowledge - Intensive Case-Based Reasoning and Sustained Lear- } \\
\text { ning”, Proceedings of 9th European Conference on Artificial Intelligence, 1990. }\end{array}$ \\
\hline
\end{tabular}

Figura 2.1: Diferentes formatos encontrados em referências bibliográficas de artigos.

Outra característica importante de um data warehouse é vincular um elemento temporal aos seus dados. Dados sobre um determinado assunto tratados em diferentes tempos são armazenados com um elemento temporal para permitir a execução de consultas que necessitem de um contexto histórico e que permitam análises de evolução e tendências.

No caso da FIP, o sistema de recuperação será executado com periodicidade definida e novos artigos serão recuperados. Isso permite analisar a persistência e volatilidade de documentos científicos na Web, utilizando-se de informações como os novos artigos que apareceram na Web ou links que foram perdidos. Estes tipos de análises serão detalhados no Capítulo 4 que trata do desenvolvimento do data warehouse da FIP.

Devido a grande quantidade de dados envolvida nas operações em um data warehouse, a carga a partir dos bancos de dados operacionais não pode ser feita a todo instante para não prejudicar o desempenho nas operações transacionais que exigem um tempo de resposta rápido. Assim, o data warehouse não é atualizado com tanta frequiência como é feito em uma base de dados operacional. Deve haver pouca ou nenhuma exclusão ou alteração dos dados de um DW, sendo a adição de 
novos dados a principal operação, realizada durante a fase de carga dos dados. Uma analogia pode ser feita sobre o data warehouse e o solo da superfície terrestre, onde camadas geológicas são adicionadas umas sobre as outras com o decorrer do tempo. Da mesma forma que um estudo sobre as camadas do solo podem fornecer uma análise histórica da região, mantendo os dados antigos no data warehouse da FIP torna-se possível fazer o mesmo tipo de análise histórica das áreas e sub-áreas relacionadas aos materiais científicos.

\subsubsection{ETL - Extração, Transformação e Carga dos Dados}

A fase da integração de dados dos sistemas de origem é considerada uma das mais complexas e trabalhosas no ciclo de vida do data warehouse. A extração, transformação e carga dos dados, necessárias à integração dos dados destes sistemas, é chamada de ETL (Extraction, Transfomation and Load). É importante não confundir a fase de ETL com a Extração de Informação, que se refere à obtenção de elementos específicos de um texto, como, por exemplo, título, autores, palavraschave, etc.

Na definição do processo de ETL de um data warehouse é necessário fazer a análise dos sistemas fontes para a compreensão e integração dos dados que se encontram de forma distribuída. A análise é necessária também para detectar inconsistências e variações de notação dos dados, além de especificar as técnicas e programas que serão utilizados.

O data warehouse da ferramenta FIP, que armazena informações de materiais científicos, possui como fonte de dados diversos sites e repositórios de artigos da Web (Figura 2.2). Assim, além de existirem diversas fontes de origem para o data warehouse, em uma mesma fonte pode haver artigos em diferentes formatos. De um ponto de vista mais amplo, os processos de recuperação dos artigos da Web, extração das informações dos documentos e a padronização dos dados poderiam ser considerados como parte do processo de ETL do data warehouse da ferrameta FIP. No projeto da ferramenta, é proposta a automatização de todos estes processos utilizando técnicas de Inteligência Artificial como métodos de Aprendizado de Máquina no módulo de recuperação de informação (Brasil, 2006) e técnicas indutivas para a Extração das Informações de textos (Alvarez, 2006). O estudo e desenvolvimento destes processos foram iniciados em outros trabalhos e fogem do escopo deste projeto de mestrado.

\subsubsection{Data Marts}

A operação de carga dos dados em um data warehouse faz com que o volume dos dados aumente com o passar do tempo, aumentando também o tempo de execução das consultas. Torna-se necessária, assim, a criação de estruturas de dados auxiliares que armazenem de forma adequada apenas as informações necessárias aos usuários. Inmon (1996b) descreve os Data Marts como estruturas de dados que contêm informações de acordo com interesse e necessidade do departamento 


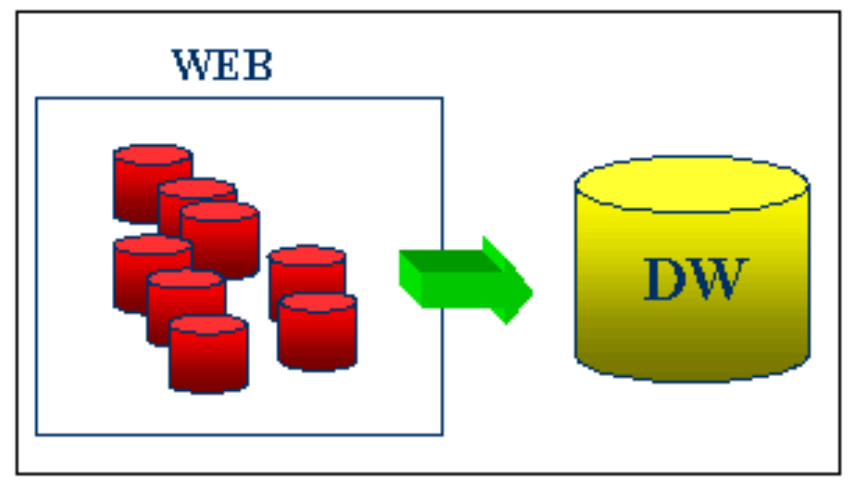

Figura 2.2: Integração de informações de documentos recuperados de diversas fontes da Web.

de uma organização, isto é, as informações são armazenadas por áreas ou assuntos específicos. Pode-se assim, restringir o acesso aos dados, tornando-o mais eficiente.

Uma estratégia de modelagem de dados comumente utilizada na construção de data marts é a modelagem multidimensional ou modelagem dimensional (Kimball, 1996), que torna as consultas realizadas nos data marts mais intuitivas. Nos data marts os dados podem ser armazenados de forma resumida, tornando mais fácil a navegação sobre os dados e diminuindo seu tempo de acesso devido a menor quantidade de tabelas e relacionamentos.

No modelo multidimensional alguns tipos de consultas podem ser realizadas com maior eficiência. Por exemplo, quantas referências ao artigo $\mathrm{X}$ foram feitas por outros artigos da Universidade Y? Quantas referências sobre o tema X foram publicados no ano Y? Ou quantos artigos do assunto $\mathrm{Z}$ foram publicados no país W? Essas informações podem ser obtidas em consultas de um banco de dados convencional, no entanto, o tempo de resposta de uma consulta em um data mart tende a ser muito menor.

Outros tipos de consultas apresentarão maior diferença no desempenho como aquelas relacionadas a tendências e que necessitam do acesso a uma grande quantidade de registros. Por exemplo, "quais foram os números de citações recebidas pelo artigo A em cada ano do período entre 1990 a 2000?”. Esse tipo de consulta apresentará um desempenho melhor em um data mart, além de possuir outras vantagens como a facilidade de uso das ferramentas OLAP que oferecem aos usuários interfaces adequadas para análises.

Nos sistemas OLTP o grande número de tabelas, com seus atributos e relacionamentos, dificulta o entendimento mesmo para usuários com maiores conhecimentos técnicos. Um pesquisador que queira fazer análises sobre o impacto de certos artigos na pesquisa em determinadas áreas pode não precisar ter o acesso a todas as informações de um banco de dados de materiais científicos. Pelo contrário, o excesso de detalhes pode atrapalhar a criação e o gerenciamento de consultas e conseqüentemente dificultar a análise. Assim, um modelo multidimensional que oferece recursos suficientes para obter o resumo das informações, como o número de citaçõs recebidas por um artigo, pode ser mais eficiente. 


\section{Modelo Estrela}

O modelo ou esquema Estrela é bastante utilizado para a modelagem multidimensional em bancos de dados relacionais. Neste modelo existem dois tipos de tabelas: a tabela fato e a tabela de dimensão (Kimball, 1996). Conforme mostrada na Figura 2.3, a tabela fato constitui o centro da estrela enquanto que as diversas possibilidades de tabelas dimensão mostradas representam as pontas da estrela.

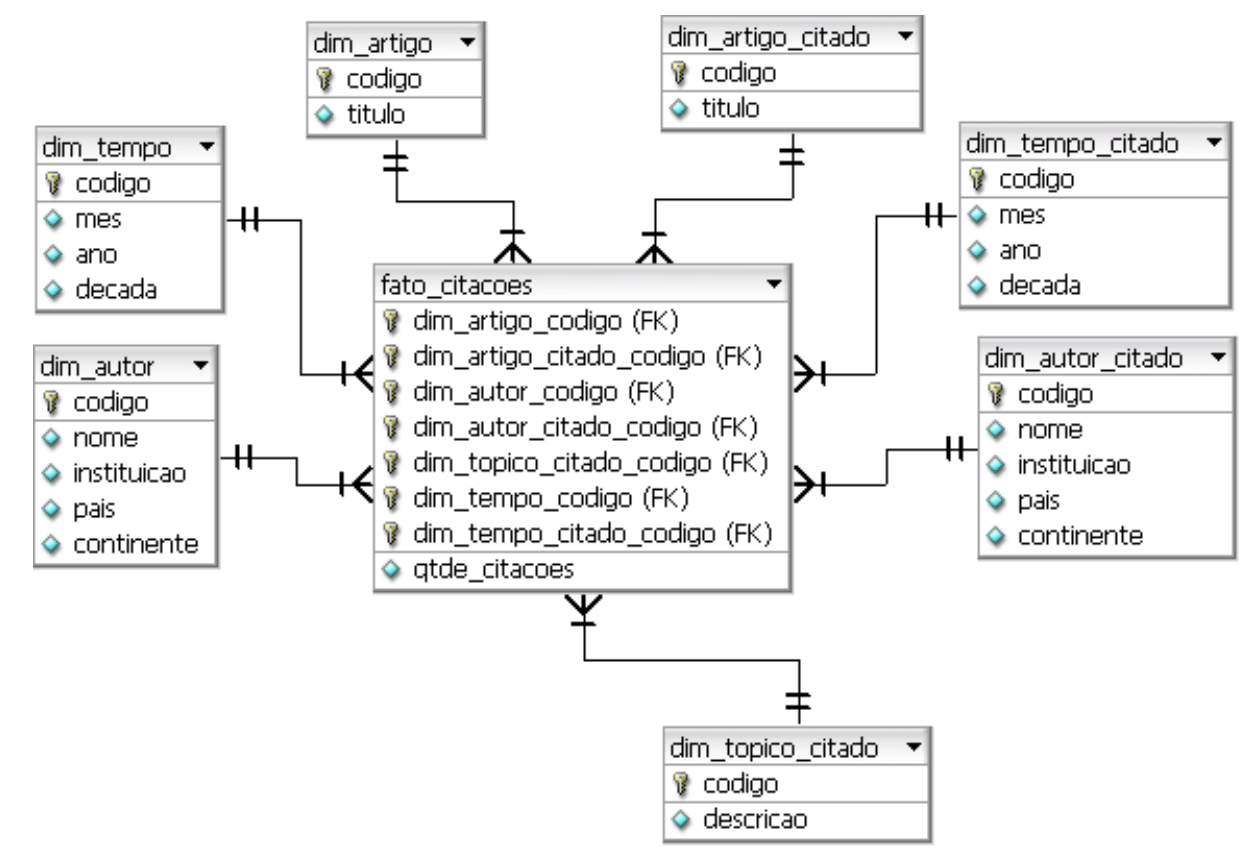

Figura 2.3: Esquema Estrela de citações entre artigos científicos

Uma tabela fato contém medidas como, por exemplo, preços, quantidade de vendas, ou no domínio dos materiais científicos, a quantidade de citações a um artigo. Estas medidas equivalem aos valores encontrados nas intersecções das dimensões dos cubos do modelo multidimensional apresentado anteriormente. A tabela fato deve estar associada a todas as tabelas dimensão por relacionamentos do tipo "muitos para um", sendo que a chave primária da tabela fato é a concatenação das chaves primárias das tabelas dimensão.

As tabelas dimensão armazenam informações descritivas e equivalem às dimensões de um cubo do modelo multidimensional como a época em que a citação foi feita, o tópico ou área abordada pelo artigo ou o autor que escreveu artigo. As tabelas dimensão geralmente não são normalizadas (Todman, 2001), apresentando redundância nos dados, e podem ser compostas por hierarquias de agregação como, por exemplo, década, ano e mês, ou ainda, continente, país e universidade do autor.

As tabelas dimensão do esquema apresentado na Figura 2.3 são:

dim_artigo: artigo que cita outro artigo.

dim_artigo_citado: artigo que recebeu a citação de outro artigo. 
dim_tempo: data de publicação do artigo que cita outro artigo.

dim_tempo_citado: data de publicação do artigo citado.

dim_autor_citado: autor do artigo citado.

dim_topico_citado: tópico do artigo citado.

Além deste modelo permitir a utilização de ferramentas de processamento analítico como as do tipo OLAP, apresentadas a seguir na seção 2.1.3, a vantagem de se utilizar o modelo estrela é a redução de operações de junção entre tabelas durante as consultas, resultando na otimização do tempo de acesso às informações.

Um esquema estrela similar a este foi utilizado na modelagem do data mart da FIP sendo que suas características e detalhes serão apresentados na Seção 4.3.1 do Capítulo 4.

\section{Esquema Snowflake}

Para evitar a redundância de dados presente no esquema estrela, pode ser utilizado o esquema Snowflake (Kimball, 1996; Inmon, 1996a) no qual as tabelas dimensão são normalizadas de forma a economizar espaço em disco e tornar a tarefa da manutenção da integridade dos dados mais eficiente nas operações que envolvem alterações nos dados.

No esquema estrela da seção anterior (Figura 2.3), a tabela dimensão de autores (dim_autor) possui dados sobre o continente, país e universidade de cada autor. Há redundância de dados nesta tabela, pois em todos os registros de autores de uma universidade de um mesmo país serão armazenados repetidamente os mesmos dados sobre aquele país e seu respectivo continente. Para evitar o armazenamento de dados repetidos, pode-se realizar o mesmo processo de normalização utilizado em bancos de dados transacionais, resultando na criação de outra tabela (país) como ilustrado na Figura 2.4. Como pode ser obervado na figura, outras tabelas dimensão que possuem hierarquias de agregação podem ser normalizadas criando outras tabelas.

Apesar do esquema estrela apresentar desvantagens em termos de espaço de armazenamento devido à redundância dos dados e, principalmente, fazer com que o desempenho diminua nas operações de atualização dos dados no qual o custo para manter a integridade é muito alto, esta característica não possui importância em um data mart por se tratar de uma estrutura de dados que sofre pouca ou nenhuma alteração. No esquema snowflake o número de relacionamentos entre as tabelas é maior, fazendo com que o tempo de execução das consultas aumente devido à necessidade de operações de junção. Durante a especificação das tabelas do data mart é importante levar em consideração estas caracteríticas de forma a normalizar tabelas somente nos casos em que não haja uma grande perda de desempenho. Em geral, recomenda-se utilizar o esquema estrela que possui tabelas desnormalizadas (Corey, 2001). 


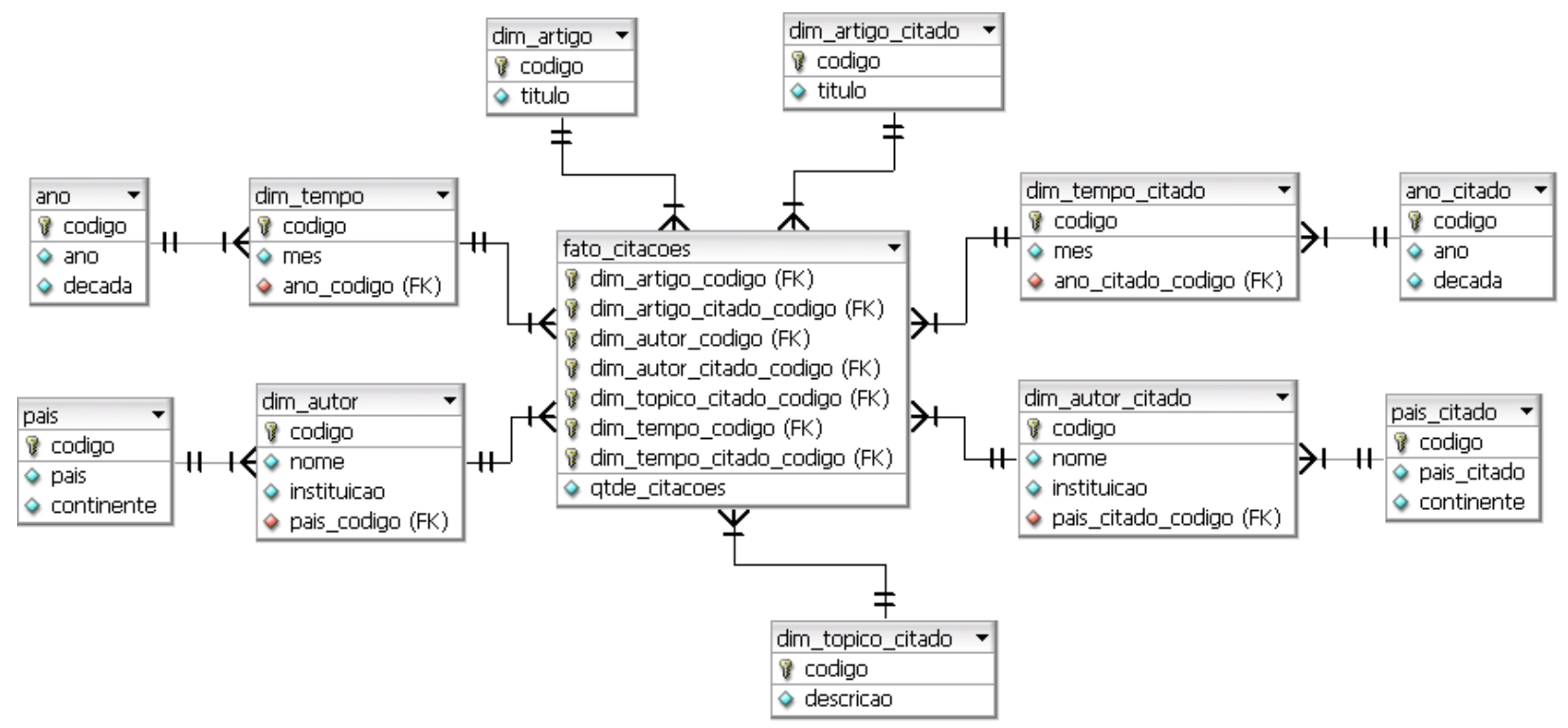

Figura 2.4: Esquema Snowflake. Normalização das tabelas do esquema estrela.

\subsubsection{Consultas OLAP}

Os modelos dimensionais, que podem ser representados por cubos, são de fácil entendimento mesmo para pessoas sem conhecimento em banco de dados como, por exemplo, gerentes de vendas. Para acessar informações em estruturas de dados deste tipo, tornam-se adequadas as ferramentas OLAP (On-Line Analytical Processing - Processamento Analítico On-Line) (Kimball, 1996; Inmon, 1996a; Berson e Smith, 1997) que permitem uma fácil visualização dos dados em diferentes perspectivas. As informações podem ser vistas em diferentes combinações de dimensões executando operações como as apresentadas a seguir. É importante observar que as informações armazenadas nos cubos são também facilmente extraídas para utilização de técnicas de Mineração de Dados convencionais.

\section{Operações em consultas OLAP}

No tipo de operação Pivot pode ser feita uma rotação no cubo de tal forma que as dimensões são trocadas para facilitar a visualização e navegação dos dados para o usuário. Na Figura 2.5, as dimensões autor e tempo são trocadas.

Com a operação Slice, pode ser feito um "corte" no cubo de dados gerando um sub-cubo que possui somente informações necessárias ao usuário. Ainda utilizando o exemplo da Figura 2.5, pode-se aplicar a operação Slice na dimensão Tópico. Dessa forma, será selecionado um tópico de pesquisa e todas as consultas serão realizadas restringindo aos artigos que abordam aquele assunto, podendo ainda navegar entre as outras dimensões Tempo e Autor.

Outra operação em bases multidimensionais é a Drill-down/up na qual o nível de detalhamento dos dados pode ser alterado. Por exemplo, é possível fazer uma pesquisa em informações relacionadas à localização dos autores como um continente ou, ao aumentar o nível de detalhamento, 


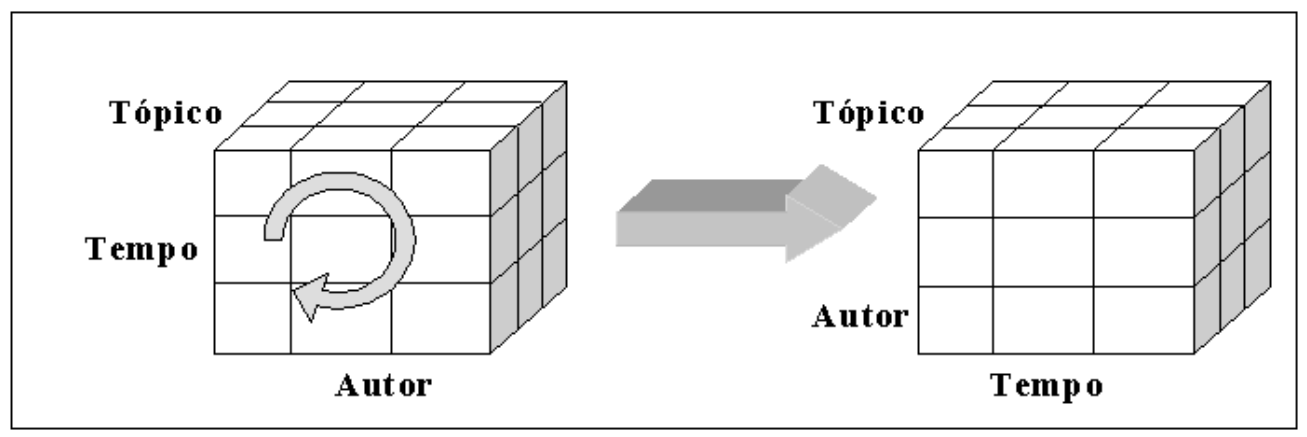

Figura 2.5: A operação Pivot rotaciona o cubo de dados

pode-se obter informações sobre um país em específico. Aumentando ainda mais o nível de detalhamento, obtém-se informações sobre instituições. Observa-se que ao descer no nível de uma hierarquia (drill-down) o nível de detalhamento aumenta.

\subsection{Mineração de Dados}

Outra tecnologia utilizada para lidar com informações em grandes bases de dados é a Mineração Dados (Data Mining). Devido a enorme quantidade de informações armazenadas em bases de dados, a tarefa da identificação de relações existentes nos dados torna-se muito difícil. Dessa forma, as técnicas de Data Mining tem por objetivo extrair conhecimentos úteis que estão implícitos nos dados (Fayyad et al., 1996a,b).

Embora seja comum usar os termos KDD (Knowledge Discovery in Databases) e Data Mining com o mesmo sentido, Fayyad (Fayyad et al., 1996b) define o KDD como todo o processo da extração de conhecimento dos dados, e data mining, uma etapa particular do KDD, na qual são aplicados os algorítmos específicos para extração de padrões dos dados.

O processo de Data Mining pode ser dividido em três etapas iterativas principais (Rezende et al., 2003): o pré-processamento dos dados, a extração dos padrões e o pós-processamento. Antes destas etapas, deve ser executada a etapa da identificação do problema, e após, a utilização do conhecimento (Figura 2.6).

A descoberta de conhecimento em bases de dados também é considerado um processo interativo, no qual existe a necessidade do conhecimento de domínio da aplicação do usuário que é utilizado desde a preparação dos dados na etapa de pré-processamento, na execução do processo de mineração de dados e na validação do conhecimento extraído. Os usuários que iteragem no processo podem ser divididos em três classes (Rezende et al., 2003): o especialista do domínio que deverá possuir entendimento do domínio da aplicação, o analista que deve entender e executar os processos da mineração de dados, e o usuário final que irá utilizar e validar o conhecimento obtido. 


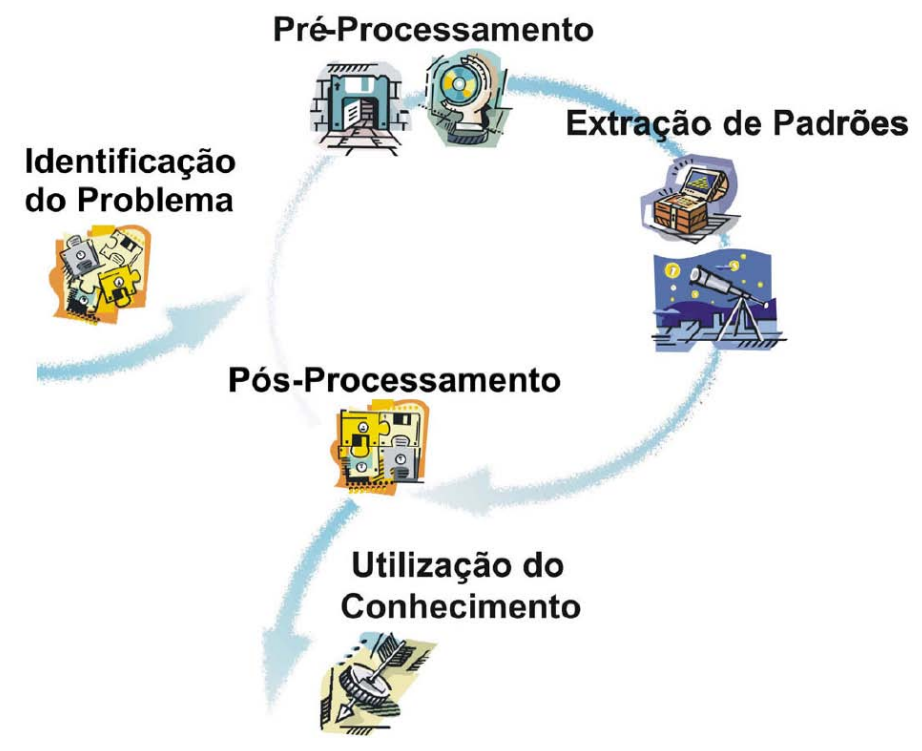

Figura 2.6: Etapas do processo de Data Mining(Rezende et al., 2003)

\subsubsection{Etapas do KDD}

O processo da descoberta de conhecimento inicia-se com a identificação do problema no qual é realizado um estudo sobre o domínio da aplicação e os objetivos a serem alcançados (Rezende et al., 2003). Nesta fase são considerados alguns aspectos relacionados às fontes de dados da aplicação e ao interesse dos usuários. Esta fase é de suma importância por determinar a escolha dos algoritmos levando-se em conta os custos e a viablidade da aplicação.

O ciclo iterativo do processo de descoberta de conhecimento inicia-se no pré-processamento dos dados. Na maioria das vezes os dados apresentam-se de forma inadequada para a utilização dos algoritmos de extração de padrões (Batista, 2000). Como muitos algoritmos requerem muitos recursos de memória e processamento, em alguns casos torna-se necessário selecionar apenas uma amostra representativa dos dados de uma base. Na maioria das vezes, tornam-se necessários os processos de limpeza e preparação dos dados devido às limitações impostas pelos algoritmos. Esta etapa é considerada a mais trabalhosa e a que toma maior parte do tempo (Pyle, 1999). Assim, o processo da descoberta de conhecimento é muito facilitado quando os dados estão armazenados em um data warehouse que possui os dados padronizados e integrados (Inmon, 1996b).

Após o pré-processamento dos dados, inicia-se a etapa de extração de conhecimento na qual são utilizados métodos e algoritmos para encontrar relacionamentos e padrões implícito nos dados. Essa etapa deve ocorrer de acordo com os objetivos definidos na etapa da definição de problemas. Alguns aspectos, como o tipo da tarefa de mineração, irão influenciar na escolha do algoritmo utilizado nesta etapa.

A tarefa da mineração de dados é classificada em dois principais tipos, a atividade preditiva e a descritiva. As tarefas de classificação e regressão são preditivas, no entanto, enquanto a primeira prediz um atributo discreto, na regressão o atributo é contínuo. Na atividade descritiva não há 
classes pré-definidas, ou seja, o usuário não as conhece previamente. As principais atividades descritivas são Clusterização, Regras de Associação e Sumarização.

Alguns parâmetros, como o tipo de tarefa de mineração de dados e a forma como os padrões serão representados, são determinados pelos interesses do usuário final e conseqüentemente influenciará na escolha do algoritmo. Por exemplo, se um usuário necessita entender o padrão obtido na mineração, não poderiam ser utilizados algoritmos como os de Redes Neurais Artificiais, que de modo geral funcionam como caixas-preta, ou seja, o padrão reconhecido por esses algoritmos não necessita ser representado de forma inteligível aos humanos (Baranauskas, 2001).

Após serem encontrados os padrões, inicia-se a etapa do pós-processamento. Nesta etapa os padrões são avaliados quanto sua qualidade e utilidade de forma que o usuário deve validar o conhecimento extraído, julgando sua relevância. Ocorre, assim, uma filtragem nos novos conhecimentos, removendo aqueles redundantes e irrelevantes para que possam ser utilizados pelo usuário final. Por último, o conhecimento extraído é disponibilizado ao usuário, constituindo a etapa da Utilização do Conhecimento.

\subsubsection{Aprendizado de Máquina}

Os algoritmos de aprendizado de máquina têm sido utilizados na tarefa da mineração de dados por possuírem a característica de adquirir novos conhecimentos por meio de exemplos. Estes algoritmos podem ser classificados em supervisionado e não supervisionado (Monard e Baranauskas, 2003). No aprendizado supervisionado, as classes dos exemplos a serem preditas são conhecidas e pré-definidas. São utilizados exemplos de treinamento rotulados, nos quais cada exemplo é representado por seus atributos, ou seja, suas características, e um atribuito especial que identifica o rótulo ou a classe a qual pertence. Todos os atributos, inclusive os rótulos, são utilizados como a entrada para os algorítmos na etapa de aprendizagem. Estes algoritmos, denominados indutores, têm o objetivo de obter um classificador capaz de classificar uma nova instância não rotulada, isto é, predizer a classe de um novo caso. O aprendizado de máquina supervisionado corresponde à tarefa de predição da mineração de dados.

Da mesma forma, o aprendizado de máquina possui um correspondente à tarefa de descrição da mineração de dados que é o aprendizado não-supervisionado, no qual não são apresentadas classes pré-definidas.

Além da classificação quanto ao aprendizado ser ou não supervisionado, ele também pode ser classificado segundo alguns dos paradigmas de Aprendizado de Máquina (Rezende et al., 2003) brevemente apresentados a seguir.

- Simbólico: estes sistemas buscam o aprendizado de um conceito através da análise de exemplos e contra-exemplos. Possui como uma das características principais a relativa facilidade na compreensão humana da representação dos classificadores induzidos. Assim, os sistemas simbólicos utilizam algum tipo de expressão lógica, árvores de decisão, regras de produção ou rede semântica para representar o aprendizado e o conhecimento. 
- Estatístico: utilizam métodos e medidas estatísticas para encontrar uma boa aproximação do conceito induzido. São utilizados métodos paramétricos, no qual se deseja, a partir dos dados, determinar os valores apropriados para os parâmetros.

- Baseado em exemplos: sistemas que classificam novos exemplos por meio de exemplos similares conhecidos.

- Conexionista: estes sistemas utilizam construções matemáticas denominadas redes neurais que são inspiradas no modelo biológico do sistema nervoso. As redes neurais realizam o processamento em paralelo de unidades simples que são altamente interconectadas entre si.

- Evolutivo: este paradigma é baseado na teoria da evolução natural partindo do pressuposto de que indivíduos com melhores características genéticas têm maiores chances de sobrevivência e de produzirem indivíduos cada vez mais aptos. O classificador evolutivo é constituído de uma população de elementos de classificação que competem entre si para fazer a predição. Aqueles que possuem melhor desempenho, ou seja, os candidatos mais promissores para a solução de um determinado problema, sobrevivem e se proliferam criando variações de si mesmos, enquanto que os demais são descartados.

Observamos que nos experimentos (Capítulo 5) de indexação automática dos documentos, isto é, a determinação dos tópicos presentes na coleção de documentos, serão utilizados os algoritmos de aprendizado simbólico ID3 e J48 (C4.5) brevemente comentados a seguir.

O ID3 é um algoritmo que gera árvores de decisão para a tarefa de classificação no qual se distingue exemplos positivos de exemplos negativos de um conceito (Mitchell, 1997). O algoritmo cria a árvore de decisão a partir dos exemplos de treinamento utilizando o método de indução TDIDT (top-down induction of decision trees).

O algoritmo ID3 é considerado não incremental, pois todos os exemplos de treinamento devem estar disponíveis no início do processo. Ele também utiliza indução por cobertura simultânea que considera todos os exemplos para a escolha de um atributo na árvore de decisão. Para a geração da árvore, são utilizados exemplos de treinamento rotulados que possuem os atributos e a classe a que pertence. Aplica-se uma função de avaliação para cada atributo verificando aquele que discrimina melhor os conceitos positivos dos negativos, deixando na raiz da árvore de decisão o atributo mais "informativo". O processo é recursivo, gerando sub-árvores até que se atenda um critério de parada, que no caso ideal seria obter nodos contendo apenas exemplos de uma mesma classe (entropia zero).

A função de avaliação é utilizada para determinar atributos com maior ganho de informação, isto é, aqueles que são os mais relevantes na discriminação de um conceito. A função baseia-se em uma medida de entropia, que pode ser entendida como uma medida de desordem na coleção de exemplos. Assim, quanto maior a entropia, mais misturados estão os exemplos na coleção.

Para deixar os atributos mais discriminante próximos à raiz da árvore, escolhe-se os atributos que possuem maior ganho de informação, que é a diferença entre entropias do conjunto inicial e dos conjuntos dos dados após seu particionamento de acordo com o teste sobre o atributo escolhido. 
A estratégia do algoritmos ID3 é maximizar a diferença de entropia entre o conjunto inicial e suas partições. No entanto, como os atributos podem não conseguir discriminar todos os exemplos das classes, a entropia pode nunca chegar ao valor zero. Assim, a condição de parada é dada quando não houver mais variação de entropia.

Assim como outros algoritmos que usam indução de árvores de decisão, o ID3 baseia-se no princípio da Navalha de Occam, que determina a preferência por explicações mais simples. Dessa forma, o viés (bias) de indução, que é a preferência por uma hipótese sobre as outras, é dada pela preferência por árvores de menor altura (com atributos que proporcionam maior ganho de informação nos nós mais próximos à raiz).

Durante a busca do melhor classificador não são avaliadas todas as hipóteses. O algoritmo faz uma "busca gulosa" ( greedy), escolhe um caminho e não volta para verificar todas as alternativas durante o processo da construção da árvore. Não há, dessa forma, a garantia de se construir o melhor modelo.

À medida que a complexidade do classificador induzido aumenta, ou seja, as árvores de decisão se tornam maiores, pode ocorrer um overfitting, que é o ajuste excessivo das árvores aos exemplos de treino. Outras características importantes do ID3 é que alterando ordem dos exemplos, a árvore gerada é a mesma e o algoritmo gera boas árvores de decisão mesmo com ruído nos dados.

O algoritmo C4.5 (Quinlan, 1993) sofreu algumas melhorias em relação ao ID3, sendo considerado um dos seus sucessores. Entre as principais melhorias, estão as estratégias da construção das árvores de decisão. Além da estratégia de divisão e conquista utilizada no ID3, o C4.5 utiliza também a cobertura seqüencial. Durante o processo iterativo da construção das árvores de decisão com a cobertura seqüencial, são criadas regras, a partir dos ramos das árvores, que cobrem a maioria das instâncias. As instâncias cobertas pelas regras são removidas e este processo é repetido gerando novas regras até que não restem mais instâncias não cobertas.

O algoritmo apresenta também uma otimização no processo de criação de janelas em relação ao algoritmo ID3. Um subconjunto dos exemplos, proporcional a quantidade de exemplos das classes de todo o conjunto de treinamento, é selecionada aleatoriamente. A partir deste subconjunto é criada uma árvore de decisão para classificar os exemplos que não foram incluídos na janela. Os exemplos classificados incorretamente são adicionados à janela e é gerada uma nova árvore de decisão. Este ciclo se repete até que todos os exemplos não pertencentes à janela sejam classificados corretamente.

Este processo é executado diversas vezes gerando diferentes árvores a partir de diferentes janelas iniciais geradas aleatóriamente. Por fim, é considerada a árvore com menor erro, fazendo com que o classificador obtido dessa forma, seja mais correto que o gerado por uma única árvore.

\subsubsection{Medidas de avaliação}

Alguns métodos são utilizados para avaliar qualidade e para escolher o melhor entre os modelos obtidos na etapa de mineração de dados. Um destes métodos é o cross-validation que estima, 
por meio de várias amostragens, a qualidade média do modelo obtido. No cross-validation são realizadas $\mathrm{N}$ iterações com o conjunto de dados dividido em $\mathrm{N}$ partições. Em cada etapa, uma das partições é utilizada como conjunto de teste, e as demais N-1 partições formam o conjunto de treinamento, a partir do qual será obtido o modelo.

O stratified cross-validation, utilizado nos experimentos deste trabalho, é muito semelhante ao cross-validation, no entanto, considera a proporção de exemplos de cada classe no momento de gerar as partições, isto é, a mesma proporção dos exemplos de cada classe do conjunto de treinamento é mantido em cada partição.

As medidas de qualidade dos modelos utilizadas no cross-validation podem ser calculadas a partir da matriz de contingência ou confusão. A Tabela 2.1 apresenta uma matriz de confusão para duas classes (classe positiva e classe negativa), na qual $t_{p}$ representa a quantidade de exemplos positivos que foram preditos como positivos (verdadeiro positivo), $f_{n}$ representa a quantidade de exemplos positivos preditos incorretamente como negativos (falso negativo), $f_{p}$ representa a quantidade de exemplos negativos preditos como positivos (falso positivo) e $t_{n}$ a quantidade de exemplos negativos preditos corretamente como negativos (verdadeiro negativo).

\begin{tabular}{c|c|c}
\hline & Predito como positivo & Predito como negativo \\
\hline Exemplos positivos & $t_{p}$ & $f_{n}$ \\
\hline Exemplos negativos & $f_{p}$ & $t_{n}$ \\
\hline
\end{tabular}

Tabela 2.1: Matriz de confusão para duas classes

Os valores da matriz de confusão podem ser aplicados no cálculo de medidas como Precision, Recall e Accuracy, utilizadas para avaliar a qualidade dos modelos obtidos.

A medida precisão (Precision) é calculada pela proporção dos exemplos positivos corretamente preditos sobre a quantidade de todos exemplos preditos como positivos. Isto é, dentre todos aqueles preditos como positivos, determina a porção dos que são de fato positivos.

$$
\text { Precision }=\frac{t_{p}}{\left(t_{p}+f_{p}\right)}
$$

A medida cobertura (Recall) é obtida pela proporção dos exemplos positivos preditos corretamente sobre todos os exemplos positivos. Ou seja, dentre todos os exemplos positivos, qual a porção dos que foram preditos corretamente como positivos.

$$
\text { Recall }=\frac{t_{p}}{\left(t_{p}+f_{n}\right)}
$$

Ao contrário das medidas anteriores que levam em conta, entre os corretamente classificados, apenas os exemplos positivos, a medida acurácia (Accuracy) considera todos os exemplos preditos corretamente, negativos e positivos. O cálculo é obtido pela proporção de todos os exemplos preditos corretamente sobre a quantidade total de exemplos. 


$$
\text { Accuracy }=\frac{t_{p}+t_{n}}{\left(t_{p}+f_{p}+t_{n}+f_{n}\right)}
$$

Neste trabalho foram utilizadas algumas técnicas de aprendizado de máquina para detecção automática de tópicos de pesquisa, visando a indexação dos documentos no data warehouse. A seguir são apresentados alguns trabalhos relacionados ao assunto.

\subsubsection{Detecção de tópicos de pesquisa}

Muitos trabalhos relacionados a identificação de tópicos de pesquisa utilizam a combinação de métodos de clusterização de documentos e extração de palavras-chave (keywords) (Das-Neves et al., 2005; Rennie, 2004). Os métodos de clusterização são utilizados para encontrar grupos de documentos similares. Cada cluster pode ser rotulado automaticamente por palavras-chave sem a necessidade da definição manual destes termos de indexação. Esta abordagem baseia-se na avaliação estatística de co-ocorrências de palavras. Não são consideradas informações semânticas explícitas, levando-se em conta apenas as frequiências de termos encontrados nos documentos. Assim, não é utilizada qualquer informação de significado das palavras em domínios como a pesquisa científica, onde há grandes e rápidas mudanças no vocabulário, e que torna difícil fixar estruturas como dicionários ou listas de palavras definidas manualmente.

Alguns métodos de busca por palavras-chave combinados com técnicas de clusterização utilizam medidas da teoria da informação como a entropia (Nürnberger, 2001). Esta combinação tem sido utilizada para possibilitar a representação gráfica, em forma de mapas, dos clusters de documentos (Hagman et al., 2000; Azcarraga et al., 2004). Para a construção destes mapas podem ser utilizadas arquiteturas de redes neurais como Growing Self-organizing Map.

Muitos dos métodos de extração de palavras-chave utilizam técnicas de processamento de língua natural (PLN), como a sumarização, onde se busca os elementos principais que possam oferecer o tema ou assunto de um texto (Hearst, 1997). Nestes métodos é comum ser utilizada uma segunda abordagem, que leva em conta análises léxicas, sintáticas e semânticas, apresentando grandes dificuldades devido a complexidade da linguagem humana (Andrade e Valencia, 1998).

Além da tarefa da obtenção de palavras-chave, técnicas de PLN são utilizadas na detecção de tópicos em textos. O termo tópico, em PLN, pode ter um significado diferente do utilizado neste trabalho de mestrado. Em comum, os dois sentidos permitem representar artigos por um conjunto de termos que, embora não sejam necessariamente como uma descrição narrativa, são compactos e têm uma representação inteligível ao ser humano. Torna-se um identificador de resumo que permite a uma pessoa rapidamente saber o assunto relacionado. A diferença da utilização do termo tópico, é que em PLN é muito comum ser representado não somente por palavras-chaves, mas por expressões ou frases inteiras que representem o texto. Apesar desse conceito também poder ser utilizado no domínio de publicações científicas, o objetivo do trabalho apresentado neste capítulo 
se restringe à obtenção de um conjunto de palavras que mais se assemelham às palavras-chave, e não a frases inteiras.

Outro aspecto importante a ser observado nas pesquisas relacionadas à obtenção automática de tópicos, é a grande variedade dos tipo de textos utilizados nas aplicações. É muito comum a utilização de textos como noticiários, e-mails e fóruns de discussão da Web (Bigi et al., 2001). É importante ressaltar que a mudança de domínios e fontes dos textos pode fazer com que os resultados das técnicas utilizadas nos experimentos também variem.

Os experimentos apresentados neste trabalho podem ser classificados como pertencentes à área chamada TDT (Topic Detection and Tracking) (Allan et al., 2000; Makkonen, 2003), que como o próprio nome diz, tem como um dos objetivos a detecção de tópicos. A quantidade de materiais recentes nesta área é muito grande, no entanto, como já mencionado anteriormente, muitas vezes o termo tópico apresenta outro sentido ou são realizados experimentos com outros tipos de documentos e domínios diferentes.

Outra abordagem recente usa regras de associação para determinação de co-ocorrências ( $n$ gram, comentado na próxima seção) que descrevem bem tópicos de conjuntos de documentos (Lopes et al., 2007). Esta abordagem, embora desenvolvida com a participação do grupo da FIP, não foi testada no âmbito deste trabalho por estar disponível na fase final do mesmo.

Este trabalho de mestrado apresenta uma técnica para obtenção automática de tópicos na qual são consideradas séries com as frequiências dos termos que aparecem nos títulos das publicações para cada ano. Não são utilizadas informações semânticas ou sintáticas para selecionar as palavras que definem o assunto de um artigo. Além disso, enquanto as técnicas como clusterização consideram um subconjunto de documentos para a extração dos tópicos, ou ainda, algumas técnicas de extração de keywords levam em conta os documentos individualmente, na técnica utilizada neste trabalho são considerados os termos extraídos de todos os títulos dos documentos. 


\section{Repositórios de Artigos Científicos}

\subsection{Introdução}

Cada vez mais os repositórios de artigos científicos tornam-se importantes para a disponibilização dos materiais científicos na Web. Estes sistemas permitem uma maior e mais rápida disseminação das informações no meio científico, facilitando seu acesso aos pesquisadores, independentemente de sua localização. À medida que a quantidade dos materiais científicos aumenta, a busca e análises automáticas sobre as informações tornam-se importantes para os pesquisadores.

A ferramenta FIP pretende armazenar artigos recuperados da Web e fazer análises sobre este material. Para tal, a FIP também contará com um repositório de artigos. O levantamento realizado sobre os repositórios existentes na Web, apresentados neste capítulo, auxiliou na etapa da especificação do repositório da FIP, proposta nesta dissertação.

Nas próximas seções são apresentados alguns dos mais importantes e representativos repositórios encontrados na Internet. Também são apresentados os índices bibliométricos utilizados pelos repositórios em suas análises e novas propostas de índices para tentar suprir eventuais deficiências encontradas nos índices tradicionais.

\subsection{Repositórios de artigos na Internet}

Os repositórios de artigos podem ser classificados pela forma como selecionam os materiais que armazenam. A seleção pode ser feita sobre as revistas ou sobre artigos individualmente ou, 
ainda, pode não haver nenhuma seleção, isto é, não havendo nenhum critério, qualquer material pode ser armazenado.

Nos repositórios onde se faz algum tipo de avaliação, há uma tendência em se manter a qualidade dos artigos. Muitos dos sites que fazem a seleção através das revistas possuem acesso restrito a pesquisadores de universidades conveniadas ou pessoas físicas que pagam para ter o acesso ao material. Em geral, para avaliar as revistas existe um comitê consultivo que adota critérios como caráter científico da revista, arbitragem por pares, periodicidade, duração e pontualidade.

Em alguns sites de artigos, a busca se restringe a recuperar materiais principalmente da própria revista. Os sites das revistas mais conhecidas e utilizadas na área de computação são o $\mathrm{ACM}^{1}(A s$ sociation for Computing Machinery) e o IEEE $^{2}$ (Institute of Electrical and Electronic Engineers). Além dos artigos, há outros materiais como livros, documentos de conferências e workshops e relatórios técnicos. Uma característica importante destes sites é a grande quantidade de documentos disponíveis desde as suas primeiras publicações permitindo análises que consideram a evolução histórica deste material e temas abordados por eles. Nesse tipo de site, existem sistemas de busca para realizar as consultas, como busca por autor, título, etc, e é utilizado algum critério de relevância para a ordenação do resultado da busca.

No sistema de busca do site da ACM, a relevância de um documento é baseada na quantidade de termos presentes no documento que foram especificados na busca. Caso o usuário especifique mais de um termo, a relevância dos documentos é determinada também pela proximidade dos termos no documento. Há também os sites como o Portal Capes ${ }^{3}$ que não possui links diretamente para artigos, mas links para outros sites de revistas.

Um dos sites mais conhecidos internacionalmente é o ISI ${ }^{4}$ (Institute for Scientific Information) que oferece acesso a mais de 7000 revistas e 1400 editoras nas áreas de Ciências Exatas e Sociais. O ISI criou o SCI (Science Citation Index) (ISI, 2003; Rousseau, 1998; Yao e Yao, 2003), que define alguns dos índices mais utilizados no meio científico. Tais índices serão apresentados nas próximas seções. A avaliação do repositório do ISI é feita sobre as revistas e não sobre os artigos individualmente. A avaliação é realizada por especialistas exigindo, assim um esforço manual e de alto custo. O ISI passou a oferecer algumas ferramentas de análises e estatísticas de citação a partir de 1997, permitindo a identificação das revistas de seu repositório citadas com maior frequiência e aquelas que têm maior impacto nas pesquisas.

A análise do ISI, feita sobre as revistas, baseia-se na Lei de Bradford, que diz: "um número relativamente pequeno de revistas publicam todos os resultados científicos relevantes" (ISI, 2003; Testa, 1998). Assim, todas as análises são feitas apenas sobre as revistas que foram aprovadas e que estão disponíveis no site. Esse critério é questionado por pesquisadores da área, como Sidiropoulos e Manolopoulos (2003), por não levar em conta a importância dos autores dos artigos que fizeram

\footnotetext{
${ }^{1}$ www.acm.org

${ }^{2}$ www.ieee.org

${ }^{3}$ www.periodicos.capes.gov.br/

${ }^{4} \mathrm{http} / / / \mathrm{www}$. isinet.com
} 
a citação, bem como a importância dos congressos e revistas nos quais foram publicados. Esse assunto será detalhado mais adiante.

No Brasil, há um repositório similar ao ISI. O SciELO ${ }^{5}$ (Scientific Eletronic Library Online) (Oliveira, 2001; Packer, 1998) divulga 52 revistas científicas e oferece acesso gratuito além das informações sobre citações e índices sobre seu material.

No sentido contrário aos sites que possuem acesso restrito, iniciativas como a Open Archives (Lagoze e de Sompel, 2001; Suleman, 2001; Smith et al., 2002) vêm estimulando a rápida e automática difusão das informações. Os Open Archives são repositórios de trabalhos científicos em forma digital que podem ou não ter sido avaliados. No entanto, esse material não é aceito como citação de produtividade do pesquisador e nem reconhecidos por agências de fomento. Neste tipo de repositório há materiais sobre conferências, monografias, relatórios técnicos, preprints (documentos que ainda não foram revisados e aceitos por uma revista), anotações e atualizações feitas por autores.

Antes de apresentarmos outros importantes repositórios, serão mostrados na próxima seção os índices bibliométricos tradicionais utilizados por estes repositórios para a criação de rankings de seus materiais.

\section{3 Índices bibliométricos ISI}

Os índices SCI (Science Citation Index) (ISI, 2003; Garfield, 1979) criados pelo ISI (Institute for Scientific Information) têm sido utilizados durante décadas pela comunidade acadêmica para avaliar revistas em diversos campos científicos, incluindo a área de ciência da computação.

Os índices bibliométricos tentam quantificar características como a qualidade, a importância e impacto de artigos, revistas, autores e universidades na pesquisa. Esses índices podem ser utilizados como medidas de produtividade para avaliar contratações de funcionários, financiamento de projetos, níveis salariais, etc. Além disso, também podem ser utilizados em estudos como tendências das pesquisas e outros de interesse de profissionais como bibliotecários, editores, redatores, autores, professores, estudantes e analistas de informações.

Para especialistas da área como Rogério Meneghini, assessor da diretoria científica da Fapesp (Fundação de Amparo à Pesquisa do Estado de São Paulo) e um dos idealizadores da SciELO, a arbitragem por pares deve ser mantida, mas deve ser combinada com outros índices durante a avaliação de uma revista (Antonio e Packer, 1998; Meneghini, 1998). "Isso é explicado pela estreita correlação entre as duas formas de se avaliar, a avaliação por pares e os índices, mostrando a validade das duas". Os índices mais conhecidos e utilizados são: fator de impacto, índice de imediação, vida média de citações, taxa de autocitação e taxa-autocitada. Tais índices são apresentados em detalhes a seguir.

\footnotetext{
${ }^{5}$ http://www.scielo.br
} 


\section{Fator de impacto}

O mais utilizado dos índices é o fator de impacto. Este índice oferece uma forma de avaliar ou comparar a importância relativa dos artigos de uma revista em relação a artigos de outras revistas do mesmo campo. Este índice, assim como os demais apresentados a seguir, são aplicados sobre o conjunto de artigos de uma revista, de tal foma a avaliar indiretamente a revista. O cálculo do fator de impacto é obtido pelo número de citações de artigos publicados em um determinado ano a artigos dos dois anos anteriores, dividido pelo número de artigos publicados nos dois anteriores.

Seja,

$y:$ o ano em questão

$C_{y-1}$ : número de citações da revista do ano $y$ a artigos publicados em $y-1$

$C_{y-2}$ : número de citações da revista do ano $y$ a artigos publicados em $y$-2

$P_{y-1}$ : número de artigos publicados em $y-1$

$P_{y-2}$ : número de artigos publicados em $y-2$

O fator de impacto $\left(F I_{y}\right)$ para o ano $y$ é dado por:

$$
F I_{y}=\frac{C_{y-1}+C_{y-2}}{P_{y-1}+P_{y-2}}
$$

Exemplo para o cálculo do fator de impacto:

\section{Fator de impacto de artigos de uma revista de 2007}

Citações em 2007 a artigos publicados em $2006=89$

Citações em 2007 a artigos publicados em $2005=114$

$\mathbf{T C}=$ Total de citações $=89+114=\mathbf{2 0 3}$

Número de artigos publicados em $2006=100$

Número de artigos publicados em $2005=96$

$\mathbf{T A P}=$ Total de artigos publicados em 2006 e $2005=100+96=\mathbf{1 9 6}$

Fator de impacto $=\mathrm{TC} / \mathrm{TAP}=203 / 196=\mathbf{1 , 0 3 6}$

Para alguns campos de investigação, pode ser útil comparar as taxas médias de citações utilizando períodos de tempo mais longos. Os períodos mais comuns utilizados são 5 e 2 anos, no entanto, pode-se utilizar qualquer valor dependendo do domínio científico e dos propósitos estatísticos.

Pode-se também desconsiderar as auto-citações no cálculo do fator de impacto. As autocitações ocorrem quando um autor de um artigo referencia outro artigo de sua própria autoria. 


\section{Índice de Imediação}

O Índice de Imediação ou Imediaticidade mede a rapidez com que artigos de uma revista são citados por outros artigos no próprio ano de sua publicação. Seu cálculo é obtido dividindo o número de citações de artigos publicados em um determinado ano pelo número total de artigos publicados naquele mesmo ano. Exemplo:

C : citações em 2007 para artigos publicados em $2007=3$

NA : número de artigos publicados em $2007=35$

Índice de imediação : $\mathrm{C} / \mathrm{NA}=3 / 35=0,086$

\section{Vida média de citações}

A vida média de citações ou meia-vida citada é o número de anos retrospectivos em que o número de citações dos artigos de uma revista se reduz a metade do seu total.

$\mathrm{Na}$ Tabela 3.1, temos as linhas das freqüências acumuladas $F(a c)$ e freqüências acumuladas relativas $F_{r e l}(a c)$ do número de citações de seus respectivos anos em cada coluna. A contagem é feita a partir do ano atual (2007) até o ano em que se atinge 50\% do total de citações feitas a um artigo.

Por exemplo, supondo que um artigo recebeu 10.000 citações desde sua publicação até o ano atual. Se no ano de 2007 ele recebeu 22 citações, sua freqüência acumulada será 22 (número de citações do ano de 2007) e a freqüência acumulada relativa será $22 / 10.000=0,22 \%$. Como a freqüência acumulada relativa não atingiu 50\%, calcula-se a freqüência acumulada relativa do próximo ano (2006) que é a porcentagem de citações dos anos de 2007 e 2006 em relação ao total $(2,28 \%)$. Este processo se repete até que o valor $50 \%$ seja atingido. Neste caso, a frequiência de $50 \%$ foi atingida no ano de 1998 (55,21\%). Após determinado o ano, é feito o cálculo da parte inteira e da parte fracionária da vida-média, explicado a seguir.

\begin{tabular}{|l||l|l|l|l|l|l|l|l|l|l|}
\hline Ano & $\mathbf{2 0 0 7}$ & $\mathbf{2 0 0 6}$ & $\mathbf{2 0 0 5}$ & $\mathbf{2 0 0 4}$ & $\mathbf{2 0 0 3}$ & $\mathbf{2 0 0 2}$ & $\mathbf{2 0 0 1}$ & $\mathbf{2 0 0 0}$ & $\mathbf{1 9 9 9}$ & $\mathbf{1 9 9 8}$ \\
\hline \hline$F(a c)$ & 22 & 228 & 742 & 1410 & 1836 & 2533 & 3377 & 4001 & 4699 & 5521 \\
\hline$F_{\text {rel }}(a c)$ & 0,22 & 2,28 & 7,42 & 14,10 & 18,36 & 25,33 & 33,77 & 40,01 & 46,99 & 55,21 \\
\hline
\end{tabular}

Tabela 3.1: Vida média de citações

\section{Parte inteira da vida-média:}

É o número de anos a partir do ano atual (2007) até o ano que a quantidade de citações permanece menor ou igual a 50\% (1997): 2007 até $1999=9$

\section{Parte fracionária da vida-média:}

A - subtraia de 50\% a porcentagem do ano (1999) que é imediatamente inferior a 50\%: 50-46,99 
$=3,01$

B - subtraia da porcentagem do ano que é imediatamente maior a 50\% (1998), a porcentagem do ano que é imediatamente inferior a 50\% (1999): 55,21-46,99 = 8,22.

$\mathbf{C}$ - divida o valor de A pelo valor de $\mathbf{B}$ : 3,01 / 8,22 = 0,366

Arredonde $\mathbf{C}$ para o próximo (maior) valor decimal: 0,4.

Vida média: 9,4

\section{Taxa de autocitação}

A taxa de autocitação é a porcentagem de citações a própria revista com relação ao total de citações a outras revistas.

$\mathbf{N}$ : número de vezes que a revista cita a si mesma.

NTF : número total de citações a todas as outras revistas.

T: taxa de autocitação.

$\mathbf{T}=(\mathrm{N} / \mathrm{NTF}) * 100$

\section{Taxa autocitada}

A taxa autocitada é a porcentagem de citações a própria revista com relação ao total de citações recebidas de outras revistas.

$\mathbf{N}$ : número de vezes que a revista cita a si mesma.

NTR : número total de citações à revista recebidas de outras revistas.

T: taxa de autocitada.

$\mathbf{T}=(\mathrm{N} / \mathrm{NTR}) * 100$

Além destes índices, os repositórios utilizam outras medidas para ordenar o resultado das buscas pelos materiais científicos. Um deles é a contagem de artigos por ano, que indica o número de artigos publicados em uma revista para um ano em particular. Há também o número de citações, que é o número total de vezes que cada revista foi citada por outras. Além da ordenação da listagem dos materiais, estes números se tornam interessantes aos pesquisadores que queiram fazer comparações entre publicações.

Vale notar que, apesar dos índices criados pelo ISI serem muito utilizados, alguns pesquisadores questionam sobre sua utilização (Sidiropoulos e Manolopoulos, 2003; Bicas et al., 2002). 
Por exemplo, se um artigo receber um grande número de críticas em outras publicações, haverá um aumento temporário no número de citações recebidas ao artigo, o que não significa necessariamente que o artigo proporcionou uma grande contribuição para a pesquisa científica. Além desse exemplo, outros podem ser dados, como as mudanças repentinas no tamanho da revista que podem afetar temporariamente o fator de impacto.

Outro problema ocorre no primeiro ano após a mudança do título de uma revista. O cálculo do fator de impacto não pode ser usado porque a contagem de artigos para os dois anos precedentes é zero. Além disso, no cálculo do fator de impacto não é considerada a "qualidade" dos pesquisadores, revistas e artigos que citam outros artigos. Para solucionar este problema, surgem propostas como atribuição de pesos aos índices. Tais índices serão apresentados na Seção 3.5 juntamente com as críticas a estas novas propostas devido à subjetividade dos fatores de qualidade utilizados para determinar os pesos.

Na próxima seção, são apresentados repositórios que fazem algum tipo de análise de citação sobre seus materiais.

\subsection{Outros importantes repositórios}

\subsubsection{Citeseer}

Juntamente com o SCI (Science Citation Index) da ISI, o Citeseer ${ }^{6}$ é um dos maiores sistemas de análise de desempenho de citações. Desenvolvido pelo Instituto de Pesquisa da NEC, o Citeseer, também conhecido como ResearchIndex, é um sistema gratuito que constrói automaticamente uma biblioteca digital utilizando agentes inteligentes (Lawrence et al., 1999a; Lawrence, 2001; Bollacker et al., 1999; Goodrum et al., 1999). O Citeseer baseia-se também no Fator de Impacto ISI e contém citações e links para textos completos de artigos de revistas, conferências e relatórios técnicos em computação e ciências relacionadas. O material armazenado em seu repositório é recuperado por um sistema que procura por artigos na Web. Existe também a opção da submissão manual que utiliza o conceito de self-archiving systems, onde os próprios autores incluem seus materiais no repositório.

O Citeseer é muito citado devido a grande automação existente em seu sistema. Ao serem recuperados, os documentos são "desmontados" e então são extraídas e indexadas informações como o nome do artigo, autor, além das referências bibliográficas (Lawrence et al., 1999b; Bollacker et al., 2000). No projeto da ferramenta FIP foi desenvolvido um trabalho semelhante para a extração e estruturação de referências bibliográficas. Foi utilizada uma técnica baseada em regras para identificar registros duplicados mesmo quando grafadas distintamente em artigos diferentes (Melo e Lopes, 2005). Bons resultados foram obtidos em relação à complexidade de tempo $\mathrm{O}(n \log (n)) \mathrm{e}$ à acurácia no processo de identificação (97\%).

\footnotetext{
${ }^{6} \mathrm{http}: / /$ citeseer.ist.psu.edu/
} 
Utilizando as informações extraídas dos documentos, o Citeseer utiliza o conceito de grafos de citação onde cada nó representa um artigo e as arestas representam os links para outros artigos. Esses links permitem que o usuário navegue entre artigos que referenciam e que são referenciados por outros, gerando o contexto da busca. É possível obter a fonte (outros artigos em que o artigo se baseou) ou os resultados e conseqüências de determinado artigo (os artigos citados). Através do grafo de citação podem ser obtidas informações estatísticas úteis para criar rankings e avaliar autores, publicações, conferências e jornais científicos, além de permitir a ordenação nas respostas das consultas.

Os grafos podem ainda ser utilizados em técnicas de data mining. Por exemplo, um conjunto de coleções científicas como livros, conferências, jornais ou relatórios técnicos poderiam ser agrupados utilizando técnicas de clustering. Da mesma forma, clusters de autores poderiam sugerir comunidades de cooperação ou citação, ou ainda encontrar clusters de autoridades, ou seja, os autores mais citados. O sistema AuthorLink, que será apresentado posteriormente, utiliza autores para análises deste tipo.

A Figura 3.1 mostra o gráfico de um artigo do Citeseer. São apresentados os números de citações feitas ao artigo em diversos períodos.

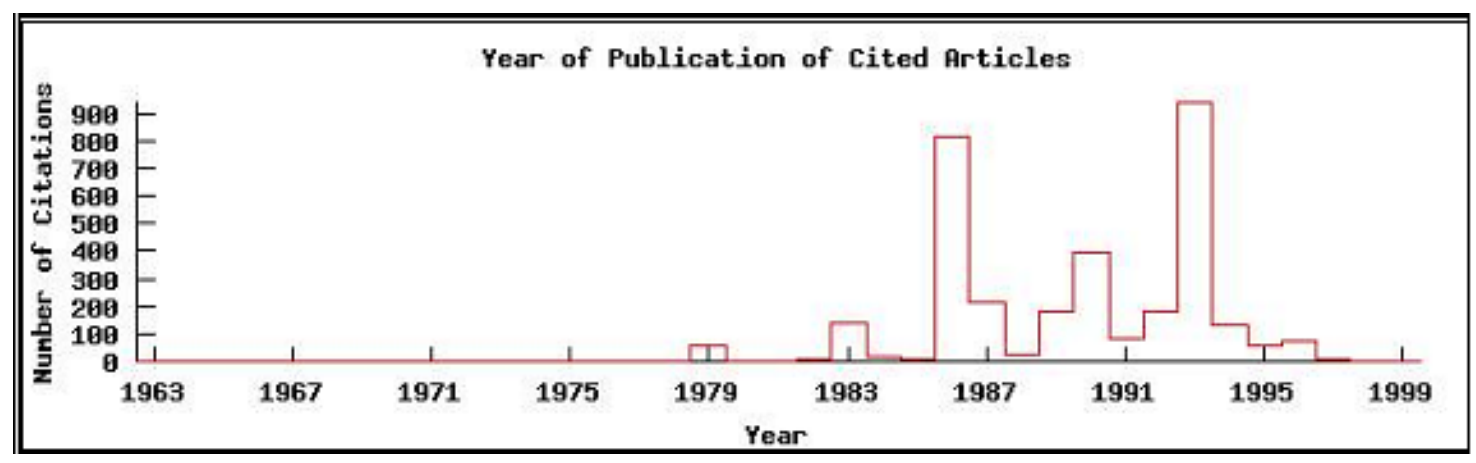

Figura 3.1: Gráfico do número de citações

\subsubsection{DBLP}

O sistema DBLP ${ }^{7}$ (Data Base and Logic Programming), desenvolvido pela Universidade de Trier, possui informações sobre importantes revistas e eventos de Ciência da Computação (Ley, 2002). Sua base de dados armazena dados bibliográficos de autores, conferências, revistas, artigos ou livros de ciências da computação principalmente na área de banco de dados e programação lógica desde 1993. Desde de que iniciou a expansão gradual do seu material para outras áreas, passou a ser chamado de Digital Bibliography and Library Project.

Mais do que um repositório de documentos, o DBLP é considerado um sistema de busca e indexação. É definido na página informativa do site do DBLP como um servidor bibliográfico. Ele oferece "rankings" dos artigos mais citados além de links para páginas pessoais e grupos de

\footnotetext{
${ }^{7}$ dblp.uni-trier.de
} 
pesquisa. Grande parte das publicações indexadas fornece recuperação para textos na íntegra. $\mathrm{O}$ DBLP dispõe seus registros na forma XML (DBLP XML ${ }^{8}$ ) para ser feito download, facilitando a utilização de seus dados por outros repositórios. Tal base foi utilizada no protótipo do data warehouse da ferramenta FIP desenvolvido neste projeto de mestrado. Mais detalhes sobre a base de dados XML do sistema DBLP serão apresentados no Capítulo 4.

\subsubsection{AuthorLink}

O AuthorLink ${ }^{9}$ é um sistema de visualização de materiais da área de humanas e artes. Possui acesso restrito ao seu material composto de 1.26 milhões de registros de publicações científicas fornecidos pelo ISI. Realiza uma busca por autor otimizada por mapas interativos que utiliza as informações de co-citações entre autores (Buzydlowski et al., 2002). Nos mapas são mostrados inicialmente os 24 principais autores. Ao selecionar um dos autores, outro mapa é construído e são expandidos outros autores ao redor do autor selecionado (Figura 3.2).

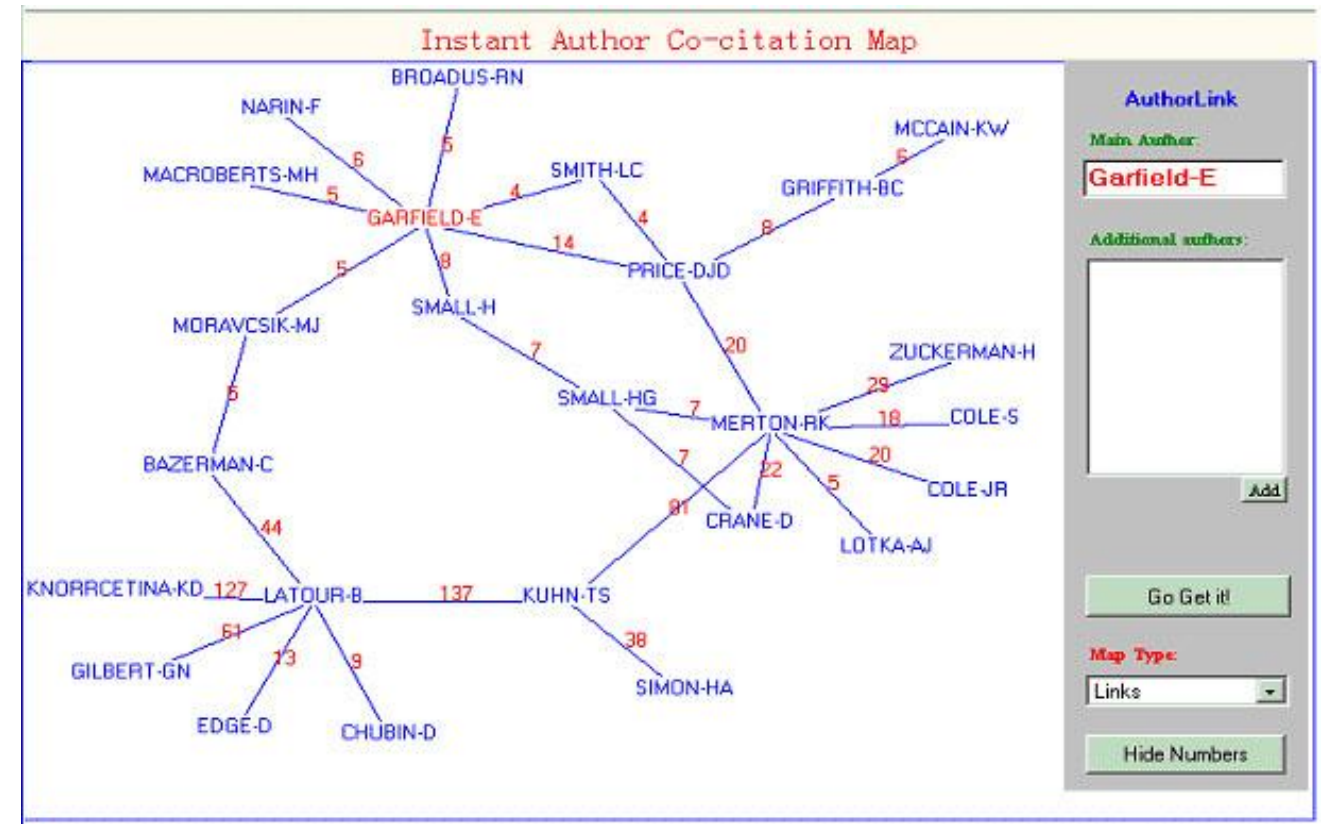

Figura 3.2: Grafo interativo de 24 autores do sistema Authorlink (Buzydlowski et al., 2002)

\subsubsection{PubSearch}

Desenvolvido na Nanyang Technological University (Singapura) por Yulan He e Siu Cheung Hui, utiliza dados do ISI Social Science Citation Index (SSCI). São realizadas técnicas de mineração de dados sobre dados de autores de um data warehouse (He e Hui, 2002, 2001). Na mineração de dados, aplicam-se técnicas de Clustering Hierárquico Aglomerativo (Jain et al., 1999) para cons-

\footnotetext{
${ }^{8}$ dblp.uni-trier.de/xml

${ }^{9}$ http://research.cis.drexel.edu/x̃lin/authorlink.html
} 
truir mapas de autores mostrando aqueles com interesses similares. O sistema possui um crawler para coleta dos dados bibliográficos que utiliza técnicas semelhantes às do Citeseer.

\subsubsection{SCEAS}

O SCEAS $^{10}$ (Scientific Collection Evaluator by using Advanced Scoring), foi desenvolvido na Aristotle University (Grécia) (Sidiropoulos e Manolopoulos, 2003). O SCEAS é um sistema disponível na Web construído com dados obtidos a partir do site do DBLP. Apresenta uma nova forma para utilização de rankings de conferências. Na Figura 3.3 o conceito de grafos de conferências é ilustrado, no qual os nós são as conferências e o peso das arestas representa a quantidade de referências dos artigos de uma conferência feitas a outra. Por exemplo, artigos da conferência Sigmod fez 497 referências a artigos da conferência Lcde.

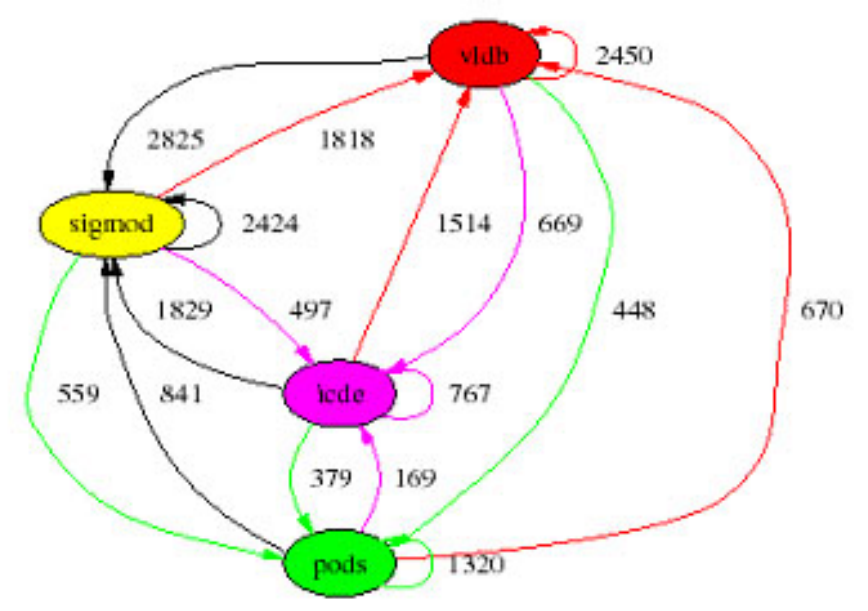

Figura 3.3: Grafo de conferências (Sidiropoulos e Manolopoulos, 2003)

\subsection{Novas propostas para índices bibliométricos}

Um dos grandes questionamentos levantados a respeito do fator de impacto ISI é o fato de não considerar a importância do pesquisador que fez a citação ou a importância da conferência na qual o artigo foi apresentado.

Por exemplo, segundo o cálculo do fator de impacto ISI, se um artigo recebeu citações de artigos escritos por pesquisadores sem importância ou de pouca produção científica e um outro artigo recebeu a mesma quantidade de citações de artigos publicados por pesquisadores renomados, os dois artigos têm o mesmo impacto na pesquisa. $\mathrm{O}$ mesmo ocorre com as conferências. Um artigo que recebeu citações de artigos de conferências importantes deveria possuir um impacto maior. No entanto, este fato é ignorado pelas métricas ISI, surgindo a proposta de utilizar pesos para autores e conferências.

\footnotetext{
${ }^{10}$ http://delab.csd.auth.gr/sceas/
} 
A seguir são apresentados os cálculos de alguns scores para conferências, Plain Score (Sc) e Plain Score per Year (SYc,y), propostos pelo sistema SCEAS (Sidiropoulos e Manolopoulos, 2003).

\section{Plain Score $\left(S_{c}\right)$}

$S_{c}$ : score para a conferência $c$.

$P_{c}$ : número de publicações na conferência c.

C : conjunto de todas as conferências.

$N_{i \rightarrow c}$ : número de citações feitas pela conferência $i$ para a conferência $c$.

$$
S_{c}=\frac{1}{P_{c}} \sum_{\forall i \in C} N_{i \rightarrow c}
$$

\section{Plain Score per Year $\left(S Y_{c, y}\right)$}

$S Y_{c, y}$ : score para conferência $c$ no ano $y$.

$P_{c, y}:$ número de publicações na conferência $c$ no ano $y$.

C : conjunto de todas as conferências.

$N_{i \rightarrow c, y}$ : número de citações feitas pela conferência $i$ para a conferência $c$ no ano $y$.

$$
S Y_{c, y}=\frac{1}{P_{c, y}} \sum_{\forall i \in C} N_{i \rightarrow c, y}
$$

Estes scores podem ser utilizados por índices bibliométricos na tentativa de suprir as limitações dos índices elaborados pelo ISI. Os scores podem ser vistos como uma classificação para as conferências e podem ser utilizados como pesos nos cálculos dos índices multiplicando seu valor pela quantidade de citações. Dessa forma, os índices aumentariam proporcionalmente de acordo com os pesos:

Seja,

$\mathbf{N}$ : número de citações recebidas de publicações de todas as conferências considerando o score.

n: número de conferências.

Sa: score da conferência $a$.

Na: número de referências recebidas de artigos da conferência $a$.

$$
N=\sum_{a=1}^{n} S_{a} N_{a}
$$

Dessa forma, o valor $\mathbf{N}$, que leva em consideração o peso das conferências, pode substituir a quantidade de citações aos artigos de uma revista no cálculo dos índices como os do sistema ISI. 


\subsection{Conclusão}

Além de auxiliar a fase de especificação dos dados a serem armazenados no data warehouse da ferramenta FIP, este levantamento sobre repositórios de materiais científicos da Web ressalta a importância dos índices bibliométricos utilizados por alguns dos repositórios. Os índices bibliométricos, tradicionais e novos, podem ser utilizados em análises que necessitem de informações relacionadas ao impacto de coleções científicas ou produtividade de pesquisadores e instituições. Tais índices se tornam importantes em consultas realizadas sobre o material da ferramenta FIP, além de poderem auxiliar na navegação dos mapas criados pela ferramenta, ressaltando, por exemplo, os artigos ou autores mais importantes apresentados.

A forma como estes índices, medidas e outras informações são armazenadas no data warehouse é apresentada no próximo capítulo. 
CAPÍTULO

\section{4}

\section{Desenvolvimento do Data Warehouse}

Neste capítulo é apresentado o projeto do data warehouse que armazena as informações dos materiais científicos da ferramenta FIP. A construção do DW foi realizada em cinco etapas baseadas em metodologias apresentadas por Inmon e Corey (Inmon, 1996a; Corey, 2001). As etapas da construção do data warehouse são descritas detalhadamente nas próximas seções.

A primeira etapa (Seção 4.1) é a justificativa para a construção do data warehouse, na qual se utilizou o modelo conceitual para a definição das necessidades e o entendimento do problema. Na Seção 4.2, é apresentado o planejamento no qual é definida a arquitetura do data warehouse. A etapa seguinte consiste na análise (Seção 4.3), na qual é feita a especificação do data warehouse e data marts. Esta etapa utiliza o modelo lógico visando a solução do problema sem se preocupar com tecnologias específicas do SGBD (Sistema de Gerenciamento de Banco de Dados). A próxima etapa é o projeto (Seção 4.4), no qual os modelos do data warehouse são refinados e detalhados, constituindo o projeto físico. Na Seção 4.5 são apresentados os detalhes da implementação do data warehouse, constituindo a última etapa.

\subsection{Justificativa}

$\mathrm{Na}$ etapa da justificativa do projeto, foi realizada a identificação do problema e das vantagens das técnicas de data warehousing para o sistema. Para a identificação do problema foi feito o levantamento de requisitos, tarefa na qual se determinou as informações relevantes sobre materiais científicos a serem armazenadas no data warehouse da ferramenta FIP. Assim, foram definidas as informações necessárias e úteis a pesquisadores em consultas e aplicação de técnicas de mineração de dados. Estas informações foram obtidas considerando as características da ferramenta FIP, 
como sua arquitetura e tipo de informações que manipula e necessita em suas análises. Tais informações foram, em parte, mostradas na seção sobre a motivação para o trabalho e a apresentação da ferramenta FIP (Seção 1.1). A complementação dos requisitos se deu com o levantamento sobre os repositórios de artigos científicos da Web apresentado no Capítulo 3, no qual foram definidas outras informações utilizadas pelos repositórios em suas análises, destacando os índices bibliométricos e medidas como as quantidades de citações entre artigos. Para a identificação das vantagens das técnicas de data warehousing no banco de dados da FIP, foi feito um estudo sobre o assunto e uma visão geral foi apresentada na Seção 2.1. O detalhamento das técnicas de data warehousing que são adequadas ao banco de dados da FIP é realizado neste capítulo.

Duas questões fundamentais que o DW da FIP deve ser capaz de responder são relacionadas com as citações entre artigos e autores. A totalização por artigos e, conseqüentemente, por publicações, eventos, instituições, etc, permitem o estabelecimento dos índices apresentados anteriormente. Observa-se que para a obtenção destes índices os artigos devem estar indexados de tal forma que mesmo quando aparecem grafados de formas diferentes, em diferentes artigos (em suas referências bibliográficas) eles possam ser identificados como um mesmo artigo.

Os sistemas de origem de data warehouses convencionais, que em geral são sistemas transacionais, possuem identificadores de seus registros. Por exemplo, em uma base de dados de origem com informações sobre clientes, cada cliente possui um identificador único definido pela chave primária. Para o DW da ferramenta FIP, cria-se uma dificuldade por não haver esse identificador para cada documento científico, diferentemente dos livros que possuem o ISBN. Na prática, um pesquisador consegue identificar um artigo científico pelo título e autores. O ano de publicação pode ser utilizado para aumentar a eficiência na identificação.

Uma forma de lidar com esse problema foi apresentado em (Melo e Lopes, 2005). Neste artigo uma "assinatura" para cada artigo composta por ano, título e autores é definida, juntamente uma métrica de distância de edição entre as seqüências que definem tais assinaturas. Uma similaridade acima de um determinado valor entre duas assinaturas implica que se trata do mesmo artigo. Os experimentos realizados com essa técnica obtiveram acurácia de 97\%. Mesmo assim, é possível determinar se duas referências dizem respeito a um mesmo artigo, mas ela não cria um identificador único para cada publicação.

Entretanto, o problema correlato, com os autores, ainda está em aberto. A identificação dos autores é bastante mais complexa, pois além de poderem estar grafados de formas distintas em diferentes publicações, podem existir homônimos, que trabalham, inclusive, na mesma área ou campo de pesquisa (Ley, 2002). Portanto, em uma primeira etapa as contagens de citações entre autores e a própria indexação de autores estará sujeita a forma como eles estão grafados. Podendo acarretar erros com relação a contagem de artigos e citações correspondentes a um pesquisador. Por exemplo, um mesmo pesquisador poderá estar cadastrado mais de uma vez, com o nome inteiro e com o nome abreviado ou omitindo algum sobrenome. Dessa forma, a assinatura será importante para a comparação dos novos documentos recuperados na Web com os já cadastrados 
no data warehouse da FIP, além da identificação dos relacionamentos estabelecidos entre artigos e suas referências bibliográficas.

Problema similar à identificação de artigos ocorre com outras informações como nome de congressos e revistas, no entanto, a identificação dos artigos é maior devido à diversidade da representação dos nomes dos autores. A criação da assinatura e problemas relacionados a identificação dos documentos serão tratados em trabalhos futuros.

A seguir, é apresentada uma característica importante do data warehouse da ferramenta FIP relacionada à persistência das informações na Web e que está diretamente relacionada ao elemento temporal do data warehouse.

\subsubsection{Persistência das informações na Web}

No quesito da integração de diferentes fontes de origem dos dados, data warehouses convencionais utilizados em organizações têm suas fontes de origem bem definidas, como outros bancos de dados de diversas áreas da empresa. Considerando como as fontes de origem de dados para o DW da FIP os repositórios de artigos científicos, sites de revistas, páginas pessoais de pesquisadores, entre outros locais na Web de onde são recuperados os artigos da FIP, a localização dessas fontes não é conhecida da mesma forma como ocorre nas origens dos data warehouses convencionais. Assim, é necessário recorrer a mecanismos como web mining, apresentado na Seção 1.1, para a localização e recuperação das informações a serem armazenadas na FIP. A tarefa de extração dos dados destas fontes torna-se ainda mais difícil devido a volatilidade existente na Web, que tem como causa a mudança de endereços (URL) dos sites e de seu material.

Um tipo de análise que não é realizado por nenhum dos repositórios citados no Capítulo 3, e que poderá ser realizado somente com o armazenamento dos históricos das informações da FIP, é aquele relacionado à persistência das informações na Web.

Um aspecto importante de um DW é o momento de fazer a atualização de seus dados, ou seja, deve ser bem definida a situação em que a extração dos dados (ETL) ocorre. Por exemplo, no caso de uma base de dados transacional da área de vendas, é importante saber quando e quais dados devem ser transferidos para o DW. Se uma venda foi realizada, mas o produto foi devolvido, esta venda poderá ser cancelada. Se as informações da venda foram extraídas para o DW e ela tiver sido cancelada, ocorrerá inconsistência nas informações do DW.

Este problema permanece no domínio das informações de documentos científicos presentes na Web. Links (URL's) de artigos encontrados nas referências bibliográficas podem deixar de serem válidos temporariamente ou permanentemente (Lawrence et al., 2001; Huebsch, 2003; Bar-Ilan e Peritz, 2004). Motivos como servidores que estão fora do ar ou que não existem mais, a troca de diretório ou nome do arquivo, podem fazer com que o link deixe de ser válido (Lawrence et al., 2000).

Pretende-se que a FIP armazene informações sobre a persistência dos artigos na Web verificando se os arquivos anteriormente recuperados continuam presentes na Web. Para verificar com 
máxima precisão se o artigo que está presente na URL é o mesmo que foi recuperado anteriormente na mesma URL, poderia ser feito o download do arquivo para fazer a comparação. Apesar de ser a forma mais eficiente em termos de precisão, este método causaria uma enorme sobrecarga na rede e no repositório da ferramenta, tornando-se uma opção inviável. Uma estratégia é apresentada a seguir para evitar tal sobrecarga.

\section{Verificação dos links de artigos na Web}

Depois que os artigos são recuperados, deve ser verificado se as URL's dos artigos recuperados ainda são links ativos. A verificação pode ser feita utilizando as informações: URL, o tamanho e data da última modificação do arquivo. A verificação do tamanho e data pode ser feita com recursos do protocolo HTTP 1.1 (Fielding et al., 1999; Yeager e McGrath, 1996). Observa-se que a URL possui implicitamente duas informações: o local onde o arquivo é armazenado, como o servidor e diretório, e o nome do arquivo. Se as quatro informações forem idênticas, o artigo presente na Web é considerado como sendo o mesmo recuperado anteriormente.

O link deve ser verificado periodicamente, com intervalo de tempo determinado de acordo com a metodologia adotada pela FIP para a recuperação dos artigos na Web. A técnica de verificação adotada aqui tem como objetivo determinar se o link de um artigo previamente recuperado continua válido. Ou seja, se o link esteve válido no intervalo de tempo entre a última verificação e a atual, é considerado como "ativo" para aquele período. Assim, não se leva em consideração se um artigo ficou inacessível durante alguns dias.

Se o artigo estiver presente na URL na verificação, o link recebe o status "ativo" para aquele período, caso contrário, são feitas verificações em intervalos regulares até se que constate que o artigo está presente. Caso o link não esteja válido após uma determinada quantidade de verificações, seu status será mudado para "indisponível". Nesta situação, serão feitas mais verificações apenas ao se procurar por novos artigos. Se durante este período o link voltar a ser válido, o status se tornará "ativo". Caso contrário, o link será considerado como "inativo" e não serão feitas mais verificações. Nestas condições, o link voltará ao status de "ativo" apenas se for encontrado novamente no processo de busca e recuperação.

Apesar de não serem totalmente eficientes, técnicas como esta deverão ser utilizadas para evitar a sobrecarga no sistema da FIP.

A seguir, é apresentado o modelo conceitual (Chen, 1976) para o data warehouse da FIP (Figura 4.1).

\subsubsection{O modelo conceitual}

As principais entidades do diagrama do modelo conceitual (Figura 4.1) estão apresentadas em destaque. Uma delas é a Documento que representa os documentos recuperados da Web, do qual foram extraídas as informações de interesse. Neste capítulo o termo publicação foi adotado para 
identificar um conjunto de documentos. Por exemplo, uma Revista, também chamada de periódico, é uma publicação composta por um conjunto de artigos. Os Anais (ou Proceedings) são os materiais publicados e apresentados em um congresso. Dessa forma, o relacionamento (no diagrama com o nome Composto) entre publicações e documentos é estabelecido: Proceedings, que estão relacionados aos congressos, são compostos pelos Inproceedings. Uma Revista é composta por Artigos e um Livro é composto por Incollections.

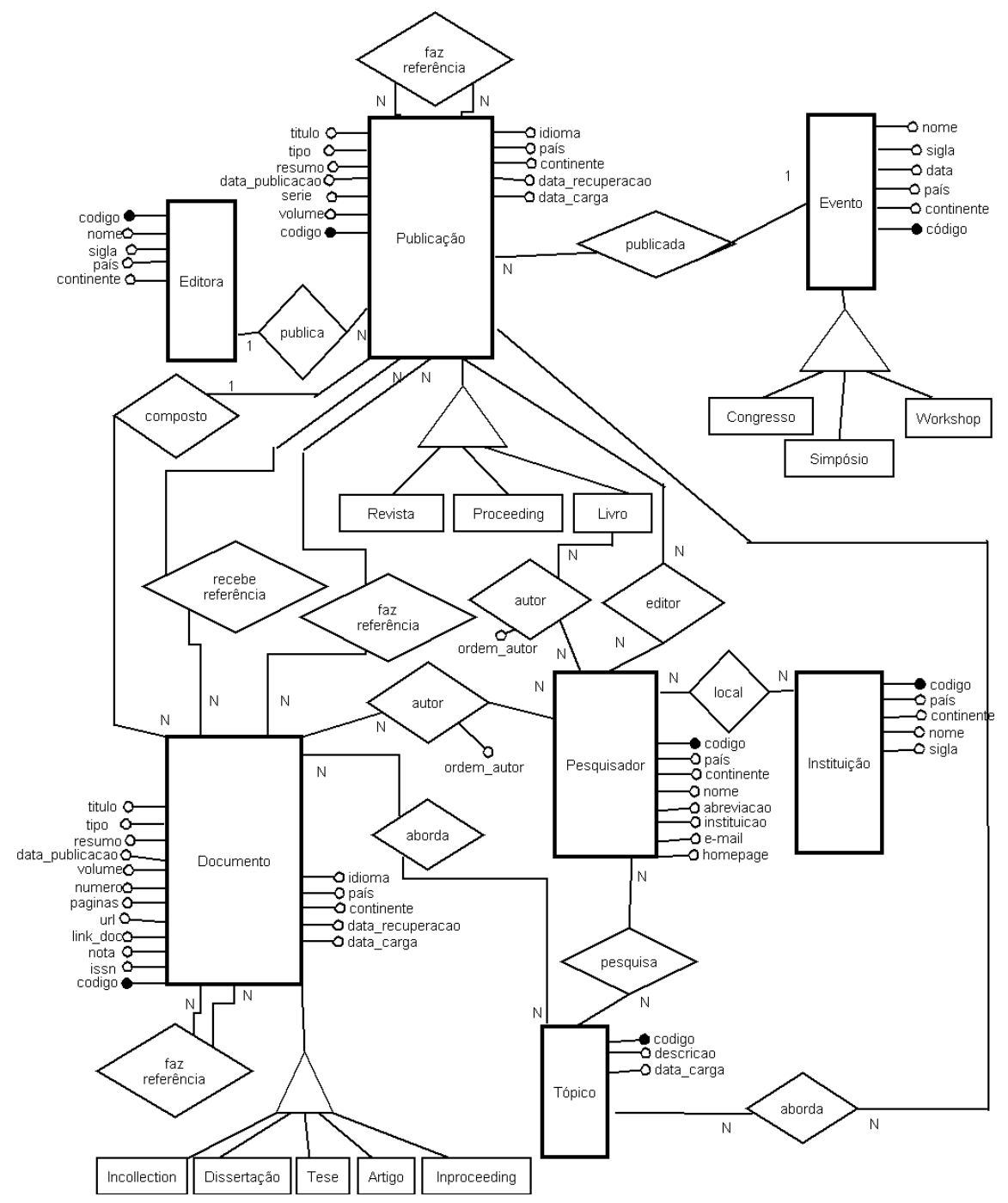

Figura 4.1: Modelo conceitual

É importante observar que pode não ser possível recuperar informações sobre a publicação de alguns documentos encontrados individualmente na Web, ou ainda, um documento pode não estar relacionado a nenhuma publicação.

Um atributo encontrado nas entidades Documento e Publicação e que é importante para as análises realizadas na FIP é data_recuperação, que representa a data em que foi feita a recuperação de um documento. O atributo é necessário para os estudos sobre a persistência da Web, como foi apresentado na Seção 4.1.1. Há ainda outro atributo, data_carga, que representa data em que as informações de um artigo foram carregadas no data warehouse. Percebe-se que há três elementos 
temporais no data warehouse da FIP, a data da recuperação do artigo na Web, a data da carga das informações do artigo no data warehouse e a data de publicação do documento.

Como visto anteriormente no capítulo sobre repositórios de artigos da Web (Capítulo 3), a quantidade de citações entre as publicações é uma das medidas mais utilizadas no cálculo de índices bibliométricos. As citações são representadas pelos relacionamentos "faz referência" e "recebe referência", entre documentos e publicações.

Outras entidades importantes são Editora, que faz a publicação de um material, e Evento que representa os congressos, simpósios e workshops. A entidade Pesquisador representa tanto os autores das publicações e materiais científicos em geral, quanto os editores (publishers). A entidade Instituição representa a localização do pesquisador, que, em geral, são as universidades.

A entidade Tópico é outra entidade importante para os propósitos da FIP. Ela representa os tópicos de pesquisa científica utilizados nos mapas de visualização de documentos. Essa informação teve grande importância neste trabalho de mestrado, como será apresentado no próximo capítulo (Capítulo 5), por serem utilizados na indexação dos documentos do DW e nas dimensões dos data marts. O diagrama possui os relacionamentos Aborda entre Documento e Tópico, indicando quando um tópico de pesquisa é um tema explorado em um documento. A entidade Tópico se relaciona também com Pesquisador. Apesar da relação entre tópicos com os pesquisadores ser definida de forma indireta, através dos documentos, este relacionamento ressalta a investigação de um pesquisador em determinados tópicos de pesquisa.

\subsection{Planejamento}

Na seção anterior foi apresentada a etapa da justificativa, visando principalmente entendimento do problema e os tipos de informações a serem armazenadas no data warehouse. Nesta seção é apresentada a etapa do planejamento na qual é definida a arquitetura do data warehouse para a ferramenta FIP. Na definição da arquitetura são consideradas características como a manipulação de fontes de origem voláteis, como a Web, e o tratamento de informações não-estruturadas como as encontradas nos documentos científicos. Nesta seção, além da arquitetura do repositório da FIP, é apresentado o detalhamento e particularidades de seus componentes.

\subsubsection{A arquitetura do repositório da FIP}

O repositório da ferramenta FIP é constituído por três componentes principais (Figura 4.2), que representam as áreas de dados com características particulares para cada tipo de informação e para o armazenamento e acesso aos dados.

O primeiro componente do repositório é o corpora de documentos recuperados na Web. O acesso a esse material poderá ser feito através do data warehouse que possui o link para o local, como o diretório do servidor da FIP, onde cada documento é armazenado. Mais informações sobre o corpora serão apresentadas posteriormente. 


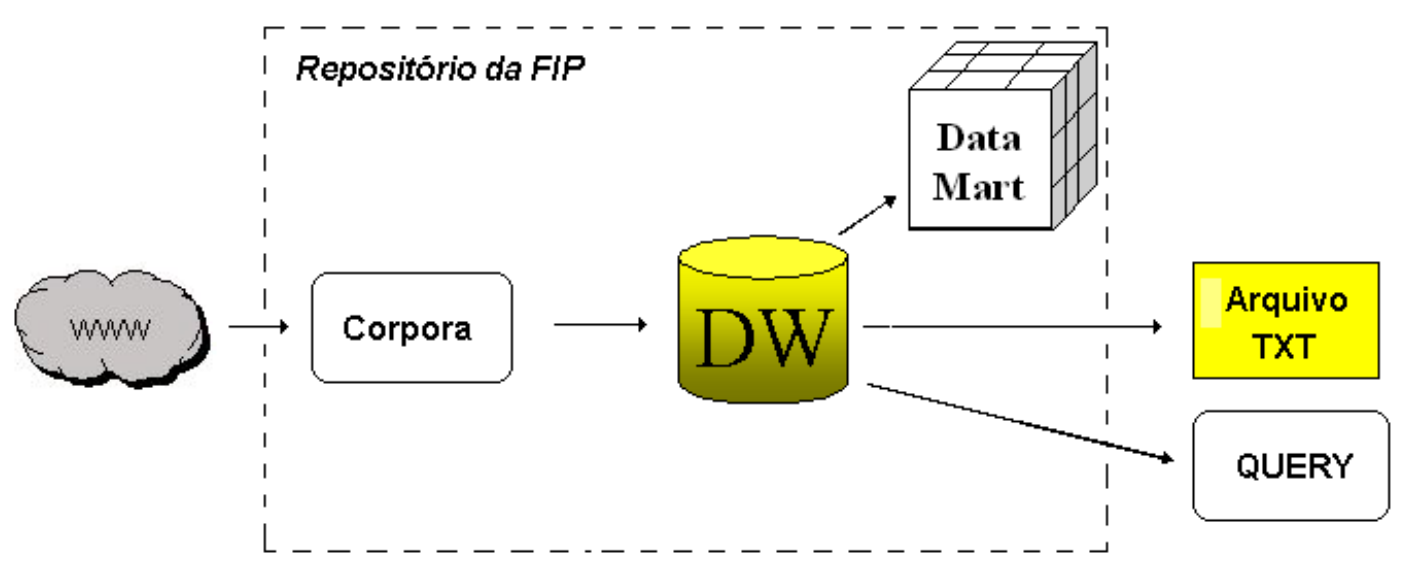

Figura 4.2: Arquitetura do repositório da ferrramenta FIP

O segundo componente é o data warehouse, que armazena as informações extraídas dos artigos.

A partir do data warehouse os dados podem ser resumidos e carregados para os data marts, ou podem ser feitas consultas (queries) comuns, como simples instruções SQL, ou ainda, serem gerados arquivos com formato dos dados para a entrada dos algoritmos de data mining. Em geral, estes algoritmos utilizam arquivos em formato texto ("Arquivo TXT" na Figura 4.2). Os índices bibliométricos não são armazenados no data warehouse por serem informações voláteis e por não ser interessante armazenar seu histórico. Estes índices podem ser obtidos em consultas SQL ou podem ser periodicamente armazenados em arquivos texto ou em outros formatos, como XML, por exemplo.

Os data marts, que proporcionam uma estrutura de sistemas de informação que permite o acesso flexível aos dados, correspondem ao terceiro elemento da arquitetura.

A seguir, é explicada com mais detalhes a função de cada componente da arquitetura do repositório da ferramenta FIP, as informações que cada um armazena e o relacionamento entre as áreas de dados.

\subsubsection{O acesso dos usuários ao corpora de documentos}

Os mapas de visualização de artigos permitirão a exploração destes documentos por uma representação gráfica e o acesso ao conteúdo dos documentos, isto é, o usuário terá acesso aos arquivos dos documentos.

O projeto da ferramenta FIP está sendo desenvolvido por pesquisadores da USP de São Carlos, no entanto, o acesso a ferramenta pode não se restringir apenas a estes usuários. Como nem todos os usuários possuem o acesso pela rede da USP, não podem também acessar todos os artigos do repositório da FIP. Assim, o acesso aos documentos deverá ser feito pela URL de onde o artigo foi recuperado. Caso o usuário esteja usando outra rede que não seja da USP, mas tenha permissão de acesso aos artigos, será feito o download da Web normalmente. Caso haja restrição de acesso 
ao artigo, o servidor do site fornecerá uma mensagem para o login ou uma mensagem de erro. A mensagem de erro será mostrada também caso o link esteja "quebrado".

Ao usuário que não tenha permissão de acesso ao artigo, poderá ser fornecido apenas o resumo do artigo, entre outras informações do documento como o título, nome dos autores, congresso e data de publicação.

Para aumentar a velocidade no acesso local e evitar o tráfego desnecessário na Internet, poderá ser feito o download dos artigos diretamente do servidor da FIP aos usuários da USP. Este tipo de controle poderá ser feito pelo IP da máquina que está acessando o servidor da FIP, ou por login, caso o usuário esteja fazendo o acesso de outra rede.

\subsubsection{A integração dos dados no data warehouse}

Para cada recuperação realizada será criado um diretório no servidor da FIP onde serão armazenados os artigos recuperados. Será criado um arquivo em XML com as informações sobre a data de recuperação, o local de onde o arquivo foi recuperado, como a URL do arquivo, URL da página do site que chega ao link do arquivo, o nome do arquivo e diretório onde o arquivo está armazenado.

Assim, os dados deste arquivo deverão ser associados ao arquivo XML gerado na fase da extração de informações dos documentos, de forma a gerar um terceiro arquivo XML com todas as informações definidas após a recuperação das informações especificadas acima, mais as informações extraídas dos documentos.

Este arquivo poderá ser alterado antes da carga no data warehouse. Após a sua geração, poderão ocorrer alguns processos referentes à complementação das informações extraídas dos documentos. Em um artigo, pode não ser possível obter todas as informações associadas a ele, como o congresso onde foi publicado. No entanto, esta informação poderia estar presente em referências de outros documentos que citam o artigo.

As informações extraídas dos artigos deverão ser carregadas apenas quando houver as informações definidas como mínimas e necessárias. Para as necessidades da FIP, considera-se como informações mínimas o título, o nome dos autores e ano de publicação, de forma a conseguir boa precisão para o reconhecimento do documento e atender aos requisitos mínimos para as análises realizadas na ferramenta FIP. Como discutido anteriormente, juntas, estas informações permitem a criação de um identificador (assinatura) para cada documento. Caso seja possível extrair estas informações sobre um artigo, todas as informações referentes ao documento serão carregadas no DW.

Uma observação a ser feita, relacionada à volatilidade das informações no data warehouse da FIP, é que as informações dos materiais científicos não são alteradas. Por exemplo, em um artigo não ocorre mudança do nome do autor, a data em que foi publicada ou o congresso onde foi apresentado. Observa-se que no data warehouse da FIP não existe alteração nas informações 
no sentido de que a cada momento os dados de um documento se apresentam de uma forma e mudam com o decorrer do tempo. Diferentemente de um data warehouse de um banco comercial, que pode ser interessante ter o histórico do saldo bancário de um cliente, em um data warehouse de publicações científicas não é necessário criar um histórico sobre as mudanças nos dados dos artigos.

Uma vez carregadas no data warehouse, as informações sobre os documentos não serão mais alteradas mesmo havendo a possibilidade da complementação de informações por novos artigos recuperados. Assim, não serão feitas alterações nas informações de um artigo que já está presente no data warehouse, como a correção do título ou a adição de uma informação como o congresso em que foi publicado.

Neste sentido, haverá adição de dados apenas quando for encontrado um novo documento ainda não cadastrado no data warehouse. A complementação das informações dos documentos será realizada somente em processos anteriores à carga no data warehouse. Após serem inseridas no data warehouse, não haverá mais alterações nas informações dos documentos.

As informações sobre os tópicos de pesquisa merecem atenção especial no processo da carga do data warehouse. Por não estarem presentes nos documentos, os tópicos serão extraídos dos documentos de forma automática por técnicas como a apresentada neste trabalho e serão associados a cada documento no arquivo XML, isto é, cada registro de documento poderá possuir uma ou mais tags de tópicos. Assim, os tópicos de pesquisa são inseridos no data warehouse durante operação da carga junto com as informações dos documentos. Se um tópico relacionado a um documento já estiver cadastrado no data warehouse, será apenas estabelecido um relacionamento entre o tópico e o novo documento. Caso contrário, o novo tópico é inserido na tabela de tópicos e, da mesma forma, será determinado o relacionamento. Assim como ocorre com os documentos, não haverá remoção ou alteração dos registros da tabela de tópicos.

Outro tipo de informação que possui características particulares na carga são as referências bibliográficas encontradas em um artigo. As referências são cadastradas na tabela de documentos, ou publicações, assim como os artigos recuperados da Web. Como as referências não possuem informações sobre suas citações, ou seja, por não possuírem informações de suas referências, estas últimas serão armazenadas apenas no momento em que o documento for recuperado da Web.

Algumas informações que constituem os metadados sobre os materiais científicos recuperados da Web possuirão grande importância no data warehouse. Entre eles estão a localização dos artigos na Web, como a URL do documento ou da página que possui o link para o documento. Estes metadados fazem o mapeamento entre a Web, que é a fonte de origem das informações da FIP, e o data warehouse. Estas informações possibilitarão o acesso às fontes do material do data warehouse, isto é, a partir das informações que estão no data warehouse, poderá ser encontrado o local de onde cada documento foi recuperado. Estas informações serão imprecindíveis para as análises da persistência da Web.

É importante ressaltar que a tarefa da extração de dados dos documentos científicos apresenta grandes dificuldades por lidar com dados não-estruturados. Assim, quando se diz que o data wa- 
rehouse da FIP apresenta dados de forma consistente, significa que podem apresentar um grau de erro em conseqüência das limitações das técnicas utilizadas.

\subsubsection{Os snapshots no data warehouse}

Em um data warehouse, concentra-se uma estrutura de dados denominada snapshot (Inmon, 1996a). As informações recuperadas podem ser comparadas a um instantâneo fotográfico do material científico disponível nos sítios visitados da Web, enquanto que o data warehouse da FIP possui o aspecto histórico formado pelo conjunto de todos instantâneos.

O instantâneo da FIP é criado como resultado da ocorrência do evento da recuperação de documentos, de tal forma a permitir comparações entre os "estados" da Web durante o tempo, no que se refere à presença dos artigos na Web. A recuperação se dará em períodos fixos e determinados, e assim, o evento é desencadeado pela passagem do tempo. Pode-se considerar que, indiretamente, a carga dos dados no repositório da FIP é disparada pelo evento da passagem do tempo. Dessa forma, é necessário que todas as informações dos documentos estejam associadas ao momento em que foi feita a carga e a recuperação dos documentos na Web.

Assim, os documentos e publicações estarão relacionados a estas duas datas. As outras informações, como autores e eventos, estarão associados aos labels de tempo de forma indireta através dos documentos. Outras informações que estarão associadas à data de carga serão os tópicos de pesquisa.

É importante lembrar também que a data de publicação é outro elemento temporal associado aos artigos. Assim, outro tipo de instantâneo pode ser definido com esta data permitindo análises que levam em conta o ano em que os documentos foram publicados e o ano que outros artigos fizeram citação a eles.

\subsection{Análise}

A etapa de análise teve como objetivo especificar as tabelas para o armazenamento dos dados do repositório da FIP. Foi realizado o mapeamento do modelo conceitual para o modelo lógico, representado pelo diagrama da Figura 4.3. A especificação das tabelas do data warehouse, os tipos dos campos, restrições, chaves primárias e estrangeiras são apresentados no Apêndice A.

Como pode ser observado nas tabelas, foram armazenadas informações redundantes com a intenção de eliminar o custo das junções em operações de seleção sobre as tabelas envolvidas. Por exemplo, na tabela Documento é armazenada a informação título da revista e código da revista. Esta medida pode trazer ganhos substanciais no momento das consultas, principalmente em tabelas que formam as dimensões dos data marts. 


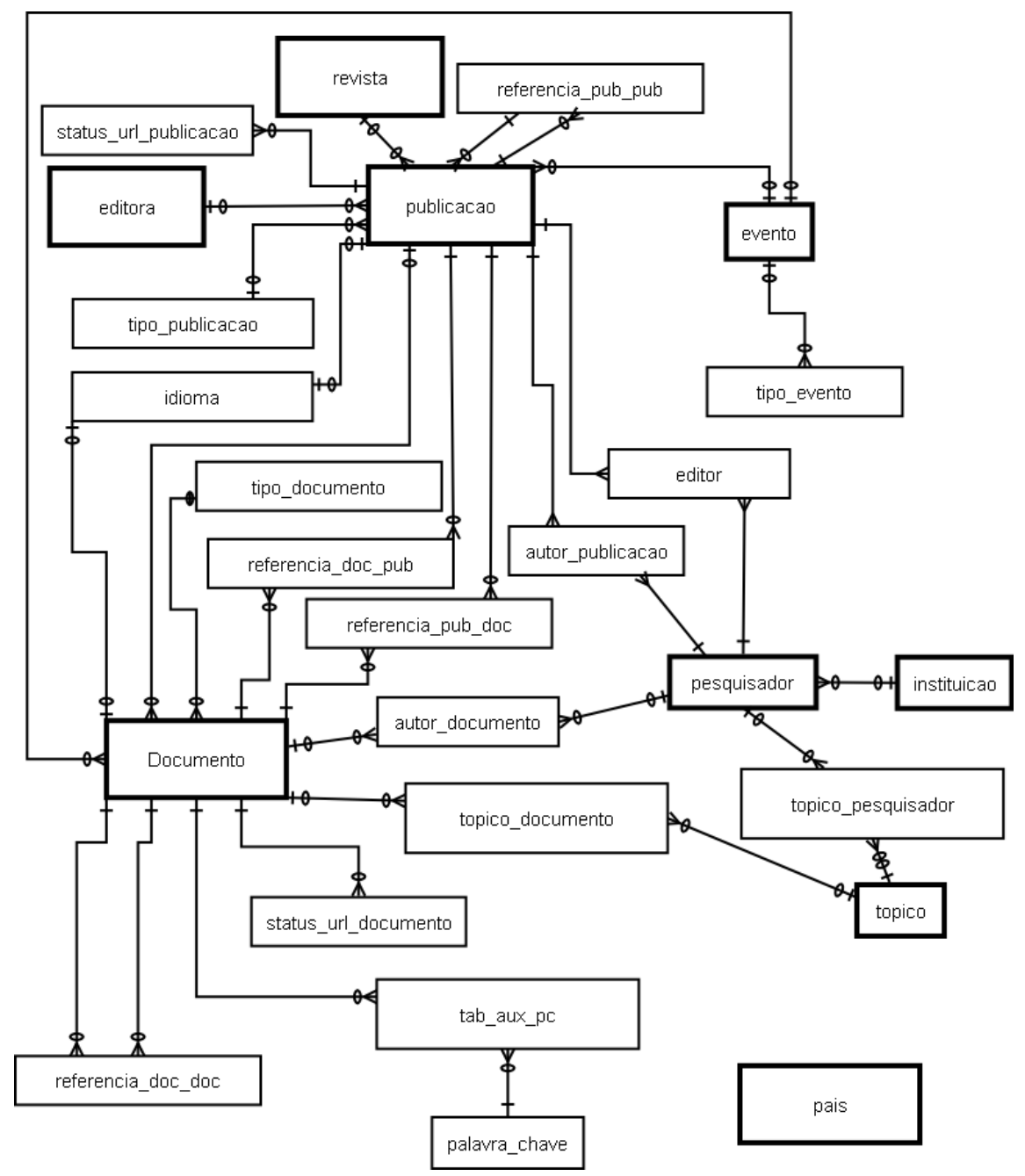

Figura 4.3: Modelo lógico do repositório relacional

\subsubsection{Data marts}

A construção de data marts para a FIP tem como principal objetivo facilitar o acesso dos dados aos usuários em análises sobre tendências e evoluções nas pesquisas. Para tal, são utilizadas as quantidades de documentos que tratam dos assuntos e tópicos de pesquisa, além das quantidades de citações a estes documentos.

A tabela fato do esquema estrela apresentado na Figura 4.4 armazena o fato de um artigo citar outro artigo. As tabelas dimensão, exceto a relacionada aos tópicos, são utilizadas para referenciar tanto os artigos que citam quanto os artigos que recebem citação. Dessa forma, na tabela fato são definidas duas chaves estrangeiras para referenciar uma mesma tabela dimensão. Uma chave estrangeira referencia informações do artigo que citou e a outra chave referencia informações do artigo citado.

As tabelas dimensão deste esquema armazenam as seguintes informações:

dim_artigo: possui o título do artigo utilizado para representar cada documento. 


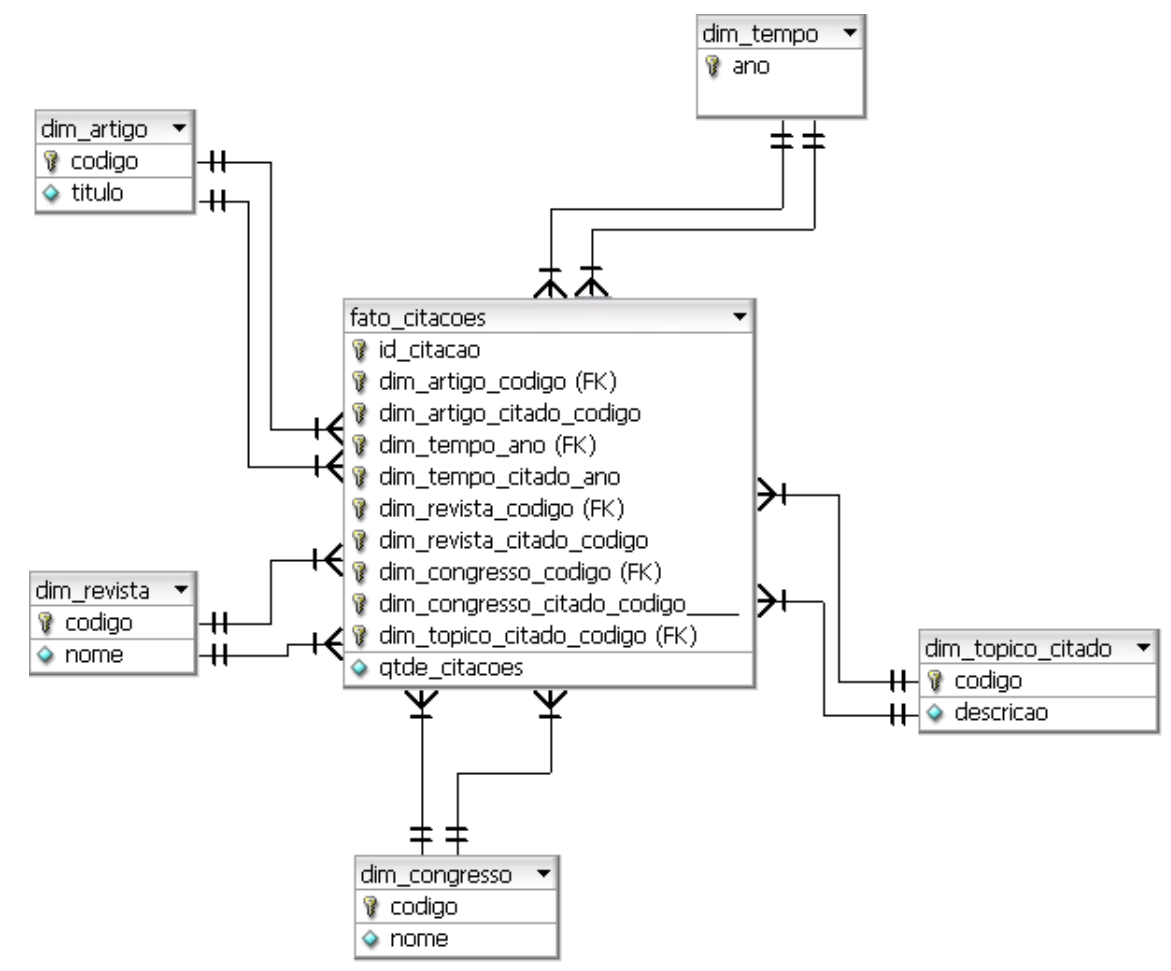

Figura 4.4: O esquema estrela utilizado no data mart.

dim_tempo: data de publicação do artigo. Observação: os próprios anos de publicação dos artigos são utilizados como chaves primárias.

dim_revista: revista do artigo.

dim_congresso: congresso do artigo.

dim_topico_citado: tópico do artigo citado.

A tabela fato armazena as quantidades de citações que um artigo faz a outro. Como será criado um registro na tabela fato somente se houver a citação e um artigo só pode citar outro artigo uma vez, o valor do fato (qtde_citacoes) será sempre 1. Este valor não será acessado nas consultas, pois não é utilizado nos critérios de contagem de registros da função de agregação COUNT( ). Dessa forma, não ocorrerá o acesso da tabela fato, mas somente dos arquivos de índices. Apesar disso, a definição de um campo para o fato é necessária para sua representação na ferramenta OLAP.

A dimensão relacionada aos tópicos (dim_topico_citado) é umas das mais importantes nas consultas com ferramentas OLAP sobre os dados da FIP. Em consultas nas quais se deseja visualizar o desenvolvimento de um tópico durante os anos, uma dimensão relacionada aos tópicos define as linhas da tabela mostrada pela ferramenta OLAP, enquanto que a dimensão do ano de publicação (dim_tempo) define as colunas na tabela. Assim, as demais dimensões são utilizadas principalmente para a operação slice que limita os registros a serem considerados nas contagens. Por exemplo, ao selecionar uma revista, considera-se somente a quantidade de publicações sobre um tópico daquela revista. 
Além das consultas com tópicos, as ferramentas OLAP possuem grande flexibilidade para alternar, ou rotacionar, as dimensões (operação pivot). Assim, as outras dimensões também podem ser utilizadas para definir as linhas e colunas da tabela. Para visualizar, por exemplo, a quantidade de citações recebidas por congressos durante os anos, pode-se definir os congressos nas linhas e os anos nas colunas das tabelas.

Uma das dificuldades para a modelagem do esquema estrela de citações entre artigos científicos ocorre devido ao tipo de relacionamento existente entre a tabela de documentos e a tabela de tópicos do data warehouse. Os artigos podem abordar diversos tópicos de pesquisa e um tópico de pesquisa pode ser abordado por diversos artigos, criando assim, um relacionamento do tipo N:N (muitos para muitos) entre as tabelas. Isto se torna uma limitação mesmo para esquemas que usam normalização de dados como o snowflake que possuem relacionamentos 1:N nas dimensões.

$\mathrm{Na}$ modelagem do esquema estrela utilizado neste data mart, a tabela tópico é definida como uma dimensão. Para cada artigo, a quantidade de registros gerada na tabela fato é igual a quantidade de tópicos abordados pelo artigo. Dessa forma, é necessário definir a função de agregação COUNT combinada com a palavra-chave DISTINCT, de forma a não fazer a contagem repetida de uma mesma citação.

Por exemplo, para obter uma tabela na ferramenta OLAP com as quantidades de citações dos tópicos durante os anos, deve ser especificada a função de agregração COUNT como na instrução SQL apresentada a seguir. Neste exemplo utilizou-se apenas os campos da tabela fato para omitir detalhes relacionados às junções das tabelas.

SELECT dim_topico_citado_codigo, dim_tempo_citado_ano,
COUNT (DISTINCT id_citacao)
FROM fato_citacoes
GROUP BY dim_topico_citado_codigo, dim_tempo_citado_ano

Observa-se que na tabela fato foi criado um identificador para cada citação (id_citacao). Poderia ser utilizada uma chave composta com os campos dim_artigo_codigo e dim_artigo_citado_codigo para determinar a citação, no entanto, por se tratar de concatenação de campos de valores numéricos, a criação desse identificador simplifica a implementação.

A forma como é modelado o data mart resolve o mesmo tipo de problema existente entre as tabelas de artigos e autores que possuem um relacionamento N:N. No entanto, outro problema surge ao utilizar a tabela dimensão de tópicos e autores no mesmo esquema estrela, sendo necessário criar registros com todas as combinações entre autores e tópicos. Um artigo que possui $n$ autores e que aborde $m$ tópicos, necessita da criação de $n \times m$ registros na tabela fato.

O problema se agrava ao utilizar dimensões de tópicos abordados por artigos que citam e tópicos abordados por artigos citados, e ainda, autores de artigos que citam e autores de artigos citados. A utilização destas 4 dimensões no data mart necessita da combinação de todos os elementos das dimensões relacionados à citação. 
Conforme visto no capítulo sobre os índices bibliométricos, muitas vezes não se deseja considerar nas contagens as auto-citações entre artigos, ou seja, as citações de artigos de um autor para outro artigo do mesmo autor. Um esquema estrela que possui dimensões sobre autores de documentos que citam e autores de documentos que recebem citações, permite a execução de consultas nas quais pode se desconsiderar as auto-citações nas contagens. No entanto, o tipo de relação entre as tabelas de artigos e autores ( $\mathrm{N}: \mathrm{N})$, discutido anteriormente, cria a necessidade de instruções SQL complexas, podendo não ser realizadas nas ferramentas OLAP. Para facilitar o acesso a esse tipo de informação, pode ser construído outro data mart que não considere as auto-citações nas contagens.

A desvantagem da divisão de um data mart em outros menores é restringir os diversos tipos de análises em uma mesma consulta. Poderia ser interessante um único data mart para permitir análises considerando, por exemplo, artigos de algum tópico que fez citação a artigos de outro tópico, ou ainda, a quantidade de artigos de um tópico publicado por um autor.

Pode-se ainda utilizar outras medidas como a diminuição do número de elementos das tabelas dimensão que resulta na redução da quantidade de registros da tabela fato. Por exemplo, poderão ser utilizados rankings para determinar os artigos e congressos mais importantes a serem carregados nas tabelas dimensão.

Algumas consultas multidimensionais realizadas com o data mart da Figura 4.4 serão apresentadas na Seção 4.5.2.

\subsection{Projeto}

$\mathrm{Na}$ fase do projeto foi feito um detalhamento das especificações definidas na etapa de análise. Nesta seção, são apresentadas algumas particularidades tecnológicas do SGBD utilizado.

Para a construção do protótipo do data warehouse da ferramenta FIP foi utilizado o SGBD Oracle Database 10g Enterprise Edition para plataforma Microsoft Windows (32-bits) e a ferramenta OLAP Oracle Discoverer para as consultas sobre os data marts. A escolha deste software foi feita devido a disponibilidade do material sobre o software da biblioteca do ICMC-USP e principalmente pelo conhecimento deste SGBD de colaboradores deste projeto na parte da implementação.

No Oracle, a organização se dá por estruturas denominadas tablespaces. Estas estruturas permitem a separação de dados de acordo com suas características de armazenamento e acesso. No data warehouse da FIP, foram utilizadas três tablespaces: uma para área de dados do data warehouse que possui a característica de haver pouca alteração e conseqüentemente pouca fragmentação. A segunda área é utilizada para os índices e a terceira área é temporária para operações como ordenação de dados.

Em alguns SGBD, como o Oracle e o DB2 (UDB), pode-se criar uma tablespace para cada dispositivo de armazenamento. Dessa forma, existe a opção para criar índices em uma tablespace e os arquivos de dados em outra e fazer o acesso em paralelo das duas áreas de dados. Em outra 
situação, pode-se configurar as tablespaces de acordo com a volatilidade dos dados. No DW, essa volatilidade é muito baixa por ser realizada apenas a operação da adição de dados, de tal forma a não fragmentar os dados no disco. Assim, a tarefa de desfragmentação de dados no DW torna-se praticamente desnecessária.

Em bancos de dados transacionais, uma quantidade muito grande de índices pode criar um overhead em operações de alteração dos dados, pois, além da atualização nas tabelas dos dados, é necessário fazer a mesma operação nas tabelas de índices. Os índices do protótipo do data warehouse foram criados visando principalmente os testes com a ferramenta OLAP e as consultas e carga dos dados do data mart. Outros assuntos relacionados aos ajustes do SGBD (tuning), otimização de memória e particionamento dos dados deverão ser tratados futuramente, assim como os assuntos relacionados à otimização do acesso aos dados dos data marts, criação de visões materializadas e verificação de desempenho nas consultas das ferramentas OLAP.

\subsection{Implementação}

Na etapa da implementação são criados os objetos físicos, codificados os scripts de povoamento dos dados do data warehouse e data mart e criadas consultas com ferramentas OLAP. Esta etapa conclui o primeiro ciclo da construção do data warehouse, permitindo a verificação da viabilidade do uso das técnicas de data warehousing no projeto da ferramenta FIP.

Para a construção e testes com o protótipo do data warehouse da FIP, foi utilizada a base de dados da DBLP, que contém grande quantidade de informações sobre materiais científicos (mais de 635 mil registros). Além de permitir que sejam realizados testes com informações reais durante o processo da construção do DW, a adoção desta base deve-se ao fato do projeto depender de outros módulos que permitem o povoamento do DW com informações de documentos recuperados da Web. Tais módulos, como os relacionados à Extração de Informação, Recuperação de Informação com web mining e mineração de dados na Web, ainda se encontravam em desenvolvimento durante o período em que este projeto de mestrado foi realizado. Além disso, a utilização da DBLP na construção do DW permitiu que as etapas de validação e testes das consultas sobre o DW e suas ferramentas de análise fossem feitas sem a perda de foco com possíveis erros que poderiam existir nos dados devido às falhas de tarefas anteriores ao povoamento dos dados no DW.

\subsubsection{A base DBLP XML}

A DBLP (Data Bases and Logic Programming) disponibiliza os registros de sua base de dados no formato XML para o download estimulando a utilização de seus dados por outros repositórios. Esta base foi utilizada para o desenvolvimento do projeto de construção do data warehouse, incluindo a etapa de indexação automática de documentos e seleção automática de tópicos de pesquisa, que será apresentada no próximo capítulo. 
A versão do arquivo de dados da DBLP XML, feito o download em 18-05-2005, contém informações sobre materiais científicos desde 1936. Os tipos e quantidades de publicações da base DBLP são apresentados na Tabela 4.1.

\begin{tabular}{|l|r|}
\hline Inproceedings: paper de uma conferência & 390.652 \\
\hline Article: artigo de um journal & 233.740 \\
\hline Proceedings: conjunto de inproceedings referentes a uma conferência & 6.450 \\
\hline WWW: páginas de Internet & 2.193 \\
\hline Incollection: compõe um livro (Book) & 1.706 \\
\hline Book & 1.193 \\
\hline Phdthesis: teses de doutorado & 84 \\
\hline Masterthesis: dissertações de mestrado & 5 \\
\hline \hline Total & 636.023 \\
\hline
\end{tabular}

Tabela 4.1: Quantidades de publicações da base DBLP

Um importante tipo de informação armazenado na base de dados DBLP XML são as citações entre suas publicações de forma a justificar sua adoção para os testes com o data warehouse da FIP. Cada registro da DBLP possui um identificador único que permite fazer referência a outras publicações como acontece no caso das citações. Conforme descrito anteriormente, as quantidades de citações entre documentos poderão ser utilizadas em alguns tipos de consultas da ferramenta FIP para a análise de seu material. Durante a verificação das informações disponíveis na base DBLP, constatou-se que nem todas publicações possuem referências, no entanto, a base atende as necessidades para os testes realizados com as ferramentas OLAP.

A seguir, são apresentadas as tags XML que definem as informações de cada registro da base. Por não terem sido encontrados documentos dos autores da DBLP descrevendo as informações da base, a especificação a seguir foi feita observando os próprios dados do arquivo XML, o arquivo de metadados dblp.dtd (DTD - Document Type Definition) e alguns materiais que traziam apenas informações parciais sobre ela. Além disso, algumas informações como nomes e siglas de revistas e congressos não estavam presentes no arquivo XML, sendo necessária a criação de scripts para extração destas informações de páginas em HTML do site da DBLP.

$<$ author $>$ - nome do autor da publicação. Obs: uma publicação pode ter mais de um autor.

$<$ editor $>$ - nome do editor da publicação (pessoa física). Obs: uma publicação pode ter mais de um editor.

$<$ title $>$ - título da publicação.

$<$ booktitle $>$ - título do livro.

$<$ pages $>$ - páginas da publicação.

$<$ year $>$ - ano de publicação.

$<$ address $>$ - endereço da publicação. Ex: cidade da publicação (New York). 
$<$ journal $>$ - nome da revista da publicação.

$<$ volume $>$ - volume da publicação. Ex: os registros de artigos possuem o volume da revista onde o artigo foi publicado.

$<$ number $>$ - número da revista onde o artigo foi publicado.

$<$ month $>$ - mês da publicação.

$<\mathbf{u r l}>$ - url da tabela de conteúdos (TOC - Table of Contents). Acessa o local da página do site da DBLP que contém informações sobre a publicação, isto é, aponta para a posição da publicação em uma tabela de conteúdos de uma página html do site da DBLP. A tabela de conteúdo da DBLP funciona como um índice em forma de lista para o acesso do seu material. O endereço para acessar a página é "http://www.informatik.uni-trier.de/ ley/" seguido da string da tag <url>. No caso do registro da dblp ser um site da Internet (www), a url se refere ao endereço do site. Este campo pode conter links absolutos (começa com http:// ou ftp://) ou links locais (é necessário adicionar o prefixo dblp "http://www.informatik.uni-trier.de/ ley/").

$<\mathbf{e e}>$ - (electronic edition) aponta para uma página de uma "edição eletrônica". A página contém um link para um abstract ou o documento do texto completo (pdf ou ps). Pode conter links absolutos (começa com http:// ou ftp://) ou links locais (neste caso, é necessário adicionar o prefixo da dblp "http://www.informatik.uni-trier.de/ ley/").

$<$ cdrom > - Além da versão em XML, a base DBLP se encontra disponível também em mídias de cd-rom. Este campo indica o diretório e o nome do arquivo da publicação.

$<$ cite $>$ - link de citação (indentificador da publicação citada). Para referências ainda não cobertas pela DBLP são utilizadas reticências. Essas tags permitem saber quais publicações são citadas pelo artigo e, indiretamente, identificar quais publicações citam o artigo.

$<$ publisher $>$ - editora da publicação. Ex: IEEE.

$<$ note $>$ - nota sobre a publicação.

$<$ crossref $>$ - referência cruzada. Ex: um artigo pode possuir referência cruzada para a revista onde foi publicada. Dessa forma, todas as informações sobre a revista também se referem aos seus artigos.

$<$ isbn $>$ - ISBN do livro.

$<$ series $>$ - nome da série da publicação.

$<$ school $>$ - instituição do autor da publicação. Em geral, encontrado apenas em teses e dissertações.

$<$ chapter $>$ - capítulo do livro correspondente ao artigo.

Como não se encontram no arquivo XML informações como as áreas de pesquisa, nem as palavras-chave que poderiam determinar o assunto dos documentos, foram realizados alguns experimentos para extrair de forma automática tópicos de pesquisa utilizando as informações disponíveis no arquivo. 
Por uma questão de organização, a descrição dos experimentos são apresentados em um capítulo separado da dissertação (Capítulo 5). A seguir, são apresentadas as consultas multidimensionais utilizando alguns tópicos obtidos com os experimentos.

\subsubsection{As consultas multidimensionais}

Conforme definido anteriormente, o arquivo XML a ser carregado no data warehouse da FIP deve possuir os tópicos associados aos documentos. O mesmo processo foi utilizado para o povoamento de dados do protótipo do data warehouse com os dados da DBLP XML na qual foram inseridas as tags de tópicos nos registros dos documentos. Foram considerados como documentos que abordam os tópicos, aqueles que possuem em seu título o tópico de pesquisa.

Para as consultas realizadas sobre o data mart, os registros de livros da tabela Publicação, que também fazem e recebem citações, foram acrescentados aos registros da tabela de dimensão de artigos.

Como na tabela fato existe uma chave estrangeira para a tabela dimensão Revista, é necessário que todos artigos estejam associados a uma revista. Assim, na tabela dimensão revista foi definido um registro com o nome "Nenhum" para ser referenciado caso o documento não estivesse associado a nenhuma revista. O mesmo ocorreu com a tabela dimensão Congresso.

Na tabela dim_topico_citado foram inseridos 100 tópicos de pesquisa formando um data mart, no qual foram consideradas somente as citações a documentos que possuíam pelo menos um tópico associado, ou seja, foram considerados os artigos relevantes para análises de tendências de tópicos de pesquisa.

Na Figura 4.5 é mostrada a tela inicial do Oracle Discoverer em uma consulta sobre o data mart de citações. Nesta consulta são apresentados os tópicos e a quantidade de citações que artigos sobre os tópicos receberam nos anos de 1960 a 2004. As quantidades com valores diferentes a zero são apresentadas em destaque (sombreado). Observa-se que o valor da quantidade de citações dos tópicos em diversos anos é igual a zero. Isto ocorreu porque muitas referências não estão cadastradas na base DBLP, sendo este fato confirmado nas consultas sobre a quantidade de publicações que serão apresentadas a seguir. Observa-se também que o último ano de citação foi o de 2000 por não existirem na base DBLP artigos citados de anos mais recentes que estão associados aos tópicos.

Uma das operações de manipulação dos dados oferecidas pelas ferramentas OLAP é a pivot que faz a rotação das dimensões. A Figura 4.6 mostra a tela do Discoverer após a rotação entre as dimensões de tópicos e congressos. Na tela são mostradas as quantidades de citações a artigos que tratam do assunto "abstract data types" por congressos.

Um recurso muito importante oferecido pelas ferramentas OLAP é a visualização dos dados em forma de gráficos. A Figura 4.7 mostra um gráfico de barras relacionado à consulta da figura anterior. 


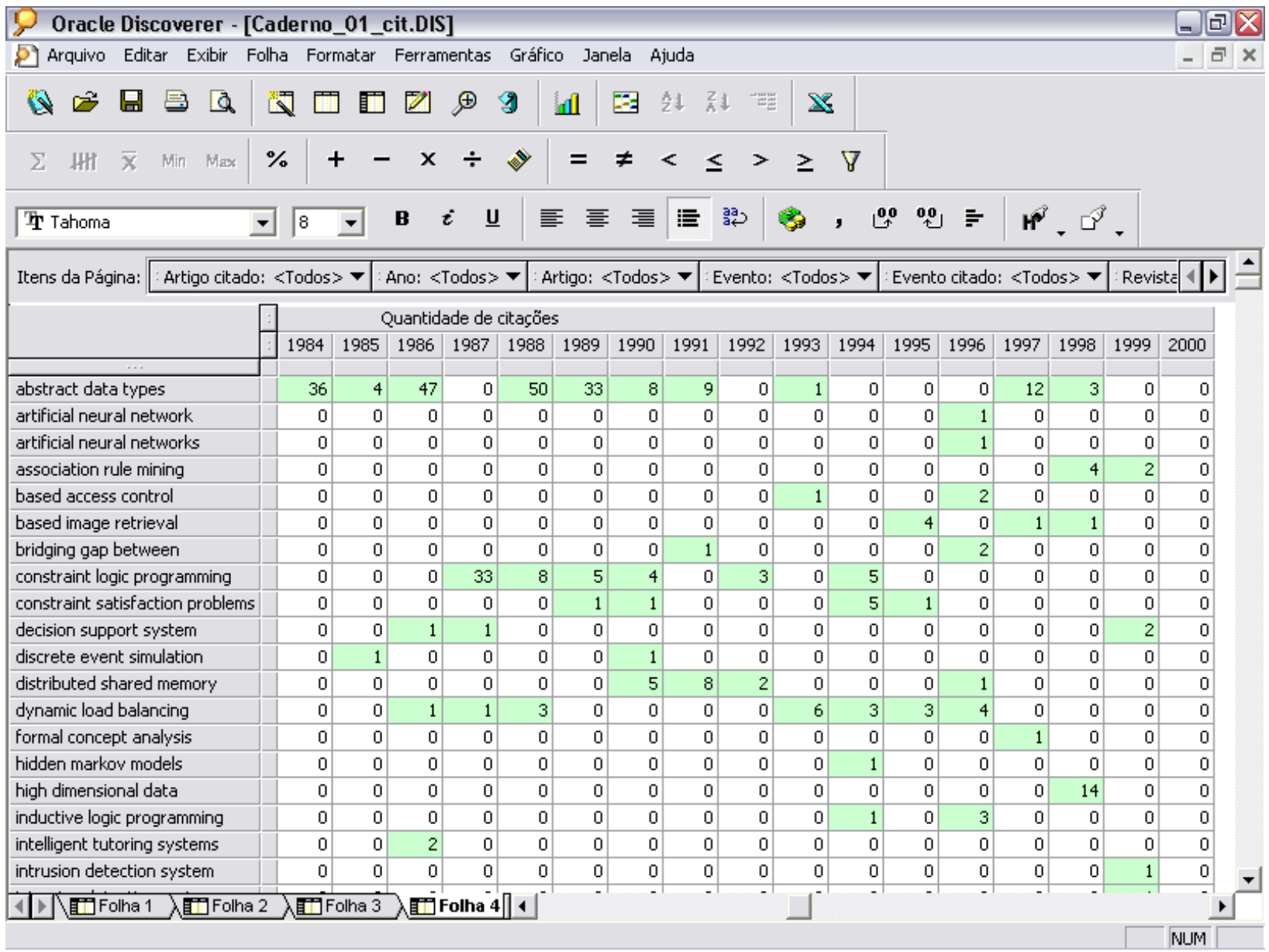

Figura 4.5: Tela do Oracle Discoverer em consulta sobre citações entre atrigos.

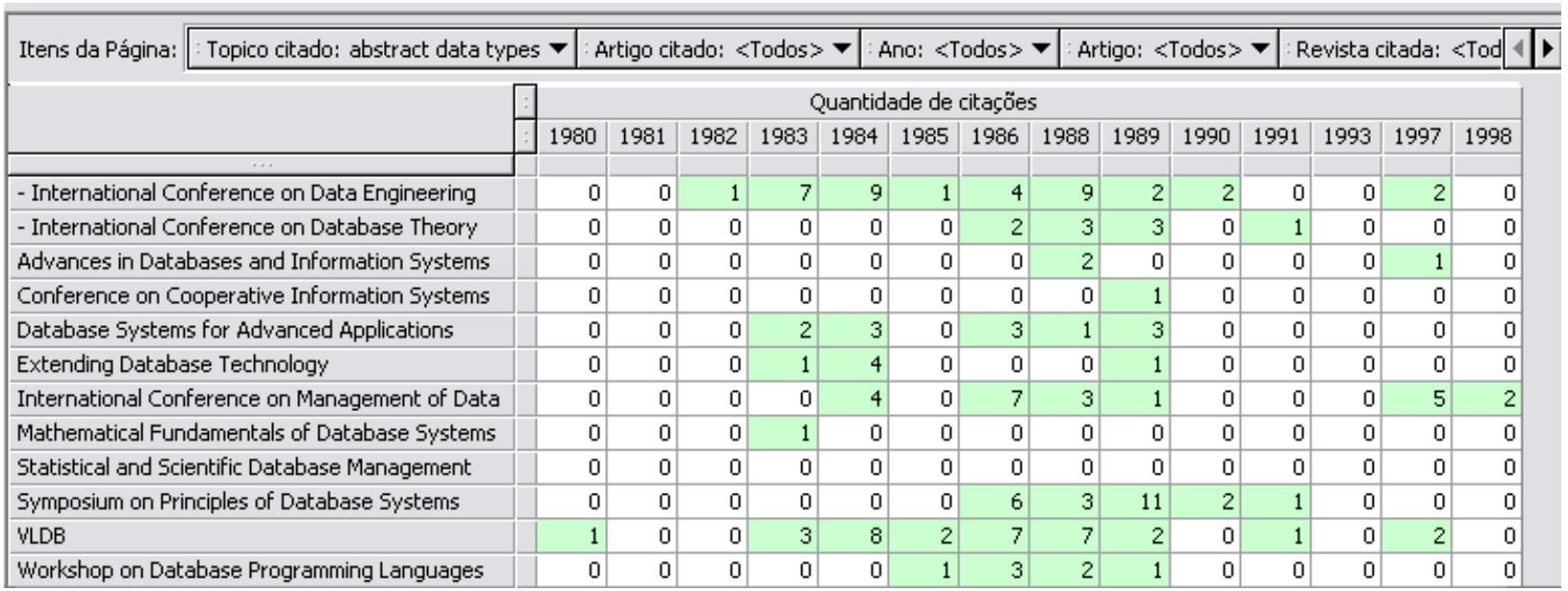

Figura 4.6: Congressos que publicaram artigos sobre o assunto abstract data types.

A ferramenta OLAP permite ainda combinar as dimensões. Na Figura 4.8 são mostradas as quantidades de citações por tópicos em cada revista. Nesta consulta os tópicos são apresentados como sub-itens da dimensão Revista.

Outro data mart foi construído possuindo como fato a quantidade de publicações. O esquema estrela do data mart é apresentado na Figura 4.9 e uma consulta é apresentada na Figura 4.10. 


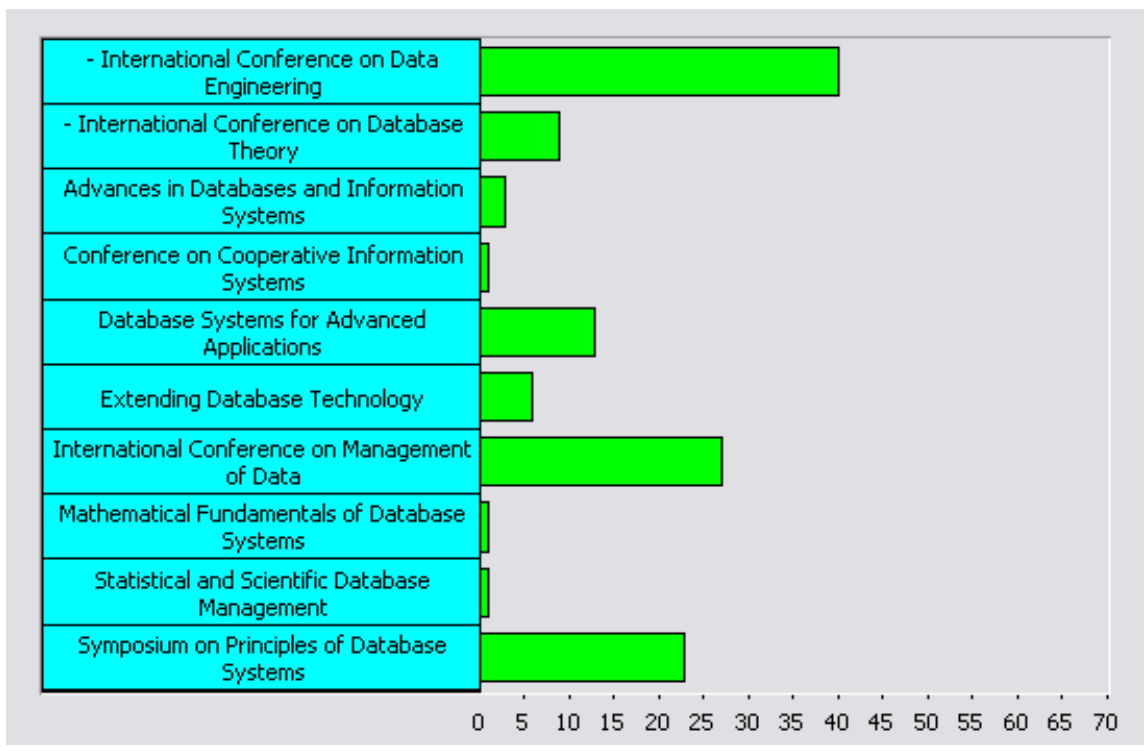

Figura 4.7: Gráfico de congressos que abordaram o tópico abstract data types e as quantidades de citações recebidas.

\begin{tabular}{|c|c|c|c|c|c|c|c|c|c|c|c|c|c|}
\hline & & 1989 & 1990 & 1991 & 1992 & 1993 & 1994 & 1995 & 1996 & 1997 & 1998 & 1999 & 2000 \\
\hline & & & & & & & & & & & & & \\
\hline \multicolumn{2}{|c|}{ Data(base) Engineering Bulletin (IE abstract data types } & 0 & 0 & 0 & 0 & 0 & 0 & 0 & 0 & 1 & 0 & 0 & 0 \\
\hline & hidden markov models & 0 & 0 & 0 & 0 & 0 & 1 & 0 & 0 & 0 & 0 & 0 & 0 \\
\hline & mining association rules & 0 & 0 & 0 & 0 & 3 & 5 & 2 & 1 & 1 & 1 & 0 & 0 \\
\hline & neural network approach & 0 & 0 & 0 & 0 & 0 & 0 & 0 & 0 & 0 & 1 & 0 & 0 \\
\hline & object oriented database & 1 & 0 & 4 & 0 & 0 & 0 & 0 & 1 & 0 & 1 & 0 & 0 \\
\hline & object oriented databases & 1 & 0 & 4 & 0 & 0 & 0 & 0 & 0 & 0 & 1 & 0 & 0 \\
\hline & world wide web & 0 & 0 & 0 & 0 & 0 & 1 & 0 & 0 & 0 & 0 & 0 & 0 \\
\hline \multirow[t]{8}{*}{ FDT - Bulletin of ACM SIGFIDET/SI } & abstract data types & 0 & 0 & 0 & 0 & 0 & 0 & 0 & 0 & 1 & 0 & 0 & 0 \\
\hline & based image retrieval & 0 & 0 & 0 & 0 & 0 & 0 & 0 & 0 & 0 & 1 & 0 & 0 \\
\hline & inductive logic programming & 0 & 0 & 0 & 0 & 0 & 1 & 0 & 0 & 0 & 0 & 0 & 0 \\
\hline & mining association rules & 0 & 0 & 0 & 0 & 3 & 3 & 5 & 1 & 0 & 0 & 0 & 0 \\
\hline & object oriented database & 0 & 0 & 1 & 0 & 0 & 0 & 0 & 0 & 1 & 0 & 0 & 0 \\
\hline & object oriented databases & 0 & 0 & 1 & 0 & 0 & 0 & 0 & 0 & 1 & 0 & 0 & 0 \\
\hline & time series data & 0 & 0 & 0 & 0 & 0 & 0 & 0 & 0 & 0 & 0 & 1 & 0 \\
\hline & world wide web & 0 & 0 & 0 & 0 & 0 & 0 & 1 & 2 & 3 & 3 & 1 & 0 \\
\hline \multirow[t]{4}{*}{ VLDB Journal } & abstract data types & 2 & 1 & 2 & 0 & 0 & 0 & 0 & 0 & 0 & 0 & 0 & 0 \\
\hline & distributed shared memory & 0 & 0 & 1 & 0 & 0 & 0 & 0 & 0 & 0 & 0 & 0 & 0 \\
\hline & high dimensional data & 0 & 0 & 0 & 0 & 0 & 0 & 0 & 0 & 0 & 1 & 0 & 0 \\
\hline & mining association rules & 0 & 0 & 0 & 0 & 3 & 2 & 2 & 1 & 0 & 0 & 0 & 0 \\
\hline
\end{tabular}

Figura 4.8: Consulta por tópicos de revistas

Observa-se que o número de valores diferentes de zero é maior em relação às consultas de citações, pois são considerados todos os documentos, e não somente os citados. Dessa forma, os artigos publicados nos últimos anos, de 2001 a 2004, também aparecem na consulta.

Outra consulta é apresentada na Figura 4.11, na qual foram utilizadas algumas funções prédefinidas do Discoverer para determinar valores como a soma de todas as publicações de um tópico em todos os anos (coluna Soma) e a maior quantidade de publicações de todos os anos (coluna Máximo). A ordenação dos dados pela coluna Soma pode facilitar a visualização dos tópicos mais publicados em todos os anos, como é apresentada nesta consulta. 


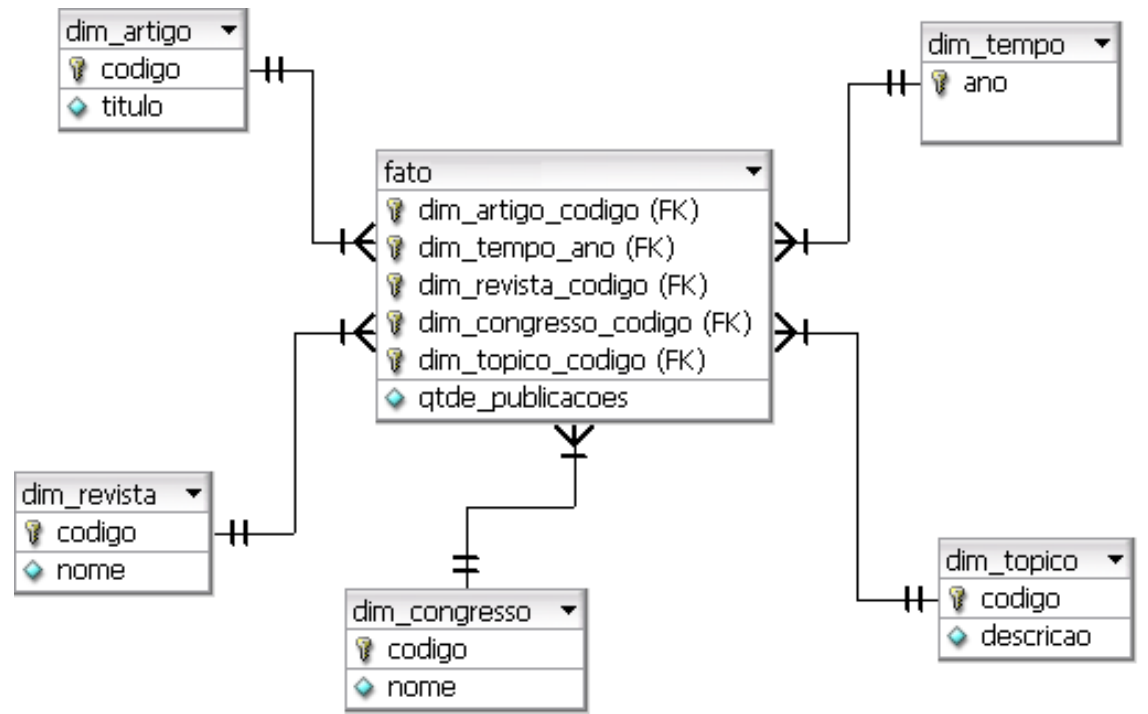

Figura 4.9: Esquema estrela de quantidades de publicações

\begin{tabular}{|c|c|c|c|c|c|c|c|c|c|c|c|c|c|c|c|c|}
\hline & 1989 & 1990 & 1991 & 1992 & 1993 & 1994 & 1995 & 1996 & 1997 & 1998 & 1999 & 2000 & 2001 & 2002 & 2003 & 2004 \\
\hline abstract data types & 9 & 10 & 5 & 5 & 6 & 16 & 4 & 6 & 4 & 4 & 5 & 6 & 3 & 1 & 1 & 0 \\
\hline ad hoc network & 0 & 0 & 0 & 0 & 0 & 0 & 0 & 0 & 1 & 5 & 16 & 35 & 75 & 151 & 273 & 381 \\
\hline ad hoc networks & 0 & 0 & 0 & 0 & 0 & 0 & 0 & 0 & 1 & 4 & 11 & 31 & 60 & 132 & 244 & 345 \\
\hline ad hoc sensor & 0 & 0 & 0 & 0 & 0 & 0 & 0 & 0 & 0 & 0 & 0 & 0 & 0 & 3 & 7 & 15 \\
\hline ad hoc wireless & 0 & 0 & 0 & 0 & 0 & 0 & 0 & 0 & 0 & 1 & 2 & 11 & 26 & 24 & 36 & 35 \\
\hline answer set programming & 0 & 0 & 0 & 0 & 0 & 0 & 0 & 0 & 0 & 0 & 0 & 3 & 5 & 6 & 24 & 28 \\
\hline ant colony optimization & 0 & 0 & 0 & 0 & 0 & 0 & 0 & 0 & 0 & 2 & 1 & 2 & 2 & 21 & 14 & 21 \\
\hline artificial neural network & 3 & 7 & 12 & 9 & 25 & 25 & 29 & 28 & 45 & 44 & 40 & 49 & 38 & 52 & 66 & 74 \\
\hline artificial neural networks & 3 & 5 & 8 & 7 & 22 & 14 & 22 & 22 & 30 & 28 & 31 & 33 & 29 & 37 & 43 & 51 \\
\hline association rule mining & 0 & 0 & 0 & 0 & 0 & 0 & 0 & 2 & 0 & 2 & 12 & 9 & 13 & 20 & 19 & 21 \\
\hline based access control & 0 & 0 & 1 & 0 & 1 & 0 & 11 & 5 & 10 & 6 & 13 & 15 & 23 & 15 & 23 & 27 \\
\hline based image retrieval & 0 & 0 & 0 & 0 & 0 & 1 & 7 & 4 & 13 & 18 & 38 & 45 & 31 & 46 & 47 & 45 \\
\hline bases de datos & 0 & 0 & 0 & 0 & 0 & 1 & 0 & 19 & 9 & 3 & 10 & 3 & 2 & 3 & 6 & 0 \\
\hline blind source separation & 0 & 0 & 0 & 0 & 0 & 0 & 0 & 1 & 5 & 5 & 1 & 4 & 10 & 8 & 9 & 41 \\
\hline boundary value problems & 0 & 0 & 1 & 1 & 4 & 1 & 1 & 3 & 3 & 4 & 2 & 3 & 6 & 20 & 16 & 17 \\
\hline bridging gap between & 0 & 1 & 2 & 2 & 5 & 6 & 5 & 4 & 8 & 8 & 3 & 6 & 6 & 9 & 21 & 14 \\
\hline call admission control & 0 & 0 & 3 & 0 & 0 & 0 & 4 & 6 & 10 & 3 & 8 & 14 & 12 & 21 & 15 & 13 \\
\hline constraint logic programming & 9 & 10 & 17 & 14 & 16 & 26 & 18 & 21 & 15 & 17 & 15 & 9 & 9 & 12 & 5 & 9 \\
\hline constraint satisfaction problems & 4 & 4 & 4 & 3 & 10 & 16 & 15 & 14 & 16 & 15 & 9 & 22 & 14 & 17 & 29 & 26 \\
\hline
\end{tabular}

Figura 4.10: Tópicos e quantidades de publicações durantes os anos.

Por fim, gráficos, como o apresentado na Figura 4.12, facilitam as análises sobre a evolução dos tópicos de pesquisa. A operação slice foi utilizada na dimensão tempo para delimitar as quantidades dos anos de 1990 a 2004.

Algumas características e informações sobre os tópicos podem ser observadas como o ano (1997) em que a quantidade das publicações de tópicos como o World Wide Web atingiram o valor máximo, podendo representar o auge do assunto nas pesquisas. Pode-se observar também tópicos mais recentes que possuem o aumento da quantidade de publicações como intrusion detection system e support vector machine que apresenta um crescimento maior e mais rápido nas pesquisas. E outros tópicos mais antigos, como decision support system, que possui publicações durante toda a década de 90 até os anos mais recentes.

É importante notar que os valores apresentados nas consultas são muito menores que as quantidades reais de publicações realizadas sobre os assuntos nas pesquisas. Essa diferença tem como uma das causas o fato de não serem considerados na contagem os sinônimos ou abreviações como 


\begin{tabular}{|c|c|c|c|c|c|c|c|c|c|c|c|c|c|c|c|c|c|c|}
\hline & 1989 & 1990 & 1991 & 1992 & 1993 & 1994 & 1995 & 1996 & 1997 & 1998 & 1999 & 2000 & 2001 & 2002 & 2003 & 2004 & Soma & Máximo \\
\hline ad hoc networks & 0 & 0 & 0 & 0 & 0 & 0 & 0 & 0 & 1 & 4 & 11 & 31 & 60 & 132 & 244 & 345 & 828 & 345 \\
\hline world wide web & 0 & 0 & 0 & 0 & 0 & 4 & 34 & 91 & 121 & 91 & 73 & 61 & 47 & 45 & 31 & 25 & 623 & 121 \\
\hline support vector machine & 0 & 0 & 0 & 0 & 0 & 0 & 0 & 1 & 3 & 14 & 23 & 46 & 70 & 107 & 142 & 157 & 563 & 157 \\
\hline artificial neural network & 3 & 7 & 12 & 9 & 25 & 25 & 29 & 28 & 45 & 44 & 40 & 49 & 38 & 52 & 66 & 74 & 549 & 74 \\
\hline support vector machines & 0 & 0 & 0 & 0 & 0 & 0 & 0 & 1 & 3 & 13 & 18 & 34 & 55 & 86 & 112 & 97 & 419 & 112 \\
\hline decision support system & 3 & 7 & 5 & 14 & 20 & 18 & 20 & 11 & 18 & 21 & 30 & 32 & 42 & 33 & 46 & 43 & 412 & 46 \\
\hline mobile ad hoc & 0 & 0 & 0 & 0 & 0 & 0 & 0 & 0 & 0 & 3 & 8 & 20 & 34 & 58 & 98 & 174 & 395 & 174 \\
\hline artificial neural networks & 3 & 5 & 8 & 7 & 22 & 14 & 22 & 22 & 30 & 28 & 31 & 33 & 29 & 37 & 43 & 51 & 386 & 51 \\
\hline based image retrieval & 0 & 0 & 0 & 0 & 0 & 1 & 7 & 4 & 13 & 18 & 38 & 45 & 31 & 46 & 47 & 45 & 295 & 47 \\
\hline distributed shared memory & 2 & 6 & 5 & 12 & 15 & 22 & 25 & 32 & 31 & 28 & 20 & 18 & 18 & 24 & 12 & 19 & 291 & 32 \\
\hline hidden markov models & 0 & 0 & 3 & 1 & 9 & 5 & 15 & 7 & 21 & 10 & 17 & 27 & 39 & 42 & 40 & 43 & 279 & 43 \\
\hline natural language processing & 4 & 11 & 9 & 17 & 6 & 9 & 10 & 19 & 23 & 7 & 9 & 20 & 16 & 15 & 25 & 14 & 264 & 25 \\
\hline neural network model & 2 & 8 & 5 & 9 & 9 & 10 & 12 & 18 & 12 & 28 & 14 & 28 & 21 & 26 & 28 & 22 & 256 & 28 \\
\hline wireless sensor networks & 0 & 0 & 0 & 0 & 0 & 0 & 0 & 0 & 0 & 0 & 1 & 2 & 14 & 32 & 58 & 136 & 243 & 136 \\
\hline radial basis function & 2 & 3 & 2 & 2 & 5 & 7 & 16 & 10 & 12 & 21 & 22 & 18 & 33 & 25 & 20 & 30 & 229 & 33 \\
\hline constraint logic programming & 9 & 10 & 17 & 14 & 16 & 26 & 18 & 21 & 15 & 17 & 15 & 9 & 9 & 12 & 5 & 9 & 226 & 26 \\
\hline abstract data types & 9 & 10 & 5 & 5 & 6 & 16 & 4 & 6 & 4 & 4 & 5 & 6 & 3 & 1 & 1 & 0 & 224 & 21 \\
\hline constraint satisfaction problem & 4 & 4 & 4 & 3 & 10 & 16 & 15 & 14 & 16 & 15 & 9 & 22 & 14 & 17 & 29 & 26 & 224 & 29 \\
\hline gene expression data & 0 & 0 & 0 & 0 & 0 & 0 & 1 & 2 & 0 & 0 & 3 & 8 & 24 & 34 & 77 & 73 & 222 & 77 \\
\hline
\end{tabular}

Figura 4.11: Outros tópicos ordenados pela quantidade de publicações total

SVM, IDS, WWW ou Web, muito utilizados em títulos. Além disso, não foram levadas em consideração outras partes do artigo, como, por exemplo, o resumo. Com a utilização dessas informações, é provável que ocorra uma associação mais precisa dos tópicos com os documentos. No entanto, mesmo com estas restrições pôde-se notar que algumas tendências são observadas nos dados do data mart.

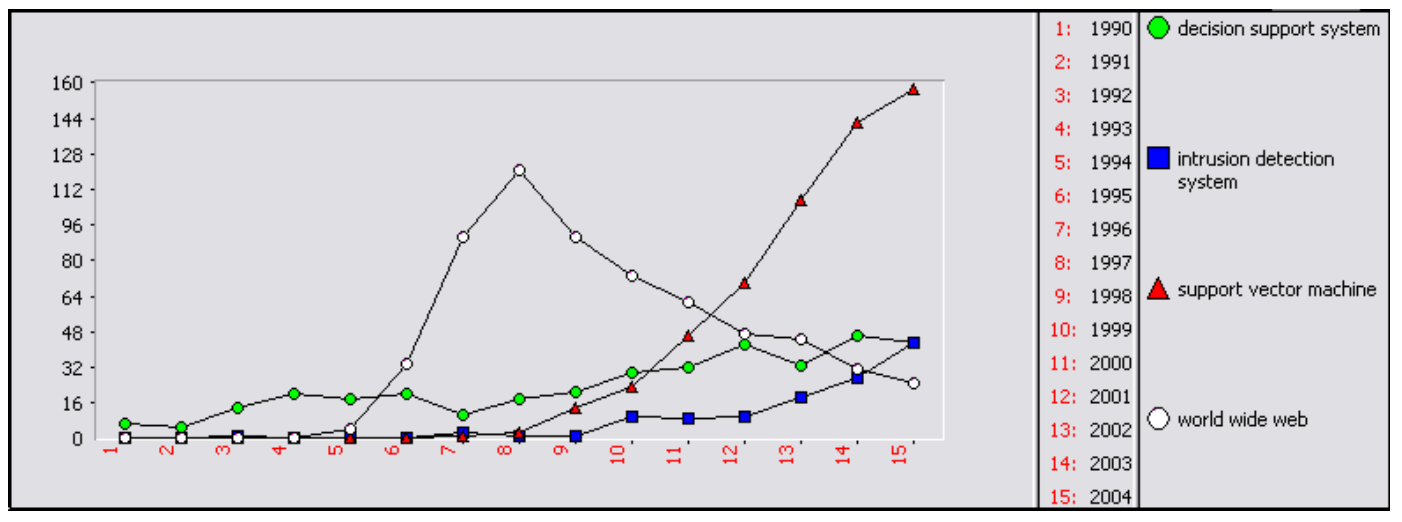

Figura 4.12: Gráfico dos tópicos e sua evolução nos anos de 1990 a 2004

Nota-se que a ferramenta OLAP oferece ao usuário uma interface amigável para a interpretação e entendimento dos dados, isolando o usuário dos detalhes físicos de um data warehouse. As consultas multidimensionais sobre tópicos encerraram o primeiro ciclo do desenvolvimento do data warehouse de FIP, no qual se pôde verificar que as ferramentas do tipo OLAP, assim como as técnicas de data warehousing permitem, como mostrado nos exemplos, a verificação de tendências, obtenção dos índices bibliométricos, além de permitir a utilização desses dados por algoritmos de mineração de dados.

A seguir serão apresentados os experimentos realizados para a extração automática dos tópicos de pesquisa utilizados nas consultas multidimensionais. 


\section{Indexação automática de documentos}

Conforme apresentado na Seção 3.4.2, a DBLP (Data Bases and Logic Programming) é um importante repositório que armazena e disponibiliza na Web uma enorme quantidade de informações sobre materiais bibliográficos dos maiores congressos e revistas da área de computação. O sistema DBLP classifica seu material por áreas de pesquisa, como Inteligência Artificial, Sistemas Distribuídos, Banco de Dados. No entanto, não é feita uma classificação individual dos artigos. A classificação é feita pelas revistas e congressos nos quais o artigo foi publicado, permitindo a identificação da área de todos os artigos da sua base.

Diferentemente da DBLP que possui as informações de materiais publicados em congressos e revistas mais importantes, a ferramenta FIP considera as informações de todo material disponível na Web. Isto cria uma dificuldade para a tarefa de identificação das áreas dos artigos, pois nem todos os materiais encontrados na Internet podem estar associados a revistas ou congressos. Assim, o processo de classificação realizado pela DBLP não pode ser aplicado à FIP.

Além das consultas por áreas, alguns tipos de análises sobre as pesquisas científicas podem levar em consideração os tópicos de pesquisa, isto é, consultas mais específicas do que aquelas feitas por áreas da computação. Dentro de uma área, digamos, Banco de Dados, poderiam ser analisados somente artigos associados a um tópico, como o Modelo Relacional. Outra importante análise, que leva em conta o aspecto histórico, pode ser feita para observar como um tópico de pesquisa evolui no decorrer do tempo, identificando tópicos que estão sendo mais explorados ou aqueles que deixaram de ser pesquisados, ou ainda, identificando tópicos emergentes ou estáveis. Assim, para a ferramenta FIP, além da obtenção de tópicos de pesquisa, é importante manter as características temporais associadas aos dados, como é normalmente feito em um data warehouse. 
Algumas medidas como a quantidade de publicações e citações entre artigos no decorrer do tempo podem ser armazenadas em data marts. As ferramentas do tipo OLAP podem acessar os data marts facilitando análises como aquelas que possuem um elemento temporal e que permitem a detecção e observação de tendências.

A Figura 5.1 apresenta um gráfico que inspirou os experimentos deste trabalho relacionados aos tópicos de pesquisa. O gráfico ilustra um tipo de consulta que poderia ser feita com ferramentas do tipo OLAP, onde é apresentada a quantidade de publicações sobre o tópico Análise Bayesiana em cada ano. Observa-se como o tema ganha destaque a partir do início da década de 90. As ferramentas OLAP também facilitam a mudança dos níveis de detalhamento e granularidade dos dados. Além das consultas sobre tópicos, poderiam ser feitas consultas em níveis mais altos como áreas da computação, ou ainda, permitir ao usuário selecionar materiais de outras áreas além da computação. É importante ressaltar que os data marts são indexados por dimensões (data, autor, país, etc) que determinam a busca e apresentação dos resultados. Entretanto, uma das dimensões mais relevantes para explorar um repositório de artigos é a de tópicos ou assuntos.

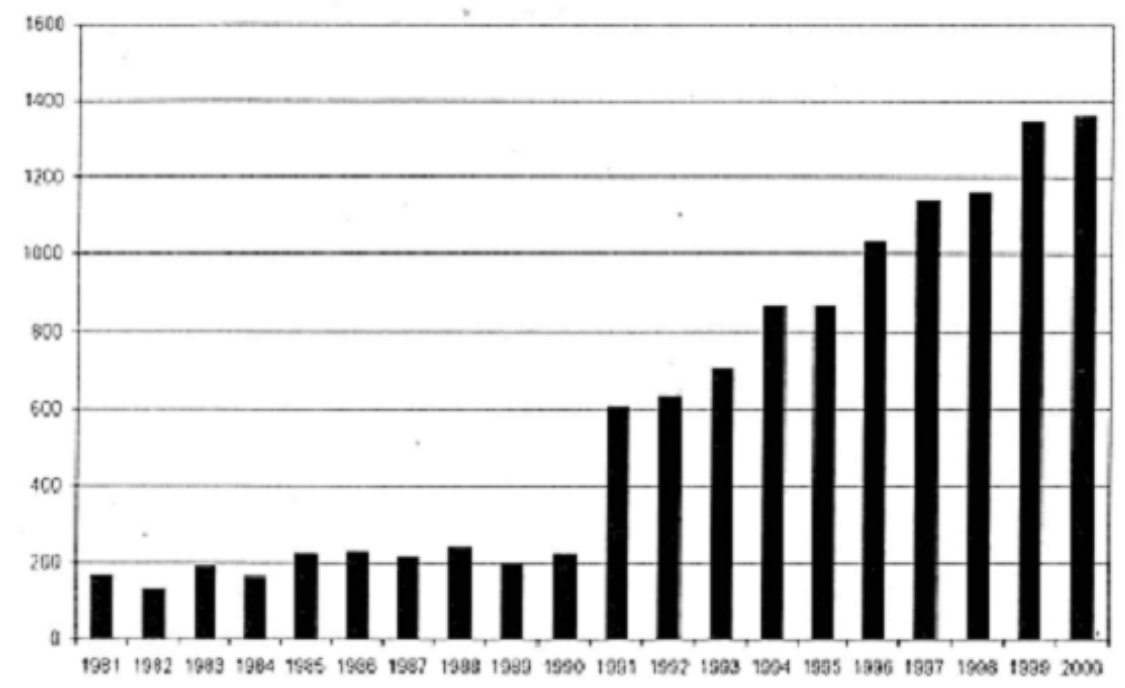

Figura 5.1: Quantidades de publicações sobre Análise Bayesiana durante os anos 1981-2001 (Corfield e Williamson, 2001).

Além de permitir análises sobre conjuntos de artigos semelhantes, a indexação por tópicos de pesquisa auxilia o usuário a encontrar os documentos desejados restringindo suas buscas em um grupo de artigos correlatos. Um usuário pode recuperar somente aqueles artigos relacionados ao tópico de interesse.

A ferramenta FIP pretende automatizar todos os processos, desde a recuperação de informações na Web até as consultas. A mesma automação é desejada no processo de indexação dos documentos e na definição dos tópicos de pesquisa dos documentos. A indexação manual de documentos traz algumas desvantagens como o alto custo da manutenção para manter a base atualizada devido a necessidade de mão-de-obra especializada. Além disso, os índices podem não refletir mudanças recentes se a atualização não for constante. 
Para automatizar este processo, os tópicos de pesquisa podem ser obtidos a partir dos próprios artigos científicos recuperados da Web por meio de informações como, por exemplo, palavraschave, que são boas candidatas para determinarem tópicos, embora nem sempre estejam disponíveis. As palavras-chave resumem os principais assuntos tratados em um artigo, enquanto que um tópico de pesquisa pode ser considerado com um assunto importante tratado nas pesquisas científicas durante um período de tempo. Apesar de serem utilizados em situações diferentes, as palavras-chave de um artigo e os tópicos de pesquisa podem ser considerados como sendo iguais.

A base DBLP XML foi utilizada para povoar o protótipo do data warehouse da FIP construído neste trabalho de mestrado. Como esta base não possui a informação palavra-chave do documento houve a necessidade de se estudar uma forma de obtenção automática. Nas próximas seções são apresentados os experimentos efetuados com a base DBLP.

\subsection{Descrição dos experimentos}

A técnica para a obtenção dos tópicos utilizada neste trabalho baseia-se nos termos que mais aparecem nos títulos das publicações. Foram extraídos dos títulos os n-grams, ou seja, todos os conjuntos de $n$ palavras consecutivas. Por exemplo, para um título com $m$ palavras e adotando o valor 3 para $n$, temos os 3-grams mostrados a seguir:

Título: PALAVRA ${ }_{1}$ PALAVRA $_{2}$ PALAVRA $_{3}$ PALAVRA $_{4} \ldots$ PALAVRA $_{m}$

Primeiro 3-gram: PALAVRA PALAVRA $_{2}$ PALAVRA $_{3}$

Segundo 3-gram: PALAVRA $_{2}$ PALAVRA $_{3}$ PALAVRA $_{4}$

$\cdots$

Último 3-gram: PALAVRA $_{m-2}$ PALAVRA $_{m-1}$ PALAVRA $_{m}$

Neste documento, "termos" e "n-grams" são tratados de forma indistinta e independente do valor de $n$.

$\mathrm{Na}$ tarefa de identificação dos tópicos de pesquisa, após a extração de todos os n-grams, com $n \in\{1,2,3\}$, são considerados somente os que aparecem com uma quantidade mínima, determinada por uma frequiência mínima de corte, e são verificados se estes termos são tópicos ou não. A freqüência mínima de corte corresponde a um número mínimo de vezes que o termo deve aparecer nos títulos da base.

Antes de extrair os n-grams dos títulos, é realizado o processo de stoplisting nos títulos de cada publicação. Neste processo, são ignoradas palavras muito comuns e que não são relevantes para a detecção de um tópico. Por exemplo, são desconsideradas preposições, artigos, pronomes e conjunções, embora esses termos apareçam em nomes de tópicos em português como em "engenharia de software”. Sinais de pontuação como pontos, vírgulas, também são desconsiderados. 
Nos experimentos descritos nesta dissertação, foram considerados somente os títulos. Se a extração dos dados for feita a partir de um córpus, coleção de documentos, poderão também ser utilizadas outras partes do artigo, como o resumo.

A seguir, é feita a descrição dos softwares utilizados para a extração dos n-grams dos títulos das publicações da DBLP e os softwares utilizados na indução de classificadores.

\subsubsection{Os softwares utilizados}

$\mathrm{Na}$ indução de classificadores foi utilizado o sistema Weka ${ }^{1}$ (Waikato Environment for Knowledge Analysis), desenvolvido na Universidade de Waikato na Nova Zelândia, o qual se encontra disponível na Internet juntamente com sua documentação. O sistema oferece uma interface intuitiva e uniforme para diferentes algoritmos de aprendizado de máquina, além de métodos de pré-processamento, no sistema chamados de filtros, e pós-processamento para avaliação dos resultados.

$\mathrm{Na}$ obtenção dos termos mais freqüentes, foram utilizados os softwares Pretext (Matsubara et al., 2003) e $\mathrm{NSP}^{2}$ (Ngram Statistics Package). Os experimentos iniciais, voltados para testes com poucos títulos, foram executados com o Pretext. No momento em que se adotou a base DBLP inteira para os experimentos, percebeu-se que a versão do software naquela época, maio de 2005, apresentava limitações para a tarefa ao consumir muitos recursos de memória, tornando o processamento impraticável. Como alternativa, foi utilizado o software NSP.

No processo de stoplisting, ou stopword, a lista de palavras a serem desconsideradas é a mesma utilizada no software Pretext em sua versão de 15-06-2005. Não foram consideradas diferenças entre letras minúsculas e maiúsculas em qualquer etapa da obtenção dos tópicos incluindo a de stoplisting.

\subsubsection{Pré-processamento}

\section{Freqüências por ano}

Um problema no processo de classificação de tópicos ocorre ao se levar em consideração a quantidade total de vezes que um termo aparece nos títulos dos artigos. Um tópico recente não possuirá tantas publicações quanto um assunto mais antigo que foi explorado durante muitos anos. Dessa forma, o tópico recente não aparece na lista dos termos mais freqüentes. Essa situação pode acontecer não somente para tópicos novos, mas também quando houver uma concentração de publicações de um assunto em um período muito curto de tempo. Isso pode acontecer quando uma área foi explorada por pouco tempo. Apesar de definir um tópico de pesquisa, mesmo que com pouca duração, um termo não irá aparecer na lista dos mais freqüientes porque os outros que

\footnotetext{
${ }^{1}$ www.cs.waikato.ac.nz/ml/weka

${ }^{2}$ http://ngram.sourceforge.net/
} 
foram pesquisados durante tempos mais longos possuirão freqüências maiores. Dependendo da freqüência de corte adotada para eliminar termos que não são tópicos, alguns tópicos também poderão não ser detectados.

Dessa forma, foi gerada uma lista para os termos com a frequiência de cada ano, que é a quantidade de vezes que os termos apareceram nos títulos dos materiais científicos da DBLP. Além das citações que podem ser armazenadas em data marts da FIP, os números de publicações em determinado ano também poderão ser utilizados nas análises de tendências de pesquisas. Tais valores também poderão ser utilizados em outros estudos que envolvam séries temporais.

Na base DBLP XML, das 636.023 publicações, 633.841 possuem informação de ano, sendo a quantidade de material científico considerada nos experimentos o último número citado. As publicações da base DBLP foram separadas por ano e, para cada ano, foi criado um arquivo com os títulos das publicações. Depois, cada arquivo foi aplicado ao software NSP, sendo gerado um arquivo para cada ano com os n-grams e suas freqüências.

\section{Análise dos termos mais freqüentes}

Após separar os títulos das publicações e calcular suas freqüências por ano, foram considerados somente termos com freqüência superior a um valor estipulado, a freqüência de corte. Alguns problemas para a determinação de tópicos mantiveram-se mesmo após separar as informações por ano. Existem partes de tópicos na lista dos 1-grams mais freqüentes como, por exemplo, o termo "mining" que é parte de tópicos de 2-grams como "data mining" ou "text mining" fazendo com que apareçam com freqüência alta. Como solução, poderiam ser ignorados termos de 1-gram que aparecem em tópicos de 2 ou 3-grams, mas surge outro problema: termos que poderiam ser considerados tópicos, como "fuzzy", não iriam aparecer porque existe o tópico "fuzzy logic" na lista de 2-grams.

Depois de verificada toda a lista de 1-gram, constatou-se que não há muitos tópicos interessantes para a indexação do DW. Como listas de termos formadas por n-grams com valores de $n$ maiores possuem quantidades de tópicos maiores, elas podem apresentar quantidade de tópicos suficiente para o DW. Possíveis tópicos de 1-gram como "fuzzy", podem ser representados por termos de 2-grams como "fuzzy logic" ou "fuzzy system", sendo possível utilizar apenas termos com quantidade de grams maiores na obtenção de tópicos de pesquisa.

A lista de 2-grams apresenta uma quantidade de tópicos maior que a lista de 1-gram. De forma geral, os tópicos mais importantes aparecem no início da lista que está por ordem de frequiência. Mas como acontece na lista de 1-gram, termos que formam tópicos de 3-grams também aparecem na lista dos 2-grams. Por exemplo, o 2-grams "unified modeling" faz parte do 3-gram "unified modeling language".

Nos primeiros experimentos para classificação automática de tópicos foram considerados os 2 e 3-grams. No decorrer dos experimentos, percebeu-se que os 3-grams apresentavam tópicos mais importantes e fáceis de identificar, passando-se a adotar somente os 3-grams. 
Tanto na lista de 2-grams como na de 3-grams, há alguns termos que, mesmo possuindo frequiência alta, não são tópicos de pesquisa como "Guest Editor". Neste documento, eles são chamados de "não-tópicos". A seguir são apresentados dois exemplos de títulos onde aparece o termo "Guest Editor":

“Guest Editor's Introduction: 1997 IEEE Real-Time Technologies and Applications Symposium".

“Guest Editor's Introduction: Current research Directions in Information Systems."

A frequiência alta de outros termos que não são tópicos também ocorre devido a outras informações apresentadas junto aos títulos, como, por exemplo, eventos e datas relacionadas à publicação. Termos como "2004 Proceedings" aparecem em diversos títulos relacionados aos workshops deste ano como no exemplo a seguir:

"Structural, Syntactic, and Statistical Pattern Recognition, Joint IAPR International Workshops, SSPR 2004 and SPR 2004, Lisbon, Portugal, August 18-20, 2004 Proceedings”

Assim, dentre os termos mais freqüentes, torna-se necessário fazer uma discriminação dos tópicos e não-tópicos. Este trabalho avaliou a utilização de técnicas de aprendizado de máquina para induzir classificadores capazes de cumprir tal tarefa.

\section{Conjunto de treinamento}

Para a indução dos classificadores, foi utilizada a lista de n-grams rotulados manualmente como tópicos e não-tópicos, sendo suas frequiências de cada ano utilizadas como atributos, além do rótulo de cada n-gram que define a classe a que pertence.

Os algoritmos utilizados foram C4.5 e o ID3, apresentados na Seção 2.2.2. Como o algoritmo ID3 apresentou resultados inferiores, apesar de muito próximos aos do C4.5, serão apresentados somente os experimentos com o C4.5.

No algoritmo C4.5 são utilizadas as freqüências de cada ano como dados de entrada, exemplificadas na Tabela 5.1. Os atributos estão definidos nas colunas representando os anos. Cada exemplo ou instância de treinamento, que representa um termo, é apresentado em uma linha. Os valores são a quantidade de vezes (freqüência) que o termo apareceu nos títulos das publicações naquele ano. Por exemplo, o termo "facial expression recognition" esteve presente nos títulos dos documentos do ano de 2004 catorze vezes. Um atributo especial é a Classe, que rotula os exemplo como tópico ou não-tópico. As freqüências de cada ano mais a classe dos exemplos servem como entrada para o algoritmo de aprendizado. Os termos em si não são utilizados como atributos na indução. 


\begin{tabular}{|l|c|c|c|c|c|c|}
\hline Termos & $F_{1936}$ & $F_{1937}$ & $\ldots$ & $F_{2004}$ & $F_{2005}$ & Classe \\
\hline \hline object oriented databases & 0 & 0 & $\ldots$ & 9 & 2 & tópico \\
\hline facial expression recognition & 0 & 0 & $\ldots$ & 14 & 0 & tópico \\
\hline 7 2001 proceedings & 0 & 0 & $\ldots$ & 0 & 0 & não_tópico \\
\hline$\ldots$ & $\ldots$ & $\ldots$ & $\ldots$ & $\ldots$ & $\ldots$ & $\ldots$ \\
\hline case based reasoning & 0 & 0 & $\ldots$ & 62 & 8 & tópico \\
\hline
\end{tabular}

Tabela 5.1: Representação dos exemplos de treinamento do algoritmo C4.5

Algumas características importantes encontradas nos dados de entrada dos experimentos foram observadas, necessitando da aplicação de técnicas como, por exemplo, a normalização das frequências dos termos com as quantidades totais de publicações dos anos. Conforme é mostrado na Figura 5.2, a quantidade de publicações aumenta a cada ano. Dessa forma o aumento da frequiência de um tópico pode apenas estar relacionado ao número da quantidade total de publicações, não significando que o tópico está sendo mais pesquisado ou em destaque. A normalização utilizada nos experimentos consiste em dividir a quantidade de vezes que um tópico aparece no ano pela quantidade total de publicações deste mesmo ano. No entanto, foram mantidos os valores dos resultados para os experimentos com os dados normalizados (E1, E3, E5, ... , E15), pois para os dados da DBLP esses experimentos leva a resultados melhores. Os experimentos com dados normalizados (E2, E4, E6, ... , E16) são apresentados nas tabelas de resultados com símbolo asterisco (*) para fazer a diferenciação.

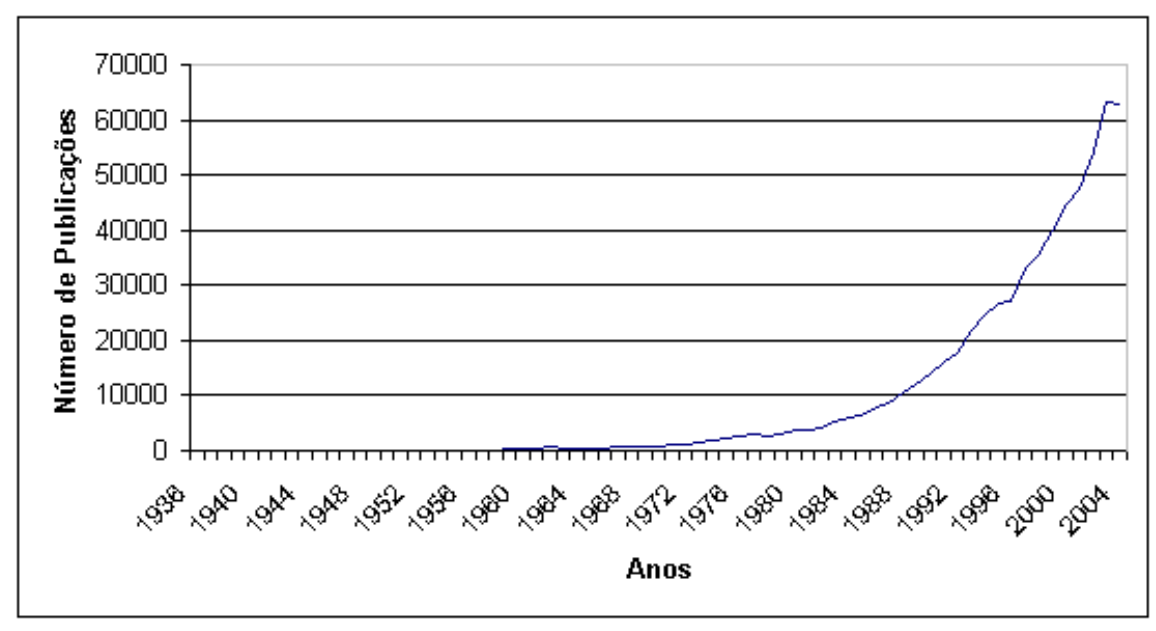

Figura 5.2: Quantidades de publicações da base de dados DBLP XML desde o ano da primeira publicação (1936) até o ano de 2004.

Além disso, como havia apenas publicações cadastradas na base DBLP até o mês de maio de 2005, os dados deste ano não foram utilizados. Ainda analisando as informações da base DBLP, verificou-se que a quantidade de publicações anteriores ao ano de 1960 era inexpressiva (Figura 5.2) fazendo com que atributos irrelevantes poderiam ser criados de forma a atrapalhar a indução dos classificadores. Assim, estes anos também foram desconsiderados. 
No conjunto de treinamento (1000 exemplos), ou treino, utilizado nos experimentos, os exemplos foram classificados manualmente em tópicos e não tópicos. Um exemplo de tópico de pesquisa é, por exemplo, “case-based reasoning”. Há aqueles termos, como "editor notes" que, apesar de aparecerem com freqüência alta nos títulos das publicações, não são tópicos. Há ainda os termos que fazem parte de um tópico. Por exemplo, o termo "peer to" (2-grams) é parte do tópico "peer to peer" (3-grams). Nos experimentos, foi necessário distinguir esses exemplos, pois, as partes de um tópico poderiam ter características parecidas com as de um tópico, atrapalhando no desempenho da classificação. Mas caso as partes de tópicos tivessem características diferentes dos tópicos, estas poderiam ser detectadas por classificadores permitindo a discriminação entre os dois tipos de termos. Assim, os experimentos foram realizados considerando as partes de tópicos como não-tópicos e depois os termos deste tipo não entraram nos experimentos para verificar se haveria diferença nos resultados. Constatou-se que não houve diferenças significativas como será apresentado posteriormente na seção da apresentação dos resultados deste documento.

Na criação do conjunto de exemplos treinamento, havia ainda a dificuldade em classificar manualmente alguns termos. Neste grupo, estão incluídos os termos em alemão. Estes foram desconsiderados nos experimentos. A distinção dos tipos de termos foi feita da seguinte forma:

1 - Tópico (Exemplo: data mining)

2 - Não é tópico (Exemplo: editor notes)

3 - Parte de um tópico (Exemplo: peer to)

4 - Desconhecido (incluindo termos em alemão)

Nesta dissertação, os tópicos são considerados exemplos positivos e os termos que não são tópicos são os exemplos negativos. Os exemplos do tipo 2 são sempre considerados como exemplos negativos. Os exemplos do tipo 3 e 4, quando utilizados nos experimentos, também foram considerados como exemplos negativos. O conjunto de treinamento inicial de 2-grams, denominado CT1, apresenta a seguinte quantidade de exemplos:

\begin{tabular}{|l|l|l|}
\hline Tipo & Quantidade & Porcentagem \\
\hline 1 & 581 & $58,0 \%$ \\
\hline 2 & 301 & $30,0 \%$ \\
\hline 3 & 96 & $9,5 \%$ \\
\hline 4 & 23 & $2,2 \%$ \\
\hline \hline Total & 1001 & $100 \%$ \\
\hline
\end{tabular}

Tabela 5.2: Conjunto de treinamento inicial de 2-grams (CT1)

O conjunto de treinamento inicial de 3-grams, denominado CT2, apresenta a seguinte quantidade de exemplos:

Para conseguir gerar cerca de 1000 exemplos (2-grams) para o treinamento, utilizou-se a freqüência de corte superior a 20. Foi feita a classificação manual desses exemplos, sendo que 


\begin{tabular}{|l|l|l|}
\hline Tipo & Quantidade & Porcentagem \\
\hline 1 & 393 & $48,5 \%$ \\
\hline 2 & 228 & $28,1 \%$ \\
\hline 3 & 112 & $13,8 \%$ \\
\hline 4 & 77 & $9,5 \%$ \\
\hline \hline Total & 810 & $100 \%$ \\
\hline
\end{tabular}

Tabela 5.3: Conjunto de treinamento inicial de 3-grams (CT2)

a quantidade de exemplos classificados como negativos variou de acordo com a utilização dos tipos (2, 3 e 4) em cada experimento.

Durante a geração dos 3-grams foi obtido um número de termos menor que o de 2-grams devido a uma limitação de recurso de memória. Foram gerados 810 exemplos com frequiência maior ou igual a 10. Todos estes termos foram classificados manualmente em um dos tipos (1, 2, 3 ou 4) e foram utilizados como exemplos de treinamento nos experimentos.'

Os dados do conjunto de treino CT2 considerando como negativo os tipos 2, 3 e 4 é denominado nos experimentos CT3.

Assim como ocorre na lista de 2-grams, os exemplos da lista de 3-grams do tipo 3 que são parte de tópicos poderiam ter características de tópicos em seus dados, e poderia também fazer com que, se considerados como negativos, o desempenho do classificador caísse. Dessa forma, os dados do conjunto de treino CT2 considerando como negativo apenas o tipos 2, é denominado nos experimentos CT4. Neste conjunto, os exemplos do tipo 3 e 4 são desconsiderados.

\subsubsection{Indução de classificadores}

Todos experimentos foram realizados com os algoritmos da ferramenta Weka e o método utilizado para estimar a qualidade do modelo foi o stratified 10-fold-cross-validation (apresentado na Seção 2.2.3). As medidas utilizadas para comparar o desempenho dos classificadores foram a acurácia (accuracy), precisão (precision) e cobertura (recall), também apresentadas na Seção 2.2.3. As medidas são apresentadas com média e desvio padrão.

Junto com estas medidas são apresentados os valores das classes majoritárias que é a proporção dos exemplos da classe que possui a maior quantidade de exemplos em relação a todo conjunto de treino.

\section{Experimentos com 3-grams}

Comparando as listas de 2 e 3-grams, notou-se que a lista de 3-grams apresentava termos que melhor descreviam os tópicos de pesquisa. Assim, a partir desse momento todos os experimentos foram realizados utilizando apenas os 3-grams. No primeiro experimento com 3-grams foi utili- 
zado o conjunto de treinamento CT3 (E1 da Tabela 5.4). Mesmo após a normalização dos dados, os valores das medidas de avaliação do classificador permaneceram iguais (E2 da Tabela 5.4).

O desempenho do experimento (E3) utilizando o conjunto de treinamento CT4, que não considera as partes de tópicos (tipo 3) e termos desconhecidos (tipo 4), é apresentado na Tabela 5.4. Apesar do desempenho do classificador ter aumentado em relação ao experimento anterior, a classe majoritária também aumentou. Novamente, a normalização dos dados não influenciou no desempenho do classificador induzido (E4 da Tabela 5.4).

\begin{tabular}{|l|l|l|l|l|}
\hline Exper. & Acurácia & Precisão & Cobertura & Classe maj. \\
\hline E1 & $61,6 \pm 6,1$ & $60,5 \pm 6,5$ & $60,0 \pm 9,9$ & 51,6 \\
\hline E2* & $61,6 \pm 6,1$ & $60,5 \pm 6,5$ & $60,0 \pm 9,9$ & 51,6 \\
\hline E3 & $77,6 \pm 4,7$ & $79,8 \pm 4,2$ & $86,5 \pm 4,8$ & 63,4 \\
\hline E4* & $77,6 \pm 4,7$ & $79,8 \pm 4,2$ & $86,5 \pm 4,8$ & 63,4 \\
\hline
\end{tabular}

Tabela 5.4: Experimentos com 3 -grams. O sinal * indica dados normalizados.

Na tarefa da definição dos exemplos de treino, na qual foi feita a classificação manual dos termos em tópicos e não tópicos, existe a dificuldade de um único especialista classificar corretamente se um termo é, de fato, um tópico devido a grande quantidade de assuntos existentes nas diversas áreas da computação. Torna-se necessária a correção dos dados de forma interativa e iterativa pelo especialista com ajuda dos próprios classificadores.

Após a execução dos experimentos descritos anteriormente, foi feita a verificação dos exemplos classificados e constatou-se que alguns exemplos haviam sido classificados de forma errada no conjunto dos exemplos de treinamento. Foram realizados novos experimentos com 620 exemplos sendo 392 exemplos positivos e 228 exemplos negativos (conjunto de treinamento CT5). No entanto, após corrigir os exemplos de treinamento e executar novamente o experimento (E5 da Tabela 5.5), os resultados continuaram a apresentar valores similares ao experimento anterior. No experimento com os dados normalizados (E6) obteve-se uma pequena diminuição da acurácia e cobertura, como é apresentado na Tabela 5.5. A partir desse momento, este conjunto de treinamento passou a ser utilizado em todos os experimentos.

\begin{tabular}{|l|l|l|l|l|}
\hline Exper. & Acurácia & Precisão & Cobertura & Classe maj. \\
\hline E5 & $77,4 \pm 5,7$ & $79,1 \pm 5,6$ & $87,5 \pm 3,5$ & 63,2 \\
\hline E6* & $76,8 \pm 5,4$ & $79,2 \pm 5,7$ & $86,5 \pm 3,4$ & 63,2 \\
\hline
\end{tabular}

Tabela 5.5: Experimento com 3-grams após correção manual

\section{Janelas de tempo}

Nos experimentos apresentados a seguir foi aplicado o conceito de janelas de tempo nos dados de entrada com a intenção de melhorar a identificação dos tópicos que surgiram em épocas distintas. Foi considerado apenas um número de anos a partir do primeiro ano em que o termo aparece 
no título de alguma publicação. Por exemplo, se a primeira aparição de um termo foi no ano de 1997, o atributo $a_{n} o_{1}$ para o classificador é a quantidade de publicações de 1997 que possuem aquele termo em seu título. O segundo atributo, $a \mathrm{no}_{2}$, é a quantidade no ano de 1998, e assim por diante, até atingir o tamanho da janela definido, que equivale ao número de anos considerados na classificação. A Tabela 5.6 apresenta alguns exemplos de treinamento utilizando uma janela de tamanho 4.

\begin{tabular}{|l|c|c|c|c|c|}
\hline Termos & $\mathbf{a n o}_{1}$ & $\mathbf{a n o}_{2}$ & $\mathbf{a n o}_{3}$ & $\mathbf{a n o}_{4}$ & Classe \\
\hline \hline object oriented databases & 1 & 3 & 1 & 8 & tópico \\
\hline facial expression recognition & 1 & 0 & 1 & 5 & tópico \\
\hline 7 2001 proceedings & 10 & 1 & 0 & 0 & não_tópico \\
\hline$\ldots$ & $\ldots$ & $\ldots$ & $\ldots$ & $\ldots$ & $\ldots$ \\
\hline case based reasoning & 1 & 0 & 0 & 3 & tópico \\
\hline
\end{tabular}

Tabela 5.6: Representação dos exemplos de treinamento usando janela de tamanho 4

Os resultados dos experimentos com janelas de tamanho de 1 a 5 são apresentados na Tabela 5.7. Observa-se que, em geral, a precisão e a acurácia diminuem com a normalização dos dados enquanto que a cobertura aumenta muito pouco.

\begin{tabular}{|c|c|c|c|c|c|c|c|}
\hline Experimento & Tam. Jan. & Exs pos. & Exs neg. & Acurácia & Precisão & Cobertura & Classe Maj. \\
\hline (E7) & 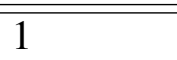 & 393 & 227 & $79,7 \pm 5,3$ & $76,6 \pm 5,1$ & $98,2 \pm 2,4$ & 63,4 \\
\hline$(\mathrm{E} 8)^{*}$ & 1 & 393 & 227 & $70,5 \pm 0,7$ & $70,5 \pm 0,7$ & $100,0 \pm 0,0$ & 63,4 \\
\hline (E9) & 2 & 393 & 191 & $79,5 \pm 3,6$ & $78,1 \pm 3,5$ & $96,6 \pm 3,2$ & 67,3 \\
\hline$(\mathrm{E} 10)^{*}$ & 2 & 393 & 191 & $72,7 \pm 1,2$ & $72,8 \pm 0,9$ & $99,7 \pm 0,8$ & 67,3 \\
\hline (E11) & 3 & 391 & 164 & $79,6 \pm 2,5$ & $78,4 \pm 2,9$ & $98,2 \pm 1,7$ & 70,5 \\
\hline$(\mathrm{E} 12)^{*}$ & 3 & 391 & 164 & $73,5 \pm 1,9$ & $73,9 \pm 0,9$ & $99,2 \pm 1,8$ & 70,5 \\
\hline (E13) & 4 & 384 & 143 & $77,6 \pm 2,7$ & $77,2 \pm 1,8$ & $97,9 \pm 2,3$ & 72,9 \\
\hline$(\mathrm{E} 14)^{*}$ & 4 & 384 & 143 & $73,8 \pm 1,7$ & $75,7 \pm 1,5$ & $96,2 \pm 5,2$ & 72,9 \\
\hline (E15) & 5 & 374 & 131 & $77,4 \pm 4,7$ & $78,3 \pm 2,3$ & $95,3 \pm 4,5$ & 74,1 \\
\hline$(\mathrm{E} 16)^{*}$ & 5 & 374 & 131 & $74,7 \pm 3,2$ & $76,1 \pm 2,2$ & $96,9 \pm 4,1$ & 74,1 \\
\hline
\end{tabular}

Tabela 5.7: Desempenho dos experimentos com diferentes tamanhos de janelas de tempo.

Nos experimentos com janelas de tamanho 1 a 3 e dados normalizados, todos os termos são preditos como tópicos, ou seja, a melhor predição é realizada pela classe majoritária.

A árvore gerada pelo C4.5 para janela de tamanho 4 é apresentada na Figura 5.3.

Apesar de ser difícil a interpretação da árvore, pode-se observar algumas características como a regra do primeiro nó (primeira linha) que determina que se a quantidade de publicações do primeiro ano não ultrapassar um valor limiar (0.000353), o termo é classificado como tópico. Provavelmente, os tópicos possuem pouca ocorrência no início e depois aumentam a medida em que a pesquisa naquele tópico é desenvolvida. A árvore gerada pelo experimento com janela de tamanho 5 apresenta a mesma característica. Por ser muito semelhante à árvore de tamanho 4, não foi apresentada neste trabalho. 


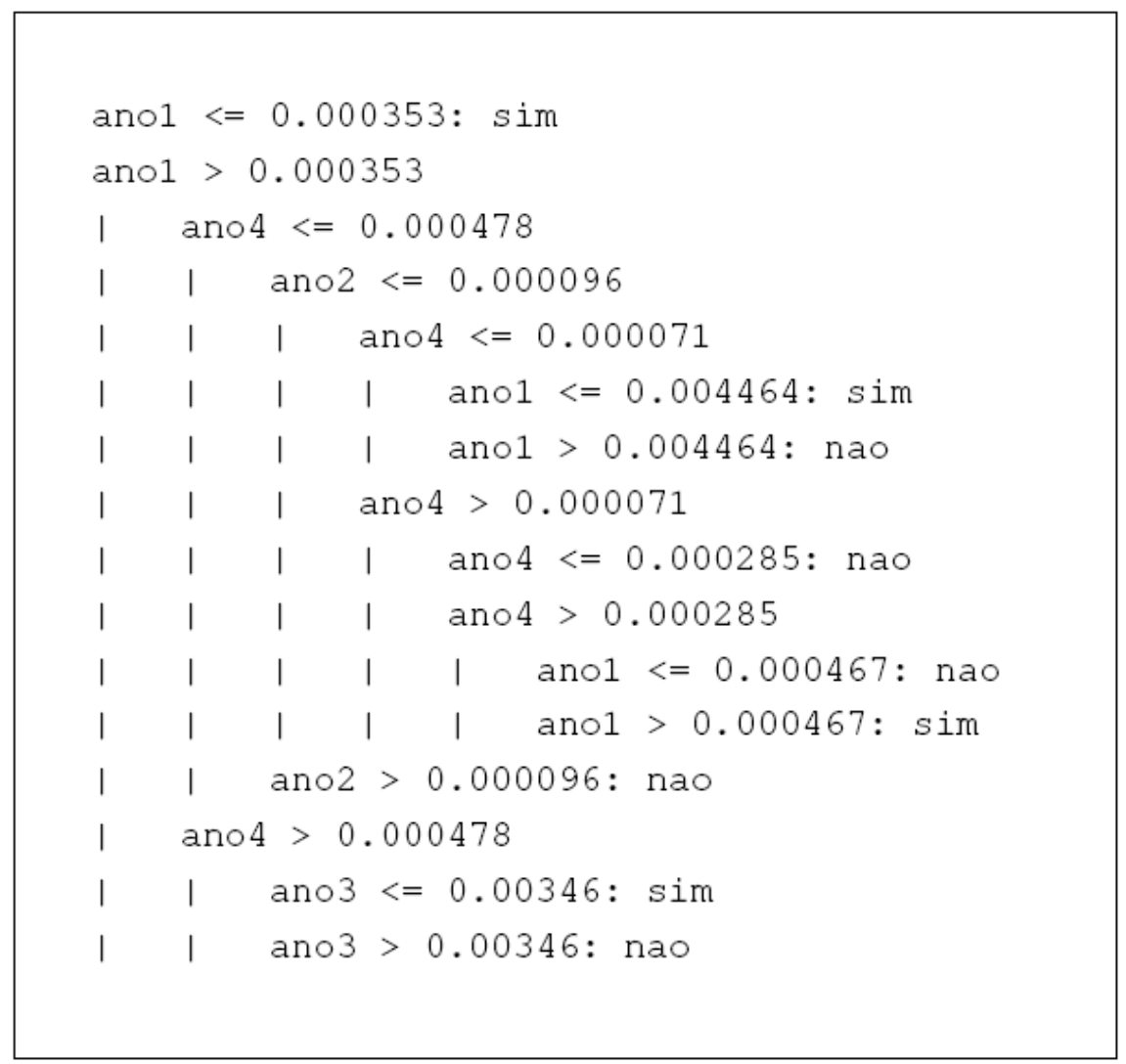

Figura 5.3: A árvore gerada para janela de tamanho 4.

\subsection{Análise dos resultados}

A seguir é apresentada a tabela com a descrição resumida dos experimentos realizados, a tabela com os números de desempenho dos experimentos e o gráfico para facilitar a comparação dos desempenhos. São apresentados apenas os experimentos com os dados normalizados.

\begin{tabular}{|l|l|}
\hline Exper. & Descrição \\
\hline \hline E2 & exemplos negativos dos tipos 2, 3 e 4 (CT3) \\
\hline E4 & exemplos negativos apenas do tipo 2 (CT4) \\
\hline E6 & exemplos de treinamento após a correção manual (CT5) \\
\hline E8 & janela de tamanho 1 (CT5) \\
\hline E10 & janela de tamanho 2 (CT5) \\
\hline E12 & janela de tamanho 3 (CT5) \\
\hline E14 & janela de tamanho 4 (CT5) \\
\hline E16 & janela de tamanho 5 (CT5) \\
\hline
\end{tabular}

Tabela 5.8: Tabela de descrição dos experimentos

Observando o gráfico da Figura 5.4, percebe-se na transição de E2 para E4 uma melhora nas medidas ao desconsiderar as partes de tópicos e termos desconhecidos. No entanto, como a classe majoritária também aumenta de forma equivalente, não se pode considerar que houve uma melhora 


\begin{tabular}{|l|l|l|l|l|}
\hline Exper. & Acurácia & Precisão & Cobertura & Classe maj. \\
\hline E2 & $61,6 \pm 6,1$ & $60,5 \pm 6,5$ & $60,0 \pm 9,9$ & 51,6 \\
\hline E4 & $77,6 \pm 4,7$ & $79,8 \pm 4,2$ & $86,5 \pm 4,8$ & 63,4 \\
\hline E6 & $76,8 \pm 5,4$ & $79,2 \pm 5,7$ & $86,5 \pm 3,4$ & 63,2 \\
\hline E8 & $70,5 \pm 0,7$ & $70,5 \pm 0,7$ & $100,0 \pm 0,0$ & 63,4 \\
\hline E10 & $72,7 \pm 1,2$ & $72,8 \pm 0,9$ & $99,7 \pm 0,8$ & 67,3 \\
\hline E12 & $73,5 \pm 1,9$ & $73,9 \pm 0,9$ & $99,2 \pm 1,8$ & 70,5 \\
\hline E14 & $73,8 \pm 1,7$ & $75,7 \pm 1,5$ & $96,2 \pm 5,2$ & 72,9 \\
\hline E16 & $74,7 \pm 3,2$ & $76,1 \pm 2,2$ & $96,9 \pm 4,1$ & 74,1 \\
\hline
\end{tabular}

Tabela 5.9: Tabela com resultados dos experimentos

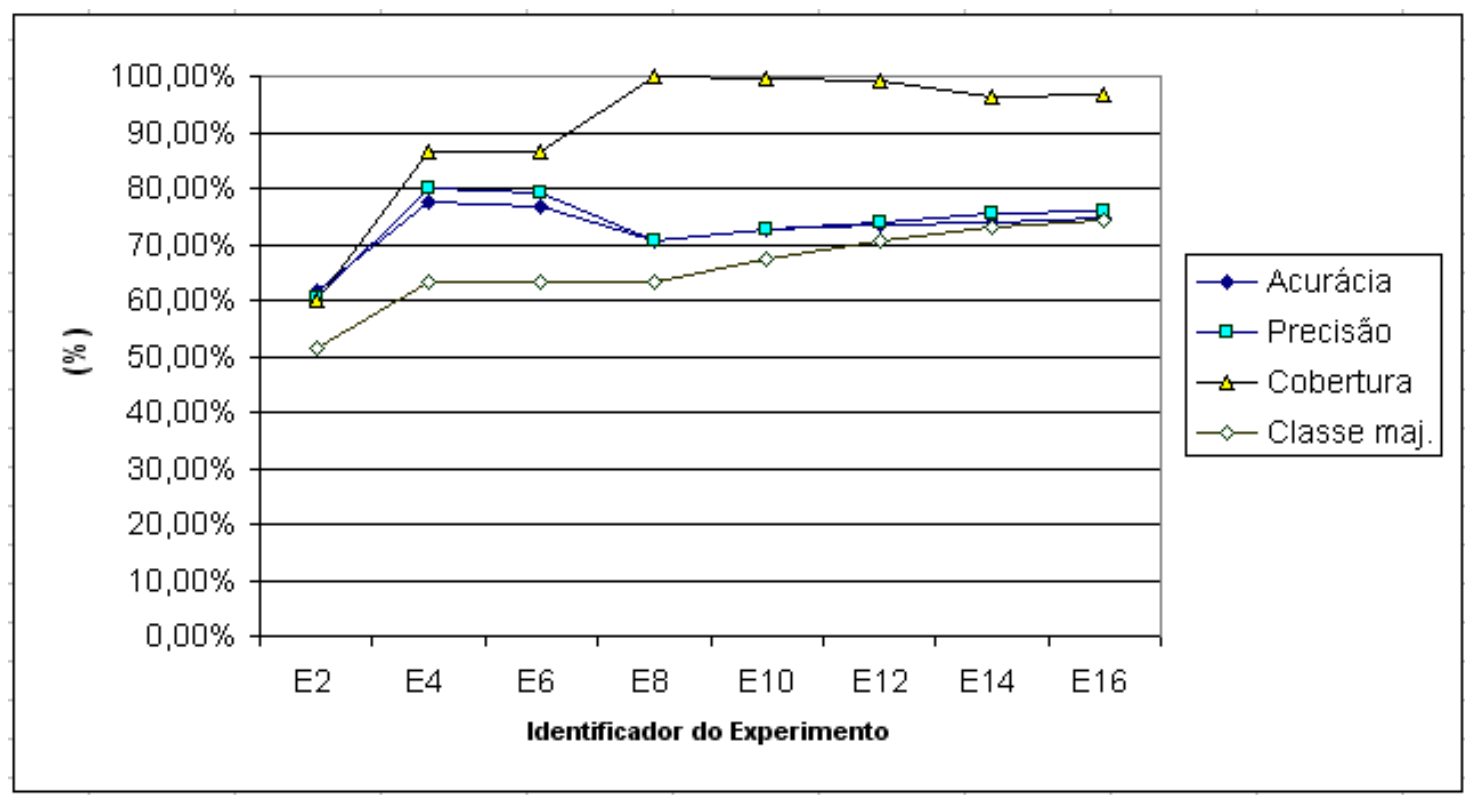

Figura 5.4: Gráfico comparativo de desempenho dos experimentos

no desempenho do classificador. Observa-se também na transição de E4 para E6 que a correção manual dos exemplos de treino não influenciou significativamente nas medidas.

Com a adoção do conceito de janelas de tempo, a acurácia e a precisão do classificador pioraram, como pode ser observado na transição de E6 para E8, sendo que houve uma queda de, aproximadamente, $10 \%$ para a janela de tamanho 1 em relação ao experimento anterior. $\mathrm{O}$ alto valor da medida cobertura nas janelas de tamanho de 1 a 3 é explicada pelo fato do classificador predizer todos os exemplos como sendo tópicos. Mesmo para as janelas de tamanho 4 e 5, nas quais foram geradas árvores de decisão, a predição para a classe majoritária é grande, proporcionando também um valor alto para esses classificadores.

Ao adotar tamanhos maiores de janelas não há grandes melhorias no desempenho em relação às medidas de acurácia e precisão. A classe majoritária dos exemplos tem um crescimento maior fazendo com que a diferença das medidas acurácia e precisão com a classe majoritária tenda a diminuir. Dessa forma, pode-se considerar que o desempenho cai ao utilizar janelas maiores. 
Essa característica torna-se uma vantagem por ser desejável conseguir detectar um novo tópico com um número mínimo de anos. Por exemplo, considerando o ano de 2004 como o atual e utilizando janelas de tamanho 5, um tópico que surgiu em 2001 não poderia ser detectado, pois entram nestes experimentos apenas os termos que possuem todos os atributos referentes aos anos de 2000 a 2004.

Ainda com relação aos experimentos com janelas, observa-se que as medidas acurácia e precisão não apresentam grandes diferenças em relação à classe majoritária. A classe majoritária fica na faixa de $63 \%$ a $74 \%$ enquanto que as medidas de acurácia e precisão apresentam-se entre $70 \%$ e 76\%. O fato da diferença ser pequena entre a classe majoritária e as outras medidas, deve-se, em parte, ao fato do valor da classe majoritária ser relativamente alto em alguns casos. Por exemplo, o experimento E16 com janela de tamanho 5 apresenta acurácia de 74,7\%, precisão 76,1\% e cobertura $96,6 \%$, mas a classe majoritária poussui um valor de $74,1 \%$. Com a remoção de termos irrelevantes, realizada no processo de stoplisting e divisão das frequiências por ano, é obtida uma quantidade grande de tópicos entre todos os termos obtidos, o que explica o alto valor para a classe majoritária.

Apesar dos classificadores induzidos nestes experimentos não terem apresentado resultados muito superiores à classe majoritária, como será visto no próximo capítulo, novos experimentos poderão ser realizados visando a melhoria dos resultados. 


\section{Conclusões}

Neste trabalho foram apresentadas técnicas de data warehousing, bem como de indexação automática de documentos apropriadas para construção de um repositório de artigos científicos.

A indexação dos documentos, a partir da detecção de tópicos ou assuntos (presentes nos documentos), permitiu a construção de data marts específicos de grande importância para a análise e entendimento da evolução de áreas e assuntos tratados nas coleções de documentos armazenados no repositório. Além disso o data warehouse projetado neste trabalho trouxe benefícios para o projeto FIP, pois:

- Permite o rápido uso dos dados no processo da mineração e da descoberta de conhecimento, uma vez que os dados estão integrados, padronizados e "limpos". A integração das informações em um único repositório, permite que os experimentos realizados pelos pesquisadores utilizem informações de uma mesma fonte.

- Consultas com ferramentas OLAP possibilitam a extração de informações do data warehouse da FIP auxiliando pesquisadores no processo de mineração, a descoberta de conhecimento no domínio específico de publicações científicas, bem como a avaliação dos resultados.

- Em conjunto com o desenvolvimento do módulo de extração de informações da FIP, o armazenamento das informações extraídas em um data warehouse facilitam a realização de experimentos que levam em consideração informações, tais como séries temporais com freqüências de termos nos documentos por ano; redes de cooperação entre autores e/ou instituições, grafos de citações entre artigos, grafos de citações entre autores, grafos de autores e tópicos de pesquisa. 
- Nestes experimentos podem ser consideradas informações temporais como data da recuperação dos artigos na Web, data da carga dos documentos no data warehouse, além da data de publicação. Assim, outros tipos de análises podem ser realizados, como os relacionados ao aspecto da volatilidade de determinadas informações disponíveis na Web;

- Análises sobre o data warehouse também podem auxiliar na atualização dos corpora recuperados, ou seja, no momento de agregar novos artigos aos corpora existentes.

Combinadas, as técnicas de data warehousing e indexação automática dos artigos auxiliam na descoberta automática de conhecimento sobre áreas específicas a partir da evolução histórica dos corpora recuperados dessas áreas. Por exemplo, determinar novas fronteiras que estão sendo exploradas, sub-áreas que estão perdendo prioridade, domínios e aplicações nos quais as técnicas estão sendo exploradas. No extremo, podem explorar até a possibilidade identificar tópicos de investigações novos a partir da mineração e visualização dos corpora.

Neste trabalho foi possível verificar a adequação das técnicas de data warehousing para tratar problemas relacionados ao armazenamento de informações de publicações científicas recuperadas da Web. O levantamento sobre repositórios de materiais cientificos permitiu identificar as informações importantes que são armazenadas e utilizadas nos variados tipos de análises, como os relacionados aos tópicos de pesquisa que possibilitam a recuperação e exploração em grandes quantidades de publicações. O estudo sobre os índices bibliométricos ressaltou a importância das citações entre documentos e a tentativa de medir e quantificar o impacto das publicações, autores e eventos na pesquisa, podendo ser utilizados para determinar os artigos mais relevantes em um conjunto de documentos.

As consultas multidimensionais realizadas com as ferramentas do tipo OLAP mostraram-se adequadas para análises de tendências e evolução nas pesquisas devido ao desempenho, facilidade de uso, flexibilidade na manipulação dos dados e variedade de operações sobre os mesmos. Dessa forma, as técnicas de data warehousing apresentam-se apropriadas para a construção do repositório da ferramenta FIP.

A continuidade do trabalho realizado com as técnicas de extração automática de tópicos pode contribuir para melhorar a indexação dos documentos do repositório da FIP. A apresentação dos resultados dos experimentos do capítulo sobre indexação de documento (Capítulo 5) foi baseada na ordem em que foram realizados, sendo apresentados apenas os mais importantes. Houve grande interatividade e iteratividade na execução destes experimentos. Muitos deles foram executados diversas vezes fazendo ajustes como a correção na classificação manual dos exemplos de treino. Alguns detalhes para a melhoria do desempenho dos indutores só puderam ser observados com a análise dos próprios resultados e sua visualização com gráficos. Durante este processo surgiram novas idéias para a adoção de diferentes técnicas, como, por exemplo, o conceito de janelas de tempo.

A idéia para a utilização das janelas de tempo surgiu durante alguns testes iniciais realizados com wavelets (Daubechies, 1990), onde se tentou melhorar o desempenho nos experimentos de 
classificação de tópicos. Essa técnica foi aplicada sobre os dados de entradas dos algoritmos de aprendizado de máquina, com a intenção de capturar características que poderiam ser importantes no momento da classificação, mas que poderiam não estar explícitas nos dados originais. Em geral, os wavelets são utilizados para a compressão de dados, principalmente em imagens. Nestes experimentos, foram utilizados para obter separadamente as características de aproximação, ou resumo, e detalhes dos sinais de freqüência. Nestes experimentos iniciais utilizou-se apenas a base Haar. Em trabalhos futuros poderão ser utilizadas outras famílias de bases de wavelets, fazendo uma análise detalhada para a escolha da base mais apropriada, além de filtros de ruídos como a transformada de Fourier (Gonzalez e Woods, 2001).

Da mesma forma, foram realizados alguns testes iniciais com SVM (Support Vector Machines) (Cristianini e Shawe-Taylor, 2000; Vapnik, 1995), que apesar de não fornecerem classificadores que podem ser interpretados por seres humanos, como as árvores de decisão, são conhecidos por conseguirem bons desempenhos na tarefa de classificação. Nestes testes preliminares foram obtidos alguns resultados indicativos de que esta técnica, assim como as utilizadas com wavelets, podem alcançar resultados promissores.

Algumas questões não foram endereçadas neste trabalho, como as que se referem às partes de tópicos encontradas entre n-grams. Em geral, percebeu-se que os 3-grams representam bem os tópicos de pesquisa, no entanto, podem existir alguns tópicos importantes compostos por 2-grams e ainda, na lista de 3-grams, encontram-se partes de 4-grams ou tópicos compostos por mais termos. Além disso, situações como as provocadas por sinônimos e siglas, tais como Wide World Web, WWW e Web, e outros termos que representam o mesmo tópico, como o plural dos termos, decision support system e decision support systems, poderão ser tratadas com a realização de um pós-processamento. Em trabalhos futuros poderá ser aplicada uma grande quantidade de técnicas e variações dos experimentos realizados neste trabalho, dentre elas, técnicas como wavelets, outros algoritmos de indução como SVM, outras formas de normalização para as frequiências e experimentos com outras informações como os resumos dos artigos.

Durante a construção e testes com o protótipo do data warehouse da FIP e dos data marts para a utilização da ferramentas OLAP, foi criada uma lista de stopwords específica para a base DBLP. Na lista de stopwords foram inseridos manualmente alguns termos comumente encontrados na DBLP que não eram tópicos, eliminando-os, dessa forma, da lista de tópicos. Assim, o uso de stoplisting, n-grams, cortes mínimos e uso de séries históricas permitiram obter bons conjuntos de termos. Esse termos possibilitaram a construção de data marts específicos e de grande importância para a análise e entendimento da evolução de áreas e assuntos tratados nas coleções de documentos.

A seguir são sugeridos trabalhos futuros relacionados às técnicas de data warehousing:

- Construção de data marts que possam ser interessantes aos pesquisadores e usuários da FIP utilizando outras dimensões como editora, tipo do documento e do evento, dimensões relacionadas a localização de autores, universidades e congressos e dimensões com características 
temporais, como a data da recuperação de informações dos artigos na Web e a data da carga dos dados no data warehouse.

- Poderão ser ainda investigados trabalhos relacionados a hierarquias formadas por tópicos, de tal forma que possam ser utilizadas nas mudanças de níveis de detalhamentos em consultas multidimensionais dos data marts.

- Análise do desempenho das ferramentas OLAP com informações dos corpora da FIP. Poderá ser necessária a seleção das informações mais importantes nas dimensões dos data marts por meio de medidas como os rankings de artigos, revistas, congressos e autores, além de outros ajustes e recursos de otimização do SGBD, técnicas de modelagem ou tecnologias de data marts para melhorar o desempenho nas consultas multidimensionais.

- Verificação das vantagens e limitações das ferramentas do tipo OLAP para os propósitos da FIP e outros tipos de ferramentas, como as de visualização, que podem ser utilizadas nas consultas sobre o data warehouse.

- Exploração de assuntos relacionados à indexação dos documentos do data warehouse, como os identificadores únicos de artigos, além do problema da identificação de autores que se apresenta como um desafio ainda sem solução para a comunidade científica. 
Allan, J.; Lavrenko, V.; Jin, H. First story detection in tdt is hard. In: CIKM '00: Proceedings of the ninth international conference on Information and knowledge management, New York, NY, USA: ACM Press, 2000, p. 374-381.

Alvarez, A. C. Extração de informação de referências bibliográficas usando pos-tagging. Relatório Técnico 281, ICMC-USP, São Carlos, SP, 2006.

Andrade, M. A.; VAlencia, A. Automatic extraction of keywords from scientific text: application to the knowledge domain of protein families. Bioinformatics, v. 14, n. 7, p. 600-607, 1998.

Antonio, I.; PACKer, A. Seminário sobre avaliação da produção científica: Relatório final. Ciência da Informação, v. 27, p. 236-238, 1998.

AzCarraga, A. P.; YAP, T. N.; TAN, J.; ChuA, T. S. Evaluating keyword selection methods for websom text archives. IEEE Transactions on Knowledge and Data Engineering, v. 16, n. 3, p. 380-383, 2004.

Bar-Ilan, J.; Peritz, B. C. Evolution, continuity, and disappearance of documents on a specific topic on the web: a longitudinal study of "informetrics". J. Am. Soc. Inf. Sci. Technol., v. 55, n. 11, p. 980-990, 2004.

BARANAUSKas, J. A. Extração automática de conhecimento por múltiplos indutores. Tese de Doutorado, ICMC-USP, 2001.

Batista, G. E. A. P. A. Pré-processamento de dados em aprendizado de máquina supervisionado. Tese de Doutorado, ICMC-USP, 2000.

Berson, A.; SMith, S. J. Data warehousing, data mining, and olap. New York, NY, USA: Computing Mcgraw-Hill, Inc., 1997. 
Bichs, H. E. A.; Rother, E. T.; Braga, M. E. R. Fatores de impacto, outros índices bibliométricos e desempenhos acadêmicos. Editorial do Arquivo Brasileiro de Oftalmologia, v. 65, n. 2, 2002.

Bigi, B.; Brun, A.; Haton, J. P.; Smaïli, K.; Zitouni, I. A comparative study of topic identification on newspaper and e-mail. In: SPIRE, 2001, p. 238-241.

Bollacker, K.; Lawrence, S.; Giles, C. Discovering relevant scientific literature on the web. IEEE Intelligent Systems, v. 15, n. 2, p. 42-47, 2000.

Bollacker, K.; LAWrence, S.; Giles, C. L. A system for automatic personalized tracking of scientific literature on the web. In: Digital Libraries 99 - The Fourth ACM Conference on Digital Libraries, New York: ACM Press, 1999, p. 105-113.

Brasil, C.; Lopes, A. A. Mineração de artigos científicos usando aprendizado de máquina. In: Jornadas Chilenas de la Computación - V Workshop de Inteligência Artificial, Arica-Chile, 2004, p. 1-7.

BRASIL, C. R. S. Abordagem simbólica de aprendizado de máquina na recuperação de artigos científicos a partir da web. Dissertação de Mestrado. ICMC/USP, 2006.

BuZydlowski, J. W.; White, H. D.; Lin, X. Term co-occurrence analysis as an interface for digital libraries. In: Visual Interfaces to Digital Libraries [JCDL 2002 Workshop], London, UK: Springer-Verlag, 2002, p. 133-144.

Chen, P. P. The entity-relationship model - toward a unified view of data. ACM Trans. Database System, v. 1, n. 1, p. 9-36, 1976.

Corey, M. Oracle 8i: data warehouse. Rio de Janeiro, RJ: Campus, 2001.

Corfield, D.; Williamson, J. Bayesianism into the 21st century. In: Foundations of Bayesianism, Kluwer Academic Publishers, p. 1-16, 2001.

CRISTIANini, N.; ShaWe-TAYlor, J. An introduction to support vector machines (and other kernel-based learning methods). 1.a ed. Cambridge, UK: Cambridge University Press, 2000.

Das-Neves, F.; Fox, E. A.; Yu, X. Connecting topics in document collections with stepping stones and pathways. In: CIKM '05: Proceedings of the 14th ACM international conference on Information and knowledge management, New York, NY, USA: ACM Press, 2005, p. 91-98.

DAubeChiEs, I. The wavelet transform, time-frequency localization and signal analysis. IIT, v. 36, p. 961-1005, 1990.

Fayyad, U.; Piatetsky-Shapiro, G.; Smyth, P. The kdd process for extracting useful knowledge from volumes of data. Commun. ACM, v. 39, n. 11, p. 27-34, 1996a. 
FAyYad, U. M.; Piatetsky-Shapiro, G.; Smyth, P. From data mining to knowledge discovery in databases. AI Magazine, v. 17, n. 3, p. 37-54, 1996b.

Ferreira, V. M. Analisando os dados do programa de melhoramento genético da raça nelore com data warehousing e data mining. Dissertação de Mestrado. ICMC/USP, 2002.

Fielding, R.; Gettys, J.; Mogul, J. C.; Frystyk, H.; Masinter, L.; Leach, P.; Berners-LeE, T. Rfc 2616. Hypertext Transfer Protocol - HTTP/1.1., 1999.

GARFIELD, E. Citation indexing. its theory and application in science, technology and humanities. New York: Wiley, 1979.

Gonzalez, R. C.; Woods, R. E. Digital image processing. Boston, MA, USA: AddisonWesley Longman Publishing Co., Inc., 2001.

Goodrum, A. A.; McCain, K. W.; Lawrence, S.; Giles, C. L. Computer science literature and the world wide web. (Preprint), 1999.

Hagman, J.; Perrotta, D.; Steinberger, R.; Varfis, A. Document classification and visualisation to support the investigation of suspected fraud. 2000.

HE, Y.; Hui, S. C. Pubsearch: a web citation-based retrieval system. Library Hi Tech, v. 19, n. 3, p. 274-285, 2001.

He, Y.; HuI, S. C. Mining a web citation database for author co-citation analysis. Inf. Process. Manage., v. 38, n. 4, p. 491-508, 2002.

Hearst, M. A. Texttiling: segmenting text into multi-paragraph subtopic passages. Comput. Linguist., v. 23, n. 1, p. 33-64, 1997.

Huebsch, R. How dead are dead links? UC Berkeley Computer Science Project Status Report, 2003.

InMon, W. H. Como construir o data warehouse. Rio de Janeiro, RJ: Campus, 1996a.

InMON, W. H. The data warehouse and data mining. Commun. ACM, v. 39, n. 11, p. 49-50, 1996b.

ISI Isi essential science indicators tutorial. Institute for Scientific Information (ISI). (Disponível em: http://scientific.thomson.com/webofknowledge/tutorials.html, acessado em novembro de 2004), 2003.

Jain, A. K.; Murty, M. N.; Flynn, P. J. Data clustering: a review. ACM Computing Surveys, v. 31, n. 3, p. 264-323, 1999. 
KIMBALL, R. The data warehouse toolkit: practical techniques for building dimensional data warehouses. New York, NY, USA: John Wiley \& Sons, Inc., 1996.

Kimball, R.; Merz, R. Data webhouse: construindo o data warehouse para a web. Rio de Janeiro, RJ: Campus, 2000.

Kimball, R.; Reeves, L.; Thornthwaite, W.; Ross, M.; Thornwaite, W. The data warehouse lifecycle toolkit: Expert methods for designing, developing and deploying data warehouses with cd rom. New York, NY, USA: John Wiley \& Sons, Inc., 1998.

LAGOZE, C.; SOMPEL, H. V. The open archives initiative: building a low-barrier interoperability framework. In: JCDL '01: Proceedings of the 1st ACM/IEEE-CS joint conference on Digital libraries, Roanoke, Virginia, United States: ACM Press, 2001, p. 54-62.

LAWrence, S. Access to scientific literature. The Nature Yearbook of Science an Technology, p. $86-88,2001$.

LAWrence, S.; Bollacker, K.; Giles, C. L. Indexing and retrieval of scientific literature. In: Eighth International Conference on Information and Knowledge Management, CIKM 99, Kansas Cite, Missouri, 1999a, p. 139-146.

Lawrence, S.; Coetzee, F.; Glover, E.; Flake, G.; Pennock, D.; Krovetz, B.; NielSEN, F.; Kruger, A.; Giles, L. Persistence of information on the web: analyzing citations contained in research articles. In: CIKM '00: Proceedings of the ninth international conference on Information and knowledge management, New York, NY, USA: ACM Press, 2000, p. $235-242$.

LAWrence, S.; Giles, C. L. Searching the web: General and scientific information access. IEEE Communications, v. 37, n. 1, p. 116-122, 1999.

Lawrence, S.; Giles, C. L.; Bollacker, K. Digital libraries and Autonomous Citation Indexing. IEEE Computer, v. 32, n. 6, p. 67-71, 1999b.

Lawrence, S.; Pennock, D. M.; Flake, G. W.; Krovetz, R.; Coetzee, F. M.; Glover, E.; Nielsen, F.; Kruger, A.; Giles, C. L. Persistence of web references in scientific research. Computer, v. 34, n. 2, p. 26-31, 2001.

LEY, M. The dblp computer science bibliography: Evolution, research issues, perspectives. In: SPIRE 2002: Proceedings of the 9th International Symposium on String Processing and Information Retrieval, Springer-Verlag, 2002, p. 1-10.

Lopes, A. A.; Minghim, R.; Melo, V. V.; Paulovich, F. V. Mapping texts through dimensionality reduction and visualization techniques for interactive exploration of document collections. In: Erbacher, R. F.; Roberts, J. C.; Gröhn, M. T.; BÖRner, K., eds. IST/SPIE 
Workshop on Visualization and Data Analysis (VDA), San Jose, California, USA, 2006, p. 0112.

Lopes, A. A.; Pinho, R.; Paulovich, F. V.; Minghim, R. Visual text mining using association rules. Computers \& Graphics: An International Journal of Systems \& Applications in Computer Graphics, v. 31, n. 6, 2007.

MAKKONEN, J. Investigations on event evolution on tdt. In: HLT-NAACL, 2003.

Matsubara, E. T.; Martins, C. A.; Monard, M. C. Pretext: Uma ferramenta para préprocessamento de textos utilizando a abordagem bag-of-words. Relatório Técnico 209, ICMCUSP, São Carlos, SP, 2003.

Melo, V.; Lopes, A. A. Identificação eficiente de referências bibliográficas duplicadas em um corpora de artigos científicos. In: II Workshop de Teses e Dissertações em Inteligência Artificial, São Luis, Maranhão, 2004a, p. 71-80.

Melo, V.; Lopes, A. A. Usando as referências bibliográficas no clustering de artigos científicos. In: Jornadas Chilenas de la Computación - V Workshop de Inteligência Artificial, Arica-Chile, 2004b, p. 1-7.

Melo, V.; Lopes, A. A. Efficient identification of duplicate bibliographical references. In: Proceedings of the 5th Congress of Logic Applied to Technology - Laptec 2005, Himeji - Japan, 2005, p. 1-8.

Melo, V.; Secato, M.; Lopes, A. A. Extração e identificação automáticas de informações bibliográficas de artigos científicos. In: Jornadas Chilenas de la Computación - IV Workshop de Inteligência Artificial, Chillán, 2003, p. 1-7.

Melo, V. V. Clustering de artigos científicos. Dissertação de Mestrado. ICMC/USP, 2005.

Meneghini, R. Avaliação da produção científica e o projeto scielo. Ciência da Informação, v. 27, n. 2, p. 219-220, 1998.

Minghim, R.; Paulovich, F. V.; Lopes, A. A. Content-based text mapping using multidimensional projections for exploration of document collections. In: ERBACHER, R. F.; ROBerts, J. C.; GröHn, M. T.; BÖRner, K., eds. Proceedings of SPIE on Visualization and Data Analysis, San Jose, California, USA, 2006, p. 1-12.

Mitchell, T. M. Machine learning. New York: McGraw-Hill, 1997.

Monard, M. C.; BARAnauskas, J. A. Conceitos sobre aprendizado de máquina. In: ReZENDE, S. O., ed. Sistemas Inteligentes - Fundamentos e Aplicações, v. 1, 1.a ed, cáp. 4, Barueri, SP: Manole, p. 89-114, 2003. 
Nestorov, S.; Jukic, N. Ad-hoc association-rule mining within the data warehouse. In: HICSS, 2003, p. 232.

NÜRNBERGER, A. Clustering of document collections using a growing self-organizing map. In: Proc. of BISC International Workshop on Fuzzy Logic and the Internet (FLINT 2001), Berkeley, USA: ERL, College of Engineering, University of California, 2001, p. 136-141.

OliveIRA, E. R. Avaliação ergonômica de interfaces da scielo - scientific electronic library online. Dissertação de Mestrado. Universidade Federal de Santa Catarina - UFSC, 2001.

PACKer, A. L. Scielo: uma metodologia para publicação eletrônica. Ciência da Informação, v. 27, n. 2, 1998.

Paulovich, F. V.; Minghim, R. Text map explorer: a tool to create and explore document maps. In: 10th International Conference on Information Visualisation, 2006.

PYlE, D. Data preparation for data mining. San Francisco, CA, USA: Morgan Kaufmann Publishers Inc., 1999.

Quinlan, J. R. C4.5: Programs for machine learning. Morgan Kaufmann Publishers, 1993.

RENnIE, J. Topcat: Data mining for topic identification in a text corpus. IEEE Transactions on Knowledge and Data Engineering, v. 16, n. 8, p. 949-964, 2004.

Rezende, S. O.; Pugliesi, J. B.; Melanda, E. A.; Paula, M. F. Mineração de dados. In: REZENDE, S. O., ed. Sistemas Inteligentes - Fundamentos e Aplicações, v. 1, 1.a ed, cáp. 12, Barueri, SP: Manole, p. 307-335, 2003.

RousseaU, R. Indicadores bibliométricos e econométricos para a avaliação de instituições científicas. Ciência da Informação, v. 27, n. 2, p. 236-238, 1998.

Sidiropoulos, A.; Manolopoulos, Y. A new perspective to automatically rank scientific conferences using digital libraries. Inf. Process. Manage., v. 41, n. 2, p. 289-312, 2003.

Smith, D. A.; Mahoney, A.; Crane, G. Integrating harvesting into digital library content. In: JCDL '02: Proceedings of the 2nd ACM/IEEE-CS joint conference on Digital libraries, ACM Press, 2002, p. 183-184.

SUlEMAN, H. Enforcing interoperability with the open archives initiative repository explorer. In: JCDL '01: Proceedings of the 1st ACM/IEEE-CS joint conference on Digital libraries, Roanoke, Virginia, United States: ACM Press, 2001, p. 63-64.

Testa, J. A base de dados isi e seu processo de seleção de revistas. Ciência da Informação, v. 27, n. 2, 1998. 
Todman, C. Designing a data warehouse: supporting customer relationship management. Upper Saddle River, N.J.: Prentice Hall, hewlett-Packard Professional Books, 2001.

VAPNIK, V. N. The nature of statistical learning theory. New York, NY, USA, 1995.

YAO, J. T.; YAO, Y. Y. Web-based information retrieval support systems: Building research tools for scientists in the new information age. In: Web Intelligence, 2003, p. 570-573.

YEAGER, N. J.; MCGRATH, R. E. Web server technology: the advanced guide for world wide web information providers. Morgan Kaufmann Publishers Inc., 1996. 

APÊNDICE

\section{$A$}

\section{Especificação das tabelas}

\section{A.1 Tabelas principais}

Nesta seção são especificadas as tabelas que estão em destaque no diagrama do modelo lógico. A chave estrangeira (Foreign Key) é representada nas tabelas abaixo pelo nome da tabela e o(s) campo(s) a que faz referência: nome_da_tabela(campo).

\begin{tabular}{|c|c|c|c|c|}
\hline Nome do Campo & Tipo & Restrição & Foreign Key & PK \\
\hline codigo & number(8) & Not Null & & $*$ \\
\hline cod_tipo & number(3) & & tipo_documento(codigo) & \\
\hline tipo & $\operatorname{varchar}(20)$ & & & \\
\hline titulo & $\operatorname{varchar}(700)$ & Not Null & & \\
\hline resumo & $\operatorname{varchar}(1000)$ & & & \\
\hline cod_evento & number(7) & & evento (codigo) & \\
\hline nome_evento & $\operatorname{varchar}(150)$ & & & \\
\hline cod_tipo_evento & number(4) & & tipo_evento(codigo) & \\
\hline tipo_evento & $\operatorname{varchar}(50)$ & & & \\
\hline cod_revista & number(8) & & revista(codigo) & \\
\hline titulo_revista & $\operatorname{varchar}(700)$ & & & \\
\hline cod_publicacao & number(10) & & publicacao(codigo) & \\
\hline titulo_publicacao & $\operatorname{varchar}(200)$ & & & \\
\hline endereco_publicacao & $\operatorname{varchar}(100)$ & & & \\
\hline
\end{tabular}




\begin{tabular}{llll} 
serie & $\operatorname{varchar}(100)$ & & \\
capitulo & $\operatorname{varchar}(4)$ & & \\
volume & $\operatorname{varchar}(30)$ & & \\
numero & $\operatorname{varchar}(20)$ & & \\
pagina_ini & number(10) & & \\
pagina_final & number(10) & & \\
mes & $\operatorname{varchar}(40)$ & & \\
ano & number(4) & Not Nullora(codigo) \\
cod_editora & number(4) & & \\
editora & $\operatorname{varchar}(200)$ & & idioma(codigo) \\
local_arquivo_fip & varchar(200) & & \\
cod_idioma & number(3) & & \\
idioma & varchar(50) & & \\
cod_instituicao_autor & number(4) & & \\
nome_instituicao_autor & varchar(100) & & \\
issn & varchar(14) & & Not Null \\
data_recuperacao & date & Not Null & \\
data_carga & date & & \\
\hline
\end{tabular}

publicacao

\begin{tabular}{|c|c|c|c|c|}
\hline Nome do Campo & Tipo & Restrição & Foreign Key & PK \\
\hline codigo & number(8) & Not Null & & $*$ \\
\hline titulo & $\operatorname{varchar}(700)$ & Not Null & & \\
\hline resumo & $\operatorname{varchar}(500)$ & & & \\
\hline cod_evento & number(7) & & evento(codigo) & \\
\hline nome_evento & $\operatorname{varchar}(150)$ & & & \\
\hline endereço_publicacao & $\operatorname{varchar}(100)$ & & & \\
\hline serie & $\operatorname{varchar}(100)$ & & & \\
\hline capitulo & $\operatorname{varchar}(4)$ & & & \\
\hline volume & $\operatorname{varchar}(30)$ & & & \\
\hline numero & number(20) & & & \\
\hline pagina_ini & number(10) & & & \\
\hline pagina_final & number(10) & & & \\
\hline mes & $\operatorname{varchar}(40)$ & & & \\
\hline ano & number(4) & & & \\
\hline editora & $\operatorname{varchar}(200)$ & & & \\
\hline cod_tipo & number(3) & & tipo_publicacao(codigo) & \\
\hline tipo & $\operatorname{varchar}(20)$ & & & \\
\hline
\end{tabular}




$\begin{array}{lll}\text { url } & \operatorname{varchar}(200) & \\ \text { link_doc } & \operatorname{varchar}(200) & \\ \text { cod_idioma } & \text { number(3) } & \text { idioma(codigo) } \\ \text { idioma } & \operatorname{varchar}(50) & \\ \text { cod_instituicao_autor } & \text { number(4) } & \\ \text { nome_instituicao_autor } & \text { varchar(100) } & \text { local(codigo) } \\ \text { cod_local_autor } & \operatorname{varchar}(50) & \\ \text { local_autor } & \operatorname{varchar}(50) & \\ \text { isbn } & \operatorname{varchar}(14) & \\ \text { local_arquivo_fip } & \text { varchar(200) } & \\ \text { data_recuperacao } & \text { date } & \\ \text { data_carga } & \text { date } & \end{array}$

evento

\begin{tabular}{|c|c|c|c|c|}
\hline Nome do Campo & Tipo & Restrição & Foreign Key & PK \\
\hline codigo & number(7) & Not Null & & $*$ \\
\hline nome & $\operatorname{varchar}(250)$ & & & \\
\hline sigla & $\operatorname{varchar}(50)$ & & & \\
\hline cod_tipo_evento & number(4) & & tipo_evento(codigo) & \\
\hline tipo_evento & $\operatorname{varchar}(50)$ & & & \\
\hline cod_pais & number(3) & & pais (codigo) & \\
\hline pais & $\operatorname{varchar}(100)$ & & & \\
\hline data_inicio & $\operatorname{varchar}(50)$ & & & \\
\hline data_termino & $\operatorname{varchar}(50)$ & & & \\
\hline ano & number(4) & & & \\
\hline
\end{tabular}

revista

\begin{tabular}{lllll}
\hline Nome do Campo & Tipo & Restrição & Foreign Key & PK \\
\hline \hline codigo & number(8) & Not Null & & $*$ \\
titulo & varchar(700) & & & \\
cod_editora & number(4) & & editora(codigo) & \\
nome_editora & varchar(100) & & & \\
\hline
\end{tabular}




\begin{tabular}{|c|c|c|c|c|}
\hline Nome do Campo & Tipo & Restrição & Foreign Key & PK \\
\hline codigo & number(10) & Not Null & & $*$ \\
\hline nome & $\operatorname{varchar}(100)$ & & & \\
\hline abreviacao & $\operatorname{varchar}(50)$ & & & \\
\hline instituicao & number(5) & & instituicao(codigo) & \\
\hline localizacao & $\operatorname{vachar}(50)$ & & & \\
\hline cod_pais & $\operatorname{varchar}(3)$ & Not Null & pais (codigo) & \\
\hline pais & $\operatorname{varchar}(100)$ & Not Null & & \\
\hline email & $\operatorname{varchar}(50)$ & & & \\
\hline home_page & $\operatorname{varchar}(200)$ & & & \\
\hline
\end{tabular}

topico

\begin{tabular}{lllll}
\hline Nome do Campo & Tipo & Restrição & Foreign Key & PK \\
\hline \hline codigo & number(6) & Not Null & & $*$ \\
descricao & varchar(100) & Not Null & & \\
data_carga & date & & & \\
\hline
\end{tabular}

editora

\begin{tabular}{lllll}
\hline Nome do Campo & Tipo & Restrição & Foreign Key & PK \\
\hline \hline codigo & number(4) & Not Null & & $*$ \\
nome & $\operatorname{varchar(100)}$ & Not Null & & \\
cod_pais & $\operatorname{varchar(3)}$ & Not Null & pais(codigo) & \\
pais & $\operatorname{varchar}(100)$ & Not Null & & \\
\hline
\end{tabular}

instituicao

\begin{tabular}{lllll}
\hline Nome do Campo & Tipo & Restrição & Foreign Key & PK \\
\hline \hline codigo & number(4) & Not Null & & $*$ \\
nome & $\operatorname{varchar}(100)$ & Not Null & & \\
localizacao & $\operatorname{varchar}(100)$ & Not Null & & \\
cod_pais & $\operatorname{varchar(3)}$ & Not Null & pais(codigo) & \\
pais & varchar(100) & Not Null & & \\
\hline
\end{tabular}

pais

\begin{tabular}{lllll}
\hline Nome do Campo & Tipo & Restrição & Foreign Key & PK \\
\hline \hline codigo & number(3) & Not Null & & $*$ \\
nome & $\operatorname{varchar}(100)$ & Not Null & & \\
continente & $\operatorname{varchar}(30)$ & Not Null & & \\
\hline
\end{tabular}




\section{A.2 Tabelas secundárias}

\begin{tabular}{lllll} 
tipo_evento & & & & \\
\hline Nome do Campo & Tipo & Restrição & Foreign Key & PK \\
\hline \hline codigo & number(4) & Not Null & & \\
nome & $\operatorname{varchar}(50)$ & & & \\
descricao & $\operatorname{varchar}(250)$ & & & \\
\hline
\end{tabular}

tipo_documento

\begin{tabular}{lllll}
\hline Nome do Campo & Tipo & Restrição & Foreign Key & PK \\
\hline \hline codigo & number(3) & Not Null & & $*$ \\
nome & $\operatorname{varchar(50)}$ & & & \\
descricao & $\operatorname{varchar}(250)$ & & & \\
\hline
\end{tabular}

tipo_publicacao

\begin{tabular}{lllll}
\hline Nome do Campo & Tipo & Restrição & Foreign Key & PK \\
\hline codigo & number(3) & Not Null & & $*$ \\
nome & $\operatorname{varchar}(50)$ & & & \\
descricao & $\operatorname{varchar}(250)$ & & & \\
\hline
\end{tabular}

palavra_chave

\begin{tabular}{lllll}
\hline Nome do Campo & Tipo & Restrição & Foreign Key & PK \\
\hline \hline codigo & number(3) & Not Null & & $*$ \\
nome & varchar(50) & & & \\
\hline
\end{tabular}

idioma

\begin{tabular}{lllll}
\hline Nome do Campo & Tipo & Restrição & Foreign Key & PK \\
\hline \hline codigo & varchar(50) & Not Null & $*$ \\
idioma & varchar(50) & Not Null & & \\
\hline
\end{tabular}

status_url_documento

\begin{tabular}{lllll}
\hline Nome do Campo & Tipo & Restrição & Foreign Key & PK \\
\hline \hline documento & number(8) & Not Null & documento(codigo) & $*$ \\
data & date & Not Null & & \\
status & varchar(10) & Not Null & & \\
\hline
\end{tabular}


status_url_publicacao

\begin{tabular}{lllll}
\hline Nome do Campo & Tipo & Restrição & Foreign Key & PK \\
\hline \hline publicacao & number(10) & Not Null & publicacao(codigo) & $*$ \\
data & date & Not Null & & \\
status & varchar(10) & Not Null & & \\
\hline
\end{tabular}

\section{A.3 Tabelas auxiliares}

Tabelas utilizadas para os relacionamentos N:N entre tabelas.

autor_documento

\begin{tabular}{lllll}
\hline Nome do Campo & Tipo & Restrição & Foreign Key & PK \\
\hline \hline documento & number(8) & Not Null & documento(codigo) & $*$ \\
pesquisador & number(10) & Not Null & pesquisador(codigo $)$ & $*$ \\
ordem_autor & number(3) & Not Null & & \\
\hline
\end{tabular}

autor_publicacao

\begin{tabular}{lllll}
\hline Nome do Campo & Tipo & Restrição & Foreign Key & PK \\
\hline \hline publicacao & number(8) & Not Null & publicacao(codigo $)$ & $*$ \\
pesquisador & number(10) & Not Null & pesquisador $($ codigo $)$ & $*$ \\
ordem_autor & number(3) & & & \\
\hline
\end{tabular}

referencia_doc_doc

\begin{tabular}{|c|c|c|c|c|}
\hline Nome do Campo & Tipo & Restrição & Foreign Key & PK \\
\hline cod_origem & number(8) & & documento(codigo) & $*$ \\
\hline cod_dest & number(8) & & documento (codigo) & $*$ \\
\hline
\end{tabular}

referencia_doc_pub

\begin{tabular}{|c|c|c|c|c|}
\hline Nome do Campo & Tipo & Restrição & Foreign Key & PK \\
\hline cod_origem & number(8) & & documento(codigo) & $*$ \\
\hline cod_dest & number(8) & & publicacao(codigo) & $*$ \\
\hline
\end{tabular}

referencia_pub_pub

\begin{tabular}{|c|c|c|c|c|}
\hline Nome do Campo & Tipo & Restrição & Foreign Key & PK \\
\hline cod_origem & number(8) & & publicacao(codigo) & $*$ \\
\hline cod_dest & number(8) & & publicacao(codigo) & $*$ \\
\hline
\end{tabular}


referencia_pub_doc

\begin{tabular}{|c|c|c|c|c|}
\hline Nome do Campo & Tipo & Restrição & Foreign Key & $\overline{P K}$ \\
\hline cod_origem & number(8) & & publicacao(codigo) & $*$ \\
\hline cod_dest & number(8) & & documento(codigo) & $*$ \\
\hline
\end{tabular}

topico_documento

\begin{tabular}{lllll}
\hline Nome do Campo & Tipo & Restrição & Foreign Key & PK \\
\hline \hline documento & number(8) & Not Null & documento(codigo $)$ & $*$ \\
topico & number(6) & Not Null & topico $($ codigo $)$ & $*$ \\
\hline
\end{tabular}

topico_publicacao

\begin{tabular}{lllll}
\hline Nome do Campo & Tipo & Restrição & Foreign Key & PK \\
\hline \hline publicacao & number $(8)$ & Not Null & publicacao(codigo $)$ & $*$ \\
topico & number $(6)$ & Not Null & topico $($ codigo $)$ & $*$ \\
\hline
\end{tabular}

topico_pesquisador

\begin{tabular}{lllll}
\hline Nome do Campo & Tipo & Restrição & Foreign Key & PK \\
\hline \hline pesquisador & number(10) & Not Null & pesquisador $($ codigo $)$ & $*$ \\
topico & number(6) & Not Null & topico(codigo $)$ & $*$ \\
\hline
\end{tabular}

tab_aux_pc

\begin{tabular}{lllll}
\hline Nome do Campo & Tipo & Restrição & Foreign Key & PK \\
\hline \hline palavra_chave & number(3) & Not Null & palavra_chave $($ codigo $)$ & $*$ \\
documento & number $(8)$ & Not Null & documento $($ codigo $)$ & $*$ \\
\hline
\end{tabular}

editor

\begin{tabular}{lllll}
\hline Nome do Campo & Tipo & Restrição & Foreign Key & PK \\
\hline \hline publicacao & number $(8)$ & Not Null & publicacao $($ codigo $)$ & $*$ \\
pesquisador & number(10) & Not Null & pesquisador $($ codigo $)$ & $*$ \\
\hline
\end{tabular}

